\title{
June 2020
}
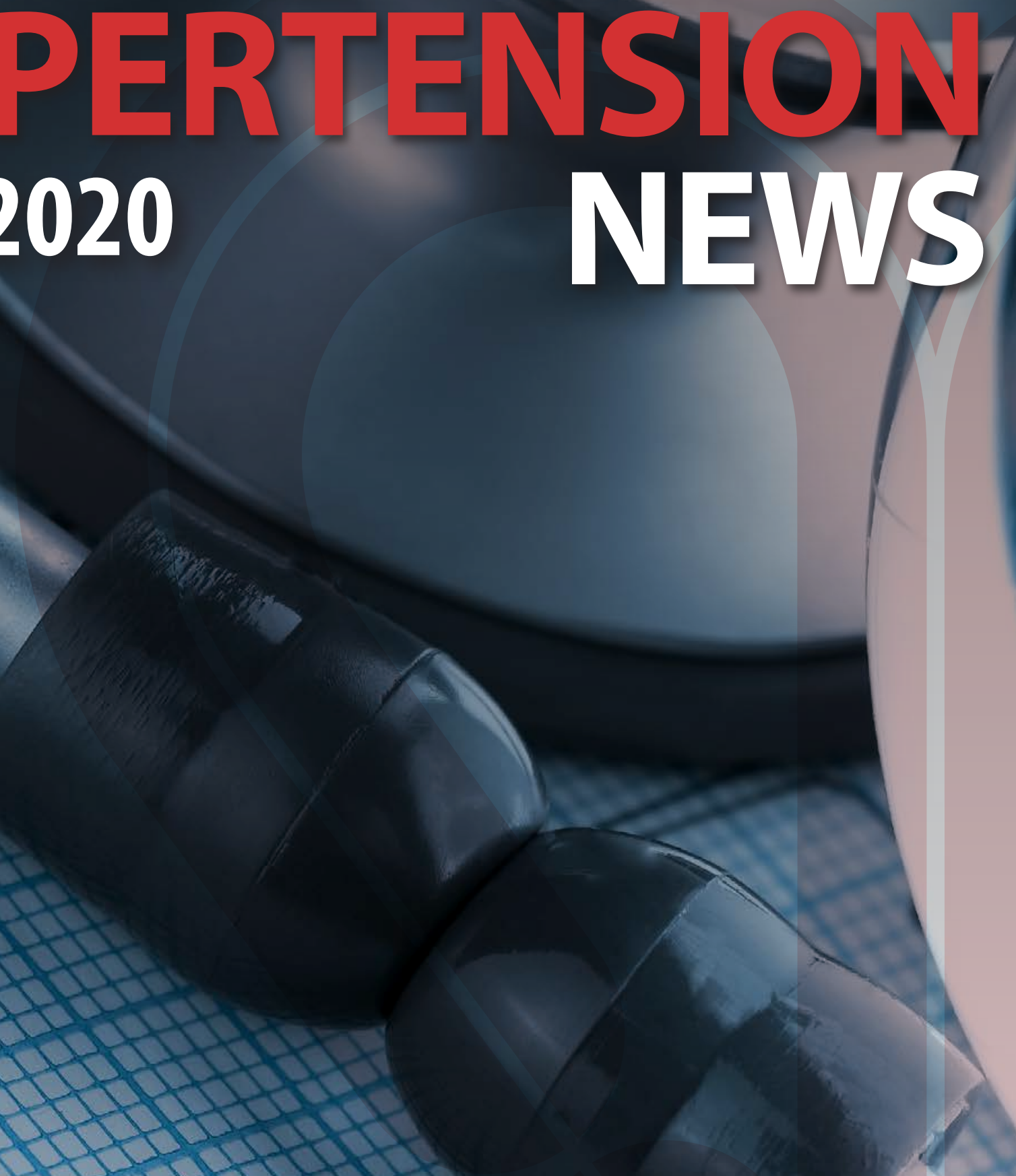

International
Society of
Hypertension 

FROM THE EDITOR

Hypertension News in corona times

FROM THE ISH PRESIDENT

HOT OFF THE PRESS: CLINICAL

Renal denervation lowers blood pressure - now what?

HOT OFF THE PRESS: BASIC

Catheter-based radiofrequency and renal denervation in the treatment of systemic arterial hypertension in patients with progressive chronic kidney disease

INVITED PAPER:

Music and blood pressure - risk,

therapeutic or simply pleasure? DATA

\section{ISH GLOBAL} HYPERTENSION GUIDELINES The New 2020 ISH Global Hypertension Guidelines: What is new, what is different?

2020 ISH GLOBAL

HYPERTENSION GUIDELINES

Interview with Professor Thomas Unger about the Writing Process of the new ISH Hypertension Guidelines

2020 ISH GLOBAL HYPERTENSION GUIDELINES

ISH returns to the fray with its own Global Guidelines, Commentary by John Chalmers

\section{9}

\section{THE CURRENT COVID-19 PANDEMIC AND HYPERTENSION} Pharmacology of renin-angiotensin-system blockers and COVID-19: confusion around ACE2

THE CURRENT COVID-19

PANDEMIC AND HYPERTENSION

COVID-19 and hypertension

THE CURRENT COVID-19

PANDEMIC AND HYPERTENSION

Japanese folk monster "A-MA-BI-E" is re-

born as the guardian to avoid COVID-19 in 2020

YOUNG INVESTIGATORS:

The "Twilight Zone" world of the COVID-19 pandemic: The place, role and future of telehealth in hypertensive patients

\section{YOUNG INVESTIGATORS:}

The cardiovascular profile of the low renin phenotype in a population of African descent

YOUNG INVESTIGATORS:

Putting the pressure on nonvalidated blood pressure monitors

YOUNG INVESTIGATORS:

Vascular ageing biomarkers: are we ready for the hypertension guidelines?

WOMEN IN HYPERTENSION RESEARCH COMMITTEE AND NEW INVESTIGATOR COMMITTEE REPORT

SUMMARY OF THE NORDICBALTIC REGION UNIVERSITY RESEARCH COURSE ISH PARTNERS IN COALITION FOR ACCESS TO NCD MEDICINES AND PRODUCTS 


\title{
FROM THE EDITOR Hypertension News in corona times
}

\author{
LARS H LINDHOLM \\ Department of Public Health and Clinical Medicine \\ Umeå University, Sweden \\ Editor
}

DOI: $10.30824 / 2006-2$

Dear ISH member,

Little did we know, when the members of the Editorial Board of Hypertension News met in London in early March to plan the June 2020 issue, that part of the world would be upside down three months later with lock-downs, travel restrictions, and social distancing. The ISH/EHS/BIHS meeting in Glasgow, planned for May 2020, was moved to April 2021 and many large cardiovascular meetings (e.g. ACC meeting in Chicago) were cancelled. This was also so, for several diabetes meetings (e.g. ADA in Chicago).

Since the biennial meeting in Glasgow was moved, we had to change the content of the June issue of the Newsletter. The reports from the young investigators on different presentations during that meeting had to be replaced by four other texts from young scientists (page 37 - 43). Also, the changes of the Executive and leadership of ISH have been moved to the October issue (Opus 62).

Today, we have two main topics to discuss in a very comprehensive Newsletter.

\section{First, the recent ISH Global Hypertension Practice Guidelines written by a committee chaired by the ISH Secretary Thomas Unger from Maastricht.}

The response to the guidelines has been overwhelmingly positive and the guidelines have already reached more than 100,000 readers on Facebook and Twitter (page 17). The video series highlighting the key components of the guidelines have been viewed by more than 2,400 times. Dylan Burger from Ottawa, who chairs the ISH Communication Committee has done an outstanding job making the recommendations known to both health professionals and the public and should be commended for doing so!

In this double issue of Hypertension News (Opera 60-61) you will find a short summary of what is new in the ISH guidelines and what is different from other recommendations (page 18). This is followed by an interview with Thomas Unger about the writing process. Why did you do it? How did you do it? Where there critical voices? Was there consensus? How did you manage to write them and get them published so quickly? Will there be an update? Finally, we have asked the 'grand old man' of ISH guidelines, John Chalmers from Sydney to share his comments and suggestions. My summary of John's Commentary is: Cum laude Thomas Unger et al., to which I add my humble "Congratulations". 


\section{Second, the Covd-19 pandemic and its link to hypertension is discussed in three papers from different parts of the world.}

An early report from Italy indicated that patients with hypertension were at greater risk of developing severe illness ${ }^{1}$. This could be so, but alternatively - as suggested from the same region of Italy - it could be explained by the confounding influence of age and co-morbidity on hypertension². Today, there are many confusing publications on hypertension treatment and COVID-19, some published in leading journals such as the N Engl I Med and The Lancet one day and then either taken back shortly thereafter ${ }^{3}$ or having expressions of concern published by the journal ${ }^{4,5}$.

First, a basic text on the pharmacology of renin-angiotensin-system blockers and COVD-19 and the confusion around ACE2 (page 29) by Reinhold Kreutz from Berlin. This is followed by a more clinical paper by Murry Esler and his daughter Danielle Esler from Melbourne. Finally, Hiroshi Itoh from Tokyo tells us (page 35) about the Japanese folk monster A-MA-BI-E which has been reborn to avoid COVID-19. A lovely drawing of the monster made by the author accompanies the paper.

There are several other high-quality papers in this issue. If I were to mention one, it would be the paper by Martin Paul from Maastricht who has written about "Music and blood pressure - risk, therapeutic, or simply pleasure? (page 13)"

Finally, as always, let me first thank the authors and then my excellent Deputy Editor Dylan Burger. Also, our lovely editorial team, now strengthened by Maria-Christina Zennaro from INSERM in Paris, who joined us in March. Last but certainly not least, special thanks to our administrator Araceli Segreto.

Have a good read!

Lars H Lindholm: lars.h.lindholm@umu.se

\section{REFERENCES}

1. Grasselli G, Zangrillo A, Zanella A et al. Baseline characteristics and outcomes of 1591 patients infected with SARS-CoV-2 admitted to ICUs of the Lombardy Region, Italy. JAMA, 2020: http://doi. org/10.1001/jama.2020.5394

2. Mancia G, Rea F, Lundergan, Apolone G. Corrao G. Renin-angiotensin-aldosterone system blockers and the risk of Covid-19. N Engl J Med, 2020. http://doi.org/10.1056/NEJMoa2006923

3. Mehra MR, Ruschitzka F, Patel AN. Retraction-Hydroxychloroquine or chloroquine with or without a macrolide for treatment of COVID-19: a multinational registry analysis. Lancet 2020. http://doi. org/10.1016/S0140-6736(20)31324-6

4. Expression of Concern: Hydroxychloroquine or chloroquine with or without a macrolide for treatment of COVID-19: a multinational registry analysis. Lancet 2020. http://doi.org/10.1016/ S0140-6736(20)31290-3

5. Expression of Concern: Mehra MR at al. Cardiovascular disease, drug therapy, and mortality in Covid-19. N Engl J Med. http://doi.org/10.1056/NEJMoa2008975 


\title{
FROM THE ISH PRESIDENT
}

\author{
ALTA SCHUTTE \\ Faculty of Medicine, University of New South Wales, \\ The George Institute for Global Health, \\ Sydney, Australia \\ ISH President 2018-2020
}

DOI: $10.30824 / 2006-3$

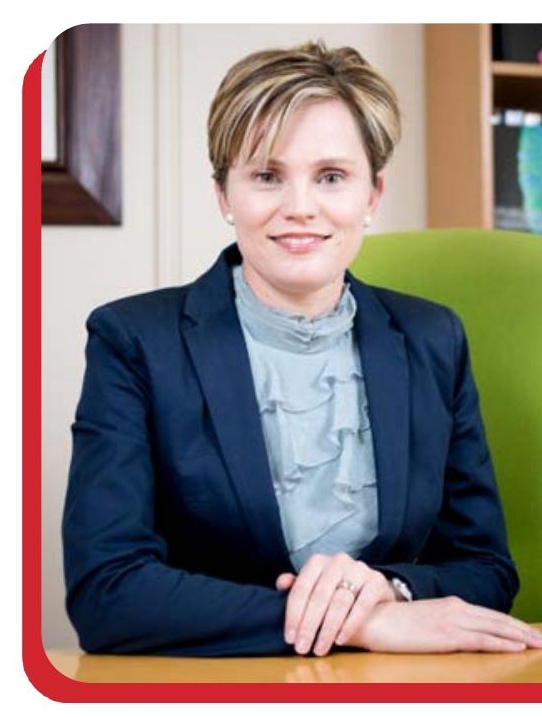

Dear Members,

It has been a rollercoaster ride since our previous Newsletter in March! It was hard not to be rather overwhelmed by the effects the SARS-CoV-2 virus had on our lives - whether closely monitoring population infection across the continents, increased hours in the clinic and hospital, or affected mentally due to social isolation during our new 'normal' life and working-from-home.

These disruptions also hold true for some of the major activities of the Society:

1. In fact, I ended my previous message to you with the words "See you in Glasgow!". Although I meant end of May, 2020, those words are still true although we have now postponed the Joint Scientific Meeting of the European and International Societies of Hypertension to 11-14 April, 2021 (www.hypertension2021. org). The meeting Chair, Anna Dominiczak, and ESH President, Reinhold Kreutz and myself will post regular updates on this website, but those who submitted abstracts for 2020 - we intend to keep the scientific programme as originally intended, and will shortly notify everyone on the way forward. Of course we also plan to include new sessions on the COVID-19 pandemic and how it impacts on cardiovascular disease. Also of note - we deeply thank Giuseppe Mancia for cancelling the ESH Milan 2021 meeting to accommodate the Joint ESH-ISH Meeting in April 2021.

2. Another disruption is that we sadly had to postpone May Measurement Month 2020. Running the risk of infecting many more people needlessly, we are focusing on MMM2021. So watch this space.

Fortunately, it is not all doom and gloom. The major highlight of recent times is that on 6 May 2020 the Society released the 2020 International Society of Hypertension Global Practice Guidelines, published in both the Journal of Hypertension and Hypertension. In this Newsletter a detailed overview will be given. To Thomas Unger as Chair and to the Guidelines Committee members, the Reviewers from across the world, and the Editors of the journals - my heartfelt thanks for the many hours and effort to get to this point. I find particular pleasure in the unique layout of the guidelines, namely, to have a two-tiered approach throughout, focusing on ESSENTIAL and OPTIMAL standards of care. This approach originated from my discussions with colleagues from Africa and other low resource settings mentioning their challenge in using the latest guidelines that were designed for affluent settings. I hope that these guidelines will serve as an important tool for many healthcare practitioners across the world. 
More details, including the guidelines, the Powerpoint presentation, and a full online webinar with all authors discussing different sections of the guidelines, are to be found on the ISH Website: https://ish-world.com/news/a/ISHGPG/.

You will also be able to see where the guidelines have been picked up by the media. Here I particularly wish to thank Dylan Burger, Communications Chair of the Society, for a stellar job in ensuring that we could share the guidelines far and wide. The Altmetric scores of our publications are also at full speed as we see many shares on Twitter and other channels.

Before I end my message, a more formal note on the implications of the postponement of our Scientific Meeting. The General Meeting for our members that were supposed to take place in Glasgow, will now form part of an online General Meeting during October 2020. At this meeting the Terms of Council Members, including myself, will come to an end, and the President-Elect, Maciej Tomaszewski will take over the reign. At our Scientific Meeting in Glasgow - April 2021 - I will Chair the proceedings as originally planned.

Friends and colleagues, during these challenging times, I wish you all good mental and physical health. Please take care and stay safe until we meet again.

With my very best wishes,
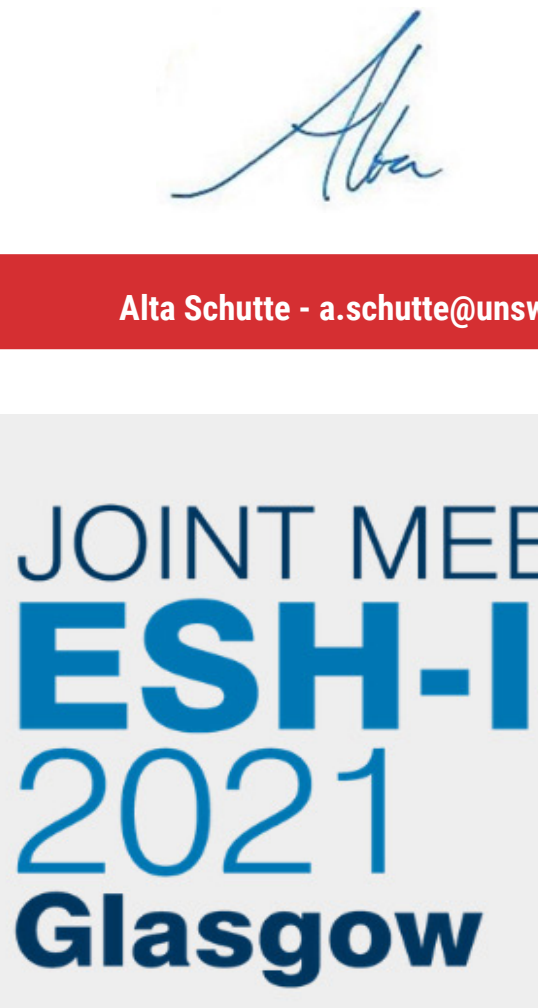

April 11-14, 2021 Scottish Event Campus Glasgow, United Kingdom www.hypertension2021.org

global hypertension hub
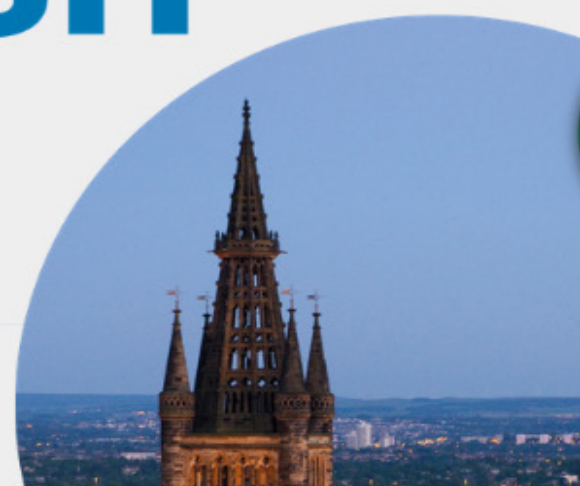

ilimes

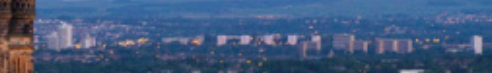

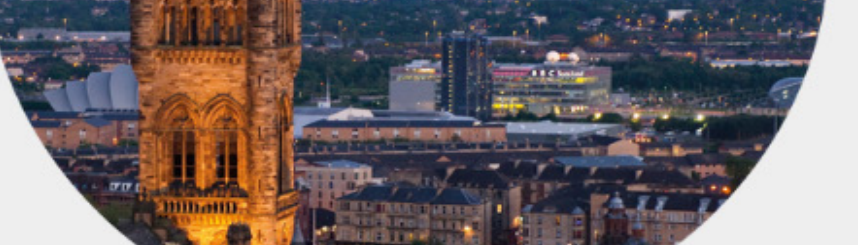

(ESH)

European

Society of

Hypertension

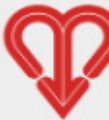

International

Society of

Hypertension

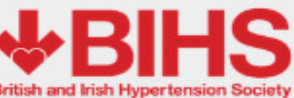

British and lish Hypertension Society

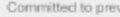




\section{THE SECRETARY'S VOICE}

Thomas Unger

CARIM - School for Cardiovascular Research, Maastricht University, Maastricht, The Netherlands

DOI: $10.30824 / 2006-4$

An exciting and highly productive period of our Society is approaching the end. In October, a new president will take over and with him a new Executive Council.

\section{Time to look back and to review the Society's achievements of the last two years under the presidentship of Alta Schutte (2018-2020).}

\section{There was of course the ISH congress} in Beijing still under the presidentship of Neil Poulter (2016-2018) which was held together with the Chinese Hypertension League $(\mathrm{CHL})$ and the Asian Pacific Society of Hypertension (APSH) in September 2018 with up to 3.000 participants. Scientifically, this meeting was a great success, and we all enjoyed the warm hospitality of our Chinese friends.

Then the tremendous activities of the May Measurement Month (MMM) led by Neil Poulter over the last three years with more than one hundred countries involved, more than two million of individuals having their blood pressure measured, and almost one million untreated or inadequately treated hypertensives detected. Beyond this, with a number of publications in high-ranking journals, MMM exerts an impact on the global awareness of hypertension as the most important cardiovascular risk factor and, in particular, features ISH as the only globally acting hypertension society. MMM takes care of a new recognition of the devastating role of high blood pressure, especially in times where hypertension tends to be rather neglected, its research is not

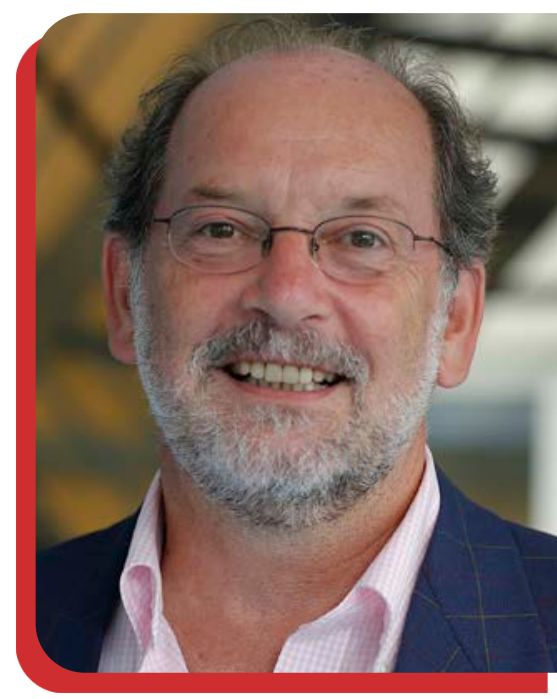

supported to a significant extent any more by funding agencies, academic institutions and the pharmaceutical industry, and where academic Departments of Hypertension dwindle.

Under these unfavourable conditions, institutions like MMM are more important than ever to maintain and even refresh the public awareness of the "silent killer number one". And, as it says on the ISH homepage, the significance of MMM can also be seen as "to collect the scientific evidence needed to help influence global health policy and make BP screening more widely available around the world".

MMM has done a tremendous job in this respect. Due to the current situation under the yoke of the Corona Pandemic, the MMM activities have been postponed for the year 2020 and will hopefully be resumed in the next year as one of the ISH flagships.

Covid-19 also prevented the planned congress of ISH together with the European Society of Hypertension (ESH) and the British and Irish Hypertension Society (BIHS) in Glasgow, UK, due to take place at the end of May 2020. The joint congress has been postponed to April 11-14, 2021 at the same venue. The Society will make sure that information about all related changes and plans including new abstract submission etc. are widely communicated in due time.

The Society will not present any awards this year as the awards ceremonies have also been postponed to the 2021 congress. A new call for award nominations will be circulated in December 2020. 
The biennial general meeting of the Society, which should have taken place during the Glasgow congress, has been postponed to October 2020 as a virtual meeting so that the current president and executive council will finish their two-year terms correctly in the autumn according to the Society's constitution. Members will be invited to an online General Meeting in October which will have normal reporting including finances and general activities of the council.

Speaking of finances, these are in good order under the supervision of the current treasurer, Markus Schlaich, thanks to his continuous, intensive efforts. The ISH Bejing meeting, despite being held under difficult financial conditions, has made a surplus, and the cancellation of this year's congress will save costs but these will of course be incurred again in April 2021 when the congress takes place.

ISH has launched a new fellowship "International Society of Hypertension Fellow (ISHF)" similar to the AHA and ESC fellowships to "recognise and honour members of the Society who have distinguished themselves through excellence in clinical practice or research in the field of Hypertension". So far, more than 100 applications have been received. Once the applications have been approved by the Executive Committee, applicants will be honoured in April 2021 at the ISH congress. A second call for nominations will be circulated before the congress.
Finally, one of the major tasks of the Society in the last two years was the creation of new ISH Hypertension Guidelines. These have been published recently in two journals, Journal of Hypertension and Hypertension, concomitantly on May 6, 2020, and printed in the respective June 2020 issues. Links to these and other means of the Guideline dissemination can be found on the ISH homepage under www.ish-world.com. The new ISH Guidelines are covered extensively in the present issue of Hypertension News.

At this point I would like to express my deep gratitude to Alta Schutte, our current president, and to the members of the Executive Committee and Council. It has been a pleasure to work with you as the Society's Secretary and Chair of the Hypertension Guidelines Committee. I highly appreciate the friendly and trustful atmosphere created by the president, allowing among others, for vivid, sometimes controversial, but always constructive discussions. Major achievements like the production of new Guidelines can only be performed under such friendly skies, and I sincerely hope they will continue in the future for the benefit of our Society and its global mission.

Thomas Unger - thomas.unger@maastrichtuniversity.nl

\section{ISH Global Practice Guidelines Resources}

All information and resources related to the 2020 ISH Global Hypertension

Practice Guidelines are available on the ISH website including:

- Publication in Hypertension

- Publication in publication in J Hypertension

- Slide deck

- Webinar in English and Chinese 


\section{HOT OFF THE PRESS: CLINICAL}

Chlorothalidon or

hydrochlorothizide for treatment of hypertension?

\section{THOMAS KAHAN}

Karolinska Institutet, Department of Clinical Sciences, Danderyd Hospital, Division of Cardiovascular Medicine, \& Department of Cardiology, Danderyd University Hospital Corporation, Stockholm, Sweden

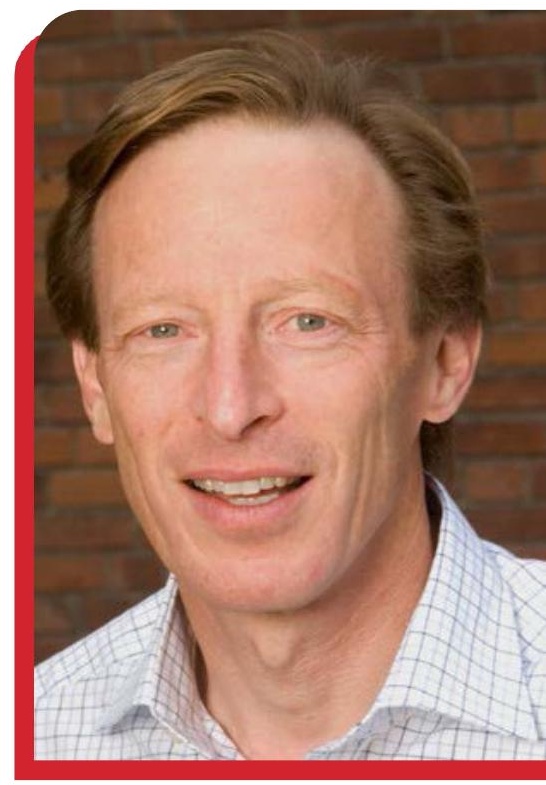

The thiazides and the closely related phtalimidine derivates introduced more than 50 years ago have remained a mainstay of antihypertensive therapy. Hydrochlorothiazide is the most commonly prescribed member of this class of thiazide and thiazide like diuretics in many parts of the world including Europe, where chlorthalidone have been little used during the last decades due to more frequent metabolic side effects (including electrolytes, lipids, glucose).

In contrast, chlorthalidone has been claimed to have a longer half-life, greater blood pressure lowering effect and better proven effect on outcome in clinical trials, and remains the favoured diuretic of this class to treat hypertension according to US guideline recommendations. However, there are no direct comparisons between hydrochlorothiazide and chlorthalidone on morbidity and mortality in the treatment of hypertension.

Recently, Hripcsak and collaborators set out to compare the effectiveness and safety of hydrochlorothiazide and chlorthalidone as newly initiated first line therapy for hypertension?. The authors used a retrospective observational comparative cohort design to performe an analysis across three large disparate US databases that each had at least 2500 patients with exposures to each drug and information on outcome. Primary outcomes were acute myocardial infarction, stroke, heart failure hospitalization, and a composite of the three events and sudden cardiac death. Also 51 safety outcomes were collected.
A large number of baseline covariates were used for balancing the two cohorts by propensity scores. The study included 730225 individuals (62\% women, mean age 52 years); 69337 received hydrochlorothiazide and had 3089 composite outcome events, and 36918 received chlorthalidone and had 149 composite events from 2001 through 2018.

The results show no significant difference in risk for acute myocardial infarction, stroke, heart failure hospitalization or the composite outcome (hazard ratios with 95\% confidence limits; lower hazard ratios favour chlorthalidone): $0.92(0.64 ; 1.31), 1.10$ (0.86; 1.41), $1.05(0.82 ; 1.34)$, and $1.00(0.85 ; 1.17)$, respectively. Chlorthalidone was associated with an increased risk for hypokalaemia, hyponatremia, acute renal failure, chronic kidney disease, and type 2 diabetes; and a lower risk for abnormal weight gain.

This study shows no difference in cardiovascular outcome between hydrochlorothiazide and chlorthalidone as first line newly initiated antihypertensive therapy. However, chlorthalidone was associated with more frequent electrolyte and glucose metabolic abnormalities, and deterioration renal function. The results are in agreement with some indirect meta-analyses, whereas other indirect meta-analyses and observational studies suggest a reduced risk for cardiovascular event with chlorthalidone. Differences in study design, patient populations, and doses studied may contribute to these differences. 
Taken together, current results do not support the use of chlorthalidone over hydrochlorothiazide. Of note, a randomized controlled study of hydrochlorothiazide versus chlorthalidone (ClinicalTrials.gov Identifier: NCT02185417) is currently in progress ${ }^{2}$ and may clarify matters.

Thomas Kahan - thomas.kahan@sll.se

REFERENCES

1. Hripcsak G, Suchard MA, Shea S, Chen R, You SC, Pratt N, Madigan D, Krumholz HM, Ryan PB, Schuemie MJ. Comparison of cardiovascular and safety outcomes of chlorthalidone vs hydrochlorothiazide to treat hypertension. JAMA Intern Med. 2020;180(4):542-51. doi:10.1001/jamainternmed.2019.7454

2. Lederle FA, Cushman WC, Ferguson RE, Brophy MT, Fiore Md LD. Chlorthalidone versus hydrochlorothiazide: A new kind of Veterans Affairs cooperative study. Ann Intern Med. 2016;165(9):663-664. doi: 10.7326/M16-1208

\section{HOT OFF THE PRESS: CLINICAL Renal denervation lowers blood pressure - now what?}

\section{MARKUS P SCHLAICH}

Dobney Hypertension Centre, School of Medicine - Royal Perth Hospital Unit / Medical Research Foundation, University of Western Australia and Departments of Cardiology and Nephrology, Royal Perth Hospital, Perth, Australia. Neurovascular Hypertension \& Kidney Disease Laboratory. Baker Heart and Diabetes Institute, Melbourne, Australia

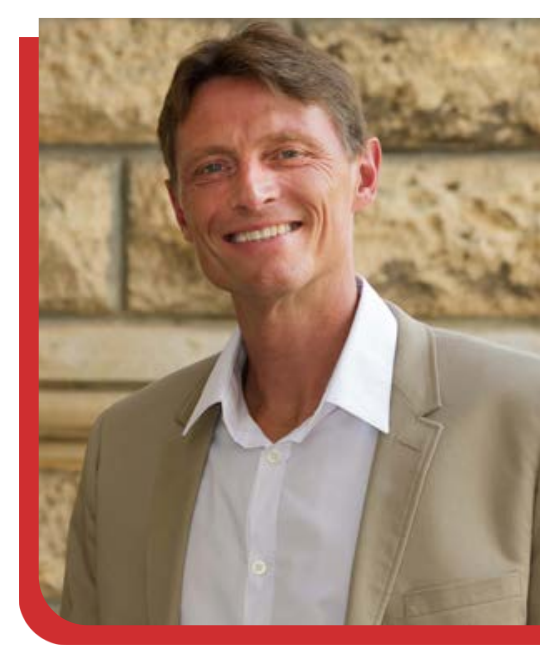

DOI: $10.30824 / 2006-6$

The controversies around renal denervation over the last decade have undoubtedly shaped the hypertension world and have brought to light some hidden truths, stimulated extensive research efforts into the phenotyope of "resistant hypertension", and helped to advance our approaches to diagnose and manage this complex aspect of hypertension medicine. Therapeutic drug monitoring revealed that a large proportion of patients requiring poly-pharmacy are indeed non-adherent with prescribed medication. The importance of 24-hour ambulatory blood pressure (BP) monitoring as a primary endpoint measure, adequate study designs including sham-procedures, optimization of procedural aspects, and the relevance of patient selection became apparent. While Symplicity HTN-1 and HTN-2 demonstrated a substantial reduction in BP, Symplicity HTN-3, the largest and first study to include a sham control failed to demonstrate a BP lowering effect beyond that observed in the sham control group and thereby questioned the utility of catheter-based renal denervation¹.

Since then, three sham-controlled studies using either radiofrequency ablation technology 2,3 or high frequency ultrasound ${ }^{4}$ in both drug-naive ${ }^{2}$ or treated hypertensive patients ${ }^{3,4}$ demonstrated clinically relevant reductions in ambulatory BP compared to respective sham control groups.

Most recently, results from the SPYRAL HTN-OFF MED Pivotal trial, an international, prospective, randomised controlled trial on the effects of renal denervation in unmedicated patients were reported 5 . In a cohort of 331 patients with hypertension assigned to either radiofrequency ablation $(n=166)$ 
or sham procedure $(n=165)$, differences between treatments were $-6.5 \mathrm{mmHg}$ (Bayesian 95\% credible interval -9.6 to -3.5$)$ for office systolic BP and -3.9 $\mathrm{mmHg}(-6.2$ to -1.6$)$ for $24 \mathrm{~h}$ systolic BP (Figure 1). Blood pressure reductions were persistent and sustained over $24 \mathrm{~h}$ (Figure 2) and no relevant procedure-related or short term safety events were reported after three months. Treatment differences in $24 \mathrm{~h} \mathrm{BP}$ in key baseline characteristic subgroup measurements showed no significant interactions between subgroups.

Advocates of renal denervation will be pleased with the findings from the SPYRAL HTN-OFF MED Pivotal for a number of reasons: It provides further robust evidence to support the validity of the concept of therapeutically targeting renal sympathetic nerves to lower BP in humans and thereby extends the unambigious evidence from experimental studies into the clinical sphere. Furthermore, it is reassuring that there was no signal for safety concerns at 3 months follow up given the substantially more aggressive treatment approach with targeting of distal branches. Additionally, the apparent "alwayson" effect (Figure 2) of renal denervation may prove advantageous particularly in patients on drugs that have short durations of action and in terms of mitigating the loss of BP control in patients who are non-adherent to drug therapy, which has become a major concern in hypertension management.

Skeptics may argue that the effects on BP observed with renal denervation, while clinically relevant, were relatively small and could equally be achieved with appropriate antihypertensive medication. They have a point... although renal denervation has been shown to exert more pronounced BP lowering effects beyond three months. Furthermore, is an interventional approach really something one would consider as an initial option in a drug-naive patient in a real world setting? Probably not....at least at this stage. Patients however, who are intolerant to antihypertensive medication or chose not to take antihypertensive drugs may well benefit from such an approach, particularly in the long term if the BP lowering effect is sustained.

Importantly, the data from this trial need to be interpreted in the broader context. With the uncertainties arising from Symplicity HTN-3 ${ }^{1}$ it was crucial to demonstrate in an appropriately designed clinical trial that renal denervation safely and reliably reduces BP. This has now been proven.

The next step is to identify patients who may benefit most from such an interventional approach and a complementary randomised trial in patients with uncontrolled hypertension despite anti-hypertensive therapy due to report in 2021 may provide some answers. Management of hypertension is a marathon, not a sprint and assessment of long term performance of renal denervation will further our understanding of the overall benefits of renal denervation.

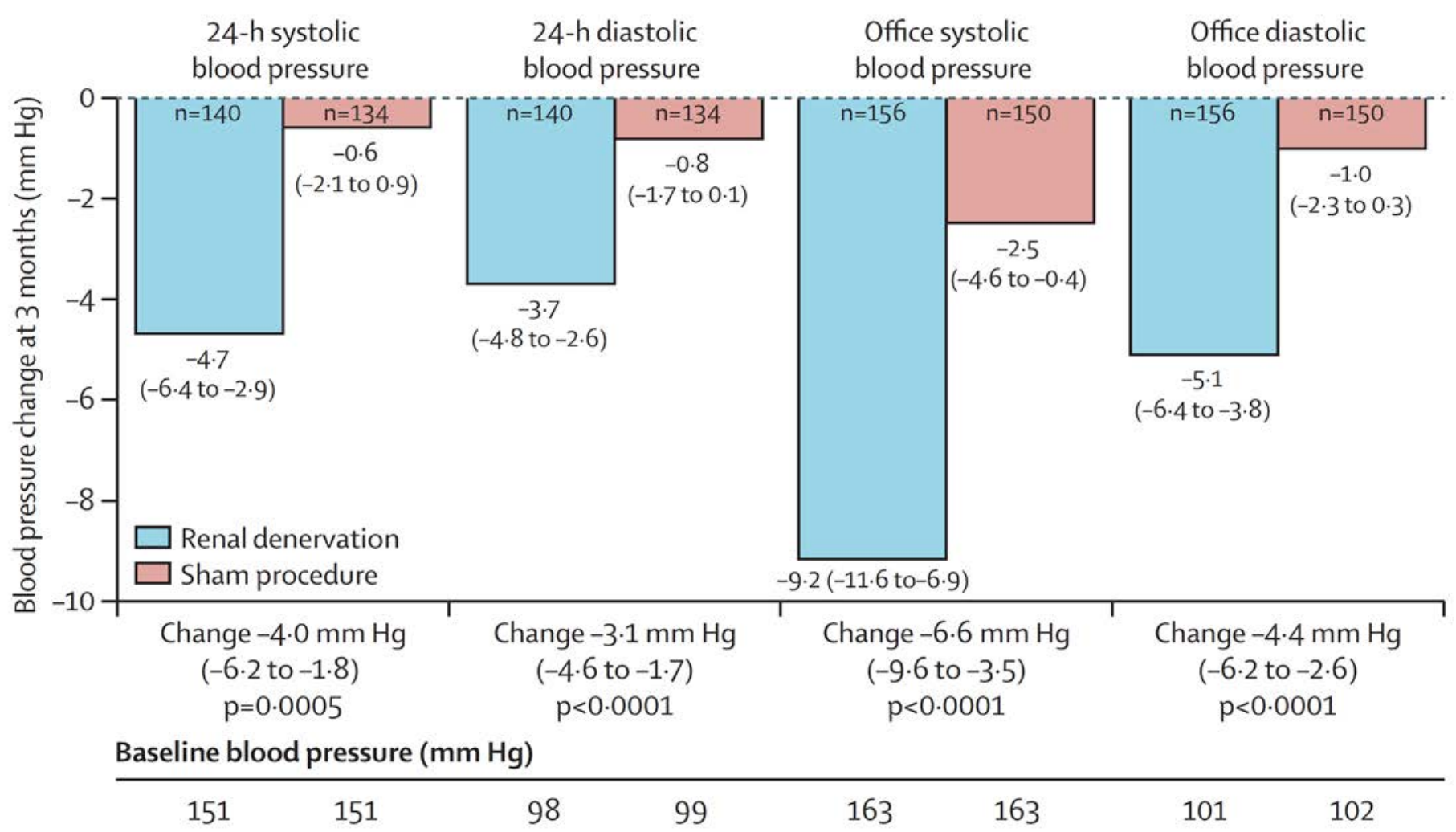

Figure 1: Changes in 24-h and office systolic and diastolic BP from baseline to 3 months (95\% CI). Source: Lancet 2020 May 2;395(10234):1444-1451 

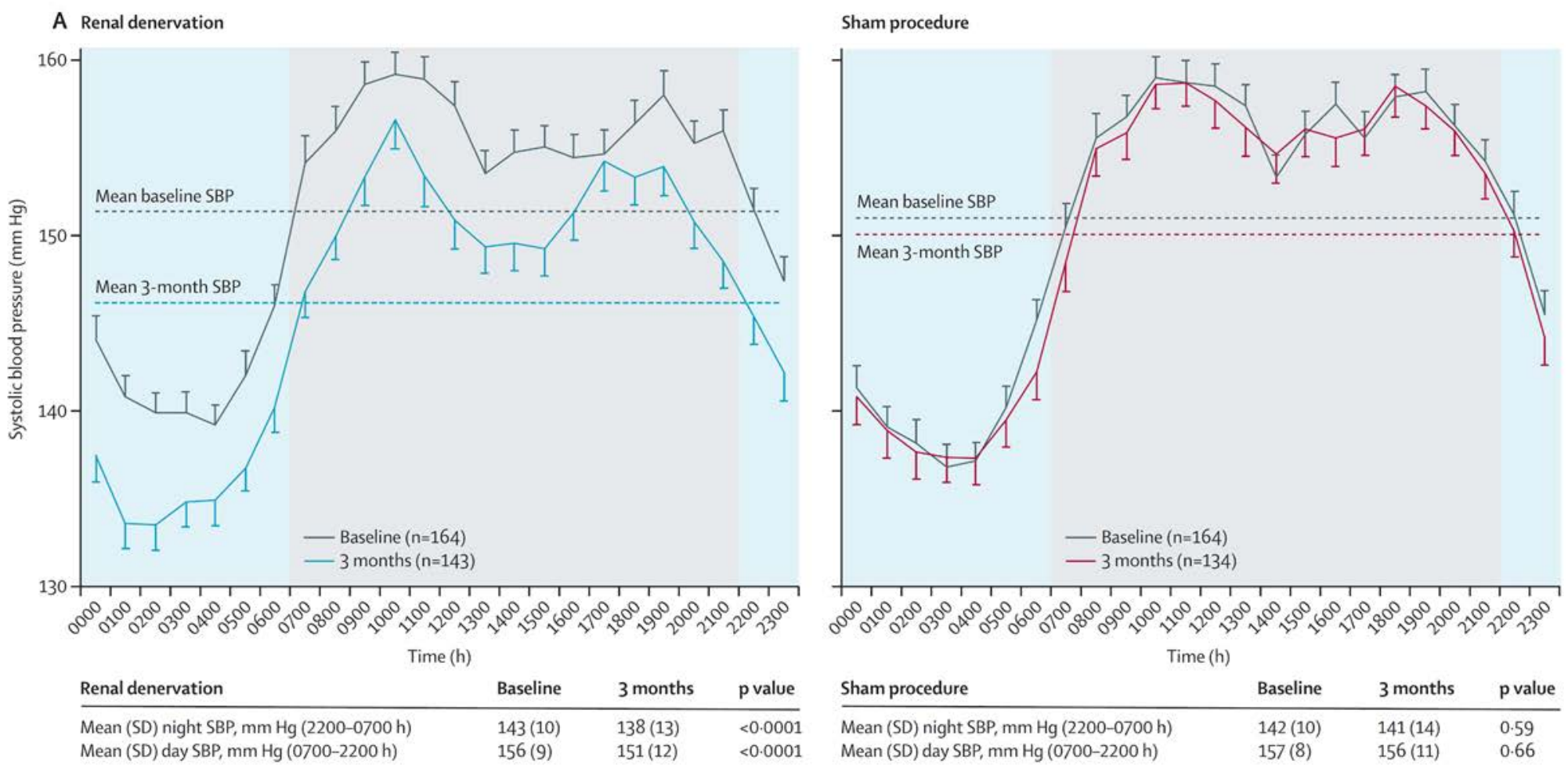

Figure 2: 24-h ambulatory systolic (SBP) at baseline and 3 months after renal denervation or shamprocedure in the overall population. Source: Lancet 2020 May 2;395(10234):1444-1451

Markus Schlaich - markus.schlaich@uwa.edu.au

\section{REFERENCES}

1.Bhatt DL, Kandzari DE, O'Neill WW, D'Agostino R, FlackJM, Katzen BT, et al. A controlled trial of renal denervation for resistant hypertension. N Engl J Med. 2014;370(15):1393-401. doi: 10.1056/NEJMoa1402670

2.Townsend RR, Mahfoud F, Kandzari DE, Kario K, Pocock S, Weber MA, et al. Catheter-based renal denervation in patients with uncontrolled hypertension in the absence of antihypertensive medications (SPYRAL HTN-OFF MED): a randomised, sham-controlled, proof-of-concept trial. Lancet. 2017; 390:2160-70. doi: 10.1016/S0140-6736(17)32281-X

3.Kandzari DE, Böhm M, Mahfoud F, Townsend RR, Weber MA, Pocock S, et al. Effect of renal denervation on blood pressure in the presence of antihypertensive drugs: 6-month efficacy and safety results from the SPYRAL HTN-ON MED proof-ofconcept randomised trial. Lancet. 2018;391:2346-55. doi: 10.1016/S0140-6736(18)30951-6.

4.Azizi M, Schmieder RE, Mahfoud F, Weber MA, Daemen J, Davies J, et al. Endovascular ultrasound renal denervation to treat hypertension (RADIANCE-HTN SOLO): a multicentre, international, single-blind, randomised, sham-controlled trial. Lancet. 2018;391:2335-45. doi: 10.1016/S0140-6736(18)31082-1

5. Böhm M, Kario K, Kandzari DE, Mahfoud F, Weber MA, Schmieder RE, et al. Efficacy of catheter-based renal denervation in the absence of antihypertensive medications (SPYRAL HTN-OFF MED Pivotal): a multicentre, randomised, sham-controlled trial. Lancet. 2020;395:1444-1451. doi: 10.1016/S0140-6736(20)30554-7 


\title{
HOT OFF THE PRESS: BASIC
}

\section{Catheter-based radiofrequency and renal denervation in the treatment of systemic arterial hypertension in patients with progressive chronic kidney disease}

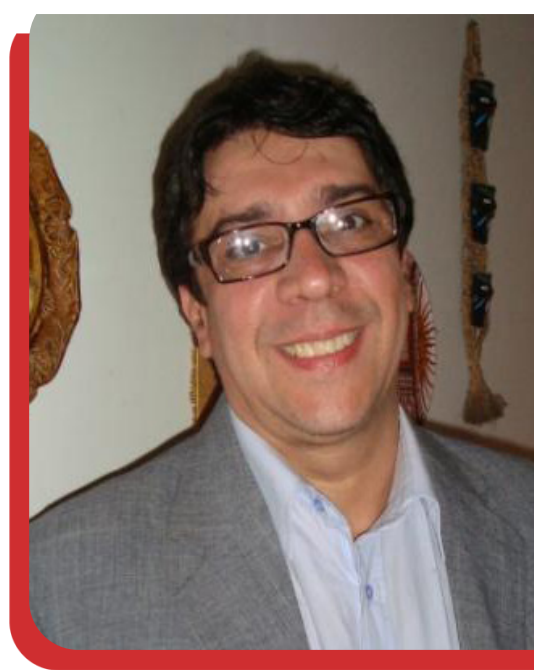

\author{
JORGE REIS ALMEIDA \\ Antônio Pedro University Hospital \\ Rio de Janeiro, Brazil.
}

DOI: $10.30824 / 2006-7$

One of the major problems in public health is non-adherence to antihypertensive medications in cases of severe or resistant hypertension. Catheter-based renal denervation has emerged as a novel approach to decrease BP and is in the centre of significant discussion ${ }^{1,2}$.

In the initial trials, a large body of evidence suggests it to be safe and effective in lowering $\mathrm{BP}$ in subjects with resistant hypertension via reduction in renal and central neural sympathetic activity $^{3}$. I will concentrate on a set of recent articles from Kiuchi and their collaborators that focused on denervation in hypertension associated with progressive chronic kidney disease $(C K D)^{3-5}$. Denervation of efferent and afferent renal nerves has long been reported to attenuate systemic arterial hypertension, thus preventing progressive deterioration of renal function ${ }^{6}$. Extending from this, catheter-based renal denervation, which targets the renal afferent and efferent sympathetic nerves, is an alternative treatment option for CKD patients with resistant hypertension.

In CKD patients, the disruption of sympathetic hyperactivity and the interruption of the reninangiotensin-aldosterone system (RAAS) feedback loop might be of particular benefit. For example, in a renovascular hypertension model, Lopes et al. ${ }^{7}$ showed that chemical afferent renal denervation reduced $\mathrm{BP}$, renal sympathetic nerve activity and reactive oxygen species in both kidneys. Beneficial effects on renal function were also observed including decreased proteinuria, reduced serum creatinine/ urea, and attenuated intrarenal RAAS activation.

Kiuchi et al. has studied a series of CKD resistant hypertensive patients who were followed up for 2 years after renal denervation. Their results indicate that renal denervation in patients with resistant hypertension and CKD (stages 2-4) provided a significant reduction in $\mathrm{BP}$, and even associated with a long-term increase in glomerular filtration 
rate and decrease in albumin excretion ${ }^{5}$. Recently, they extended these work with a cohort study that evaluated different patterns of ablation placement spots along the renal artery vasculature.

Interestingly, they found that the sum of ablations performed in distal segment and branches presented a significant correlation to the systolic BP lowering effect after renal denervation. This correlation was not seen between the total number of ablated spots and ABPM. Taken together these data suggest that a beneficial effect may be achieved by targeted radiofrequency treatment on the distal elements of the renal artery leading to significant and relatively uniform reductions in catecholamine and renal cortical sympathetic axon density.

Such observations may partially explain the variability in response to renal ablation therapy that has been seen to date. Although encouraging, the data are from a post hoc analysis and must be validated in a larger and properly designed study to address this specific aim.

Jorge Reis Almeida - jorgereis@id.uff.br

1. Krum H, Schlaich M, Whitbourn R, Sobotka PA, Sadowski J, Bartus K, et al. Catheter-based renal sympathetic denervation for resistant hypertension: a multicentre safety and proof-of-principle cohort study. Lancet. 2009;373(9671):1275-81. doi: 10.1016/S0140-6736(09)60566-3

2. Symplicity HTNI, Esler MD, Krum H, Sobotka PA, Schlaich MP, Schmieder RE, et al. Renal sympathetic denervation in patients with treatment-resistant hypertension (The Symplicity HTN-2 Trial): a randomised controlled trial. Lancet. 2010;376(9756):1903-9. DOI: 10.1016/S0140-6736(10)62039-9

3. Kiuchi MG, Chen S, Andrea BR, Kiuchi T, Carreira MA, Graciano ML, et al. Renal sympathetic denervation in patients with hypertension and chronic kidney disease: does improvement in renal function follow blood pressure control? J Clin Hypertens (Greenwich). 2014;16(11):794-800. doi: 10.1111/jch.12415

4. Kiuchi MG, Schlaich MP, Chen S, Villacorta H, Ho JK, Carnagarin R, et al. Relevance of Targeting the Distal Renal Artery and Branches with Radiofrequency Renal Denervation Approaches-A Secondary Analysis from a Hypertensive CKD Patient Cohort. J Clin Med. 2019;8(5). doi: 10.3390/jcm8050581

5. Kiuchi MG, Graciano ML, Carreira MA, Kiuchi T, Chen S, Lugon JR. Long-Term Effects of Renal Sympathetic Denervation on Hypertensive Patients With Mild to Moderate Chronic Kidney Disease. J Clin Hypertens (Greenwich). 2016;18(3):190-6. doi: 10.1111/jch.12724

6. Campese VM, Kogosov E, Koss M. Renal afferent denervation prevents the progression of renal disease in the renal ablation model of chronic renal failure in the rat. Am J Kidney Dis. 1995;26(5):861-5. doi: 10.1016/0272-6386(95)90456-5

7. Lopes NR, Milanez MIO, Martins BS, Veiga AC, Ferreira GR, Gomes GN, et al. Afferent innervation of the ischemic kidney contributes to renal dysfunction in renovascular hypertensive rats. Pflugers Arch. 2020;472(3):325-34. doi: 10.1007/s00424-019-02346-4

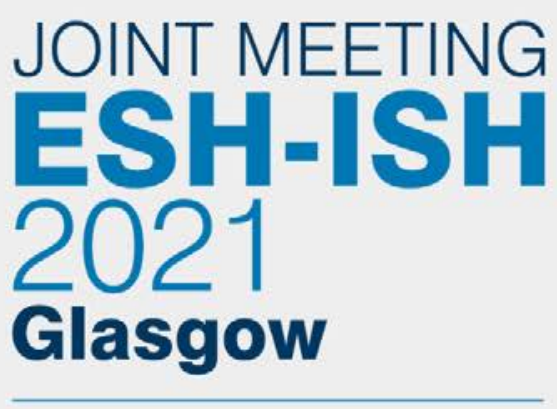

\author{
April 11-14, 2021 \\ Scottish Event Campus \\ Glasgow, United Kingdom \\ www.hypertension2021.org
}
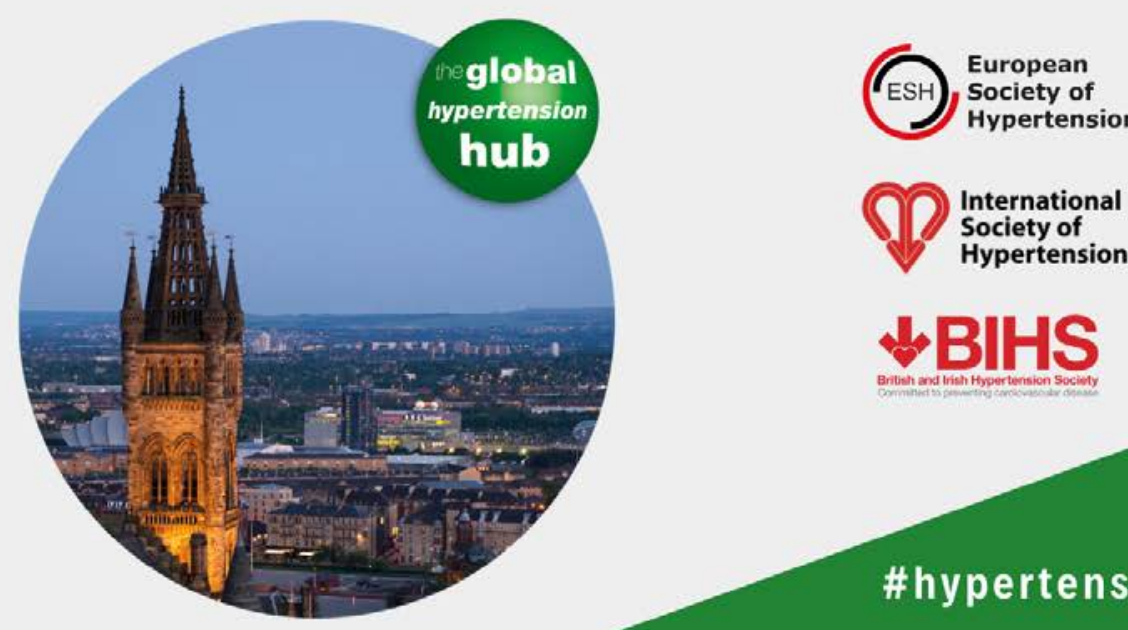

Hypertension

International Society of Hypertension
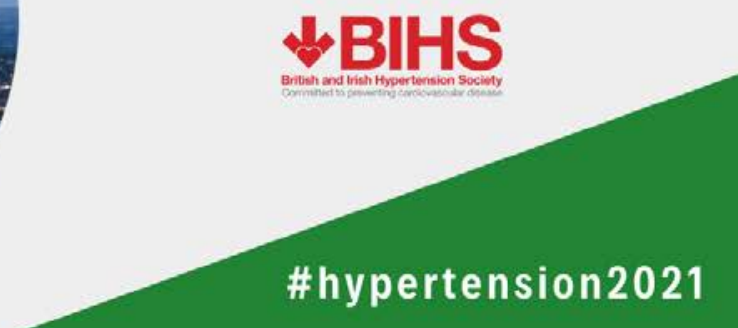


\section{INVITED PAPER:}

\section{Music and blood pressure - risk, therapeutic or simply pleasure?}

Martin Paul

Chair, Clinical Pharmacology

Maastricht University, Maastricht, The Netherlands

\section{DOI: $10.30824 / 2006-8$}

Is music a cardiovascular risk factor? Yes, if one believes the events unfolding in the second act of Jacques Offenbach's opera fantastique "The tales of Hoffmann" which is based on the short stories of E.T.A. Hoffmann, a German writer who lived at the turn of the 18th to the 19th century. In this opera Antonia, the young daughter of a respected city councilor in Munich, is suffering from a mysterious condition where she has to refrain from singing, which has had deleterious effects on her health. Unfortunately, after being tricked to break into song (after all it is an opera) by a malicious house guest she tragically dies from an apparent heart attack in front of the eyes of her father and her unfortunate lover, Hoffmann (Figure 1).

\section{Of course, this fantastic story is pure} fiction, but what do we know about the cardiovascular effects of music in the real world?

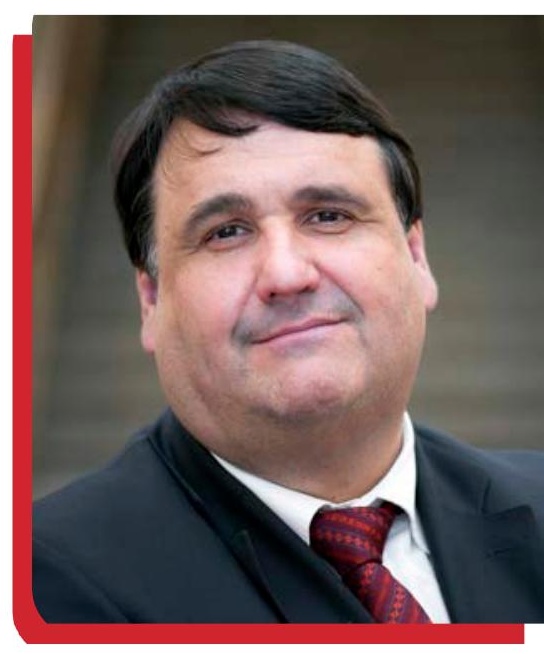

Music is not a one-dimensional entity. It is characterized by several elements that could have individual or combined effects: timbre (sound quality), pitch (frequency), tempo (fast or slow), duration and sound dynamics (loud or quiet), just to name a few. Studies investigating the effects of music on cardiovascular function mostly ignore the multifactorial impact of music on body and mind, making it difficult to pinpoint physiological and pathophysiological effects induced by single factors.

Independently thereof, it is generally accepted that music has effects on heart rate and blood pressure as has been shown in many studies that have been elegantly summarized by Koelsch and Jaehnke ${ }^{6}$. Emotional arousal by exciting music leads to (relatively mild) increases in heart rate and blood pressure through sympathetic pathways whereas calming music has the opposite effects by inducing parasympathetic mechanisms. In addition, heart rate variability is consistently lower by listening to exciting rather than calming music.

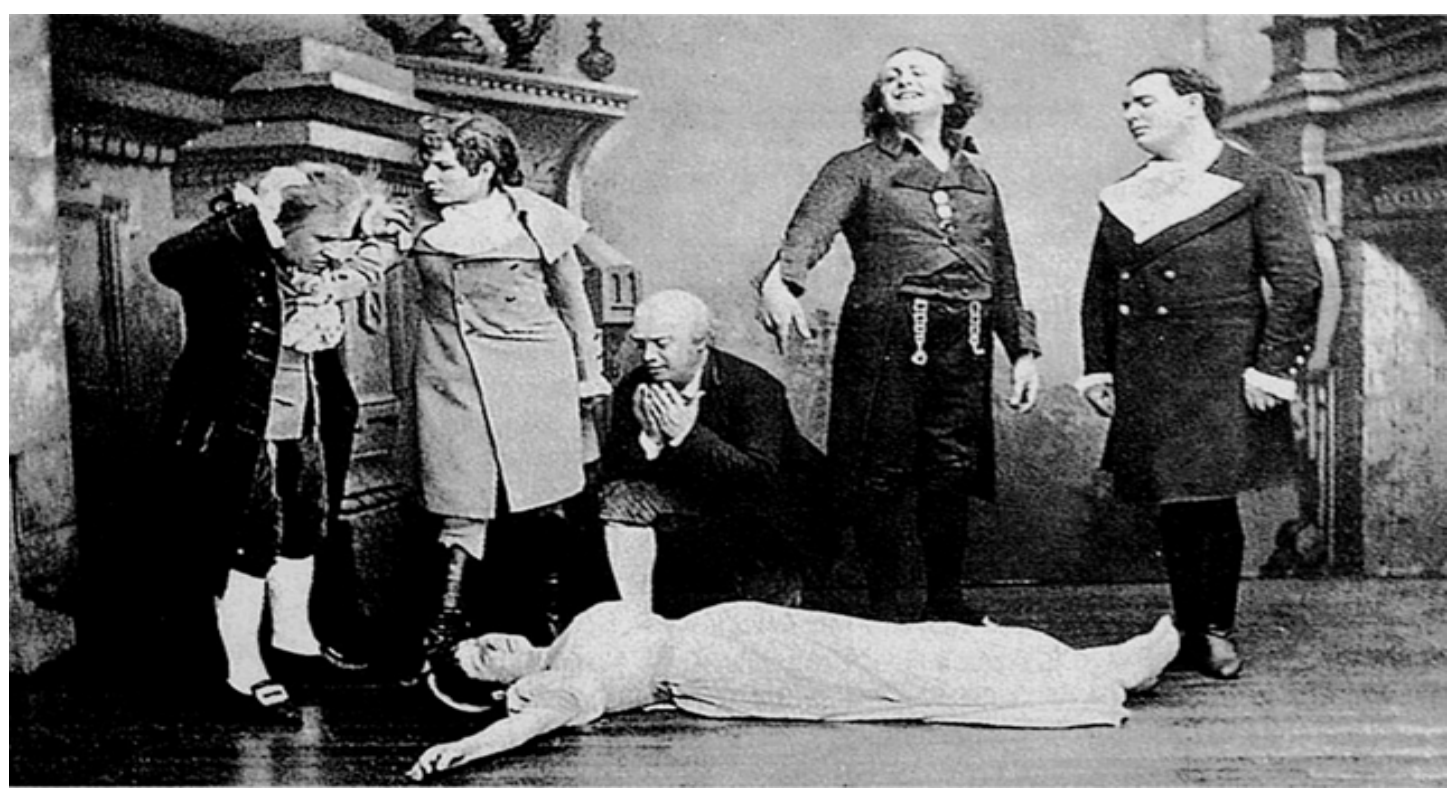

Figure 1: The death of Antonia. Photograph from the premiere performance of "The tales of Hoffmann", Opera Paris, 1881 
These principles have also been the scientific basis to investigate "music therapy" as a means to lower blood pressure. In a study by Sutoo and Akiyama ${ }^{10}$, spontaneously hypertensive rats were subjected to a soothing piece by Mozart (Adagio from Divertimento Nr. 7, KV 205) and systolic blood pressure was significantly and dramatically decreased by 13 to $24 \mathrm{~mm} \mathrm{Hg}$. By pharmacological characterization, the authors largely attributed the mechanism to the calcium-calmodulin induced brain synthesis of dopamine reducing blood pressure through the D2 receptor.

Similar effects have also been described in studies investigating the effects of music on blood pressure in humans. Chafin et al ${ }^{2}$ assigned study participants to a challenging arithmetic test and then made them listen to different styles of music, demonstrating that classical music (as opposed to other musical styles) facilitated the blood pressure recovery from stress. A metanalysis by Kuehlmann and coworkers ${ }^{7}$ showed blood pressure lowering trends of both, systolic (Figure 2) and diastolic blood pressure but could not confirm causality between musical intervention and blood pressure lowering effects. Nevertheless, the authors suggested that listening to music could be used as a complementary approach to pharmacological hypertension therapy.

But going back to the story of poor Antonia mentioned above, what about the potential negative effects of music on the cardiovascular system? It has been suggested that those exposed extensively to a musical environment, such as orchestra musicians, have significant health risks.

As discussed previously in a review published in German $^{9}$ several studies have shown that the level of psychosocial stressors among members of symphony orchestras is higher than in the average working population ${ }^{5}$, although psychosocial stress patterns are variable and related to different musical styles. A number of external factors must be considered in this context that are independent of the exposure to music and due to stress triggers such as irregular working hours, lack of time and pressure to meet deadlines as well as nervousness before the start of a performance (stage fright). Mulcahy et al. ${ }^{8}$ investigated the influence of rehearsals and performances of various concerts in an English Symphony Orchestra by ECG monitoring. The authors were able to show that the heart rate of musicians was significantly increased during rehearsals and performances, in conjunction with shifts in circadian rhythm. Interestingly, this effect was also dependent on the compositional style. For example, results showed that the heart rate was significantly higher in performances of pieces by Tchaikovsky and Rachmaninov than in performances of music by Mozart. Interestingly, the fluctuations in heart rate were also present and even more pronounced among the supporting staff.

Bernardi et al. ${ }^{1}$ investigated the influence of different musical styles and movements on cardiovascular, cerebrovascular, and respiratory changes and examined both musicians and non-musicians. They were able to demonstrate that at fast tempos and rhythms, blood pressure, heart and respiratory rate were increased and cerebral flow velocity and baroreflex activity decreased. Interestingly, a habituation effect after repetition of the musical stimuli could not be measured. Musicians had a more pronounced respiratory response if they were compared to non- musicians. The authors concluded that music induces an "arousal effect" and that this effect is mainly associated with fast tempi. Slow tempi and pauses in contrast, tended to lead to a relaxation reaction.

Next to rhythm, sound levels and dynamics can also influence cardiovascular function and be related to blood pressure effects and hypertension. This has been studied in large human populations outside the musical arena. A case-control study by Zeeb et al. ${ }^{12}$ conducted in the vicinity of an international airport in 137,577 cases and 355,591 controls, for example, has pointed to a clear association between (traffic) noise levels and clinical hypertension. Fogari et al. ${ }^{4}$ had already reported earlier that chronic noise exposure above a threshold of 80 decibels was associated with an increased prevalence of hypertension in over 8000 workers in a metal processing factory. These exposures are comparable to noise levels in the orchestra pit and a study of orchestra musicians ${ }^{11}$ showed that values of sometimes well over $90 \mathrm{db}$ are also reached in this area, which could indicate an increased cardiovascular risk in this population similar to the populations mentioned above. However, there are no detailed studies yet that establish a causal connection between the cardiovascular risk, blood pressure effects and increased sound levels in the orchestra environment. For other areas exposed to chronically elevated sound volumes, such as traffic noise, the underlying mechanisms point 
towards a pathophysiological role of oxidative stress and vascular inflammation, as recently has been summarized by Daiber et $\mathrm{al}^{3}$, attributed to dysregulation of endothelial/neural nitric oxide synthase (NOS). It remains to be seen if similar effects are relevant in the orchestra pit. Interestingly, there have been some anecdotal reports of cardiovascular events of orchestra conductors occurring during the performance ${ }^{9}$, but one cannot conclude from these singular cases that there are causal links between sound exposure and the disease event.

In summary, it must be noted that music can have a variety of effects on cardiovascular function. Factors such as sound dynamics, volume, tempo and rhythm lead to changes in parameters such as blood pressure and heart rate. However, the evidence is not sufficient at this stage to attribute an increased cardiovascular risk to the workplace in the orchestra pit and on the concert stage, as there are no large case-control studies in humans in this area. Concerning the possible beneficial effects of music therapy, at one can at best suggest that this approach could be used as a complementary measure to established therapies. In terms of risk management, hypertensive individuals should certainly continue to enjoy listening to music. As with everything (and I am thinking again about poor Antonia in Offenbach's opera) maybe one should not overdose, as is the advice attributed to the medieval physician Paracelsus who supposedly said that "the dosage makes it either a poison or remedy".

\section{Martin Paul - m.paul@maastrichtuniversity.nl}

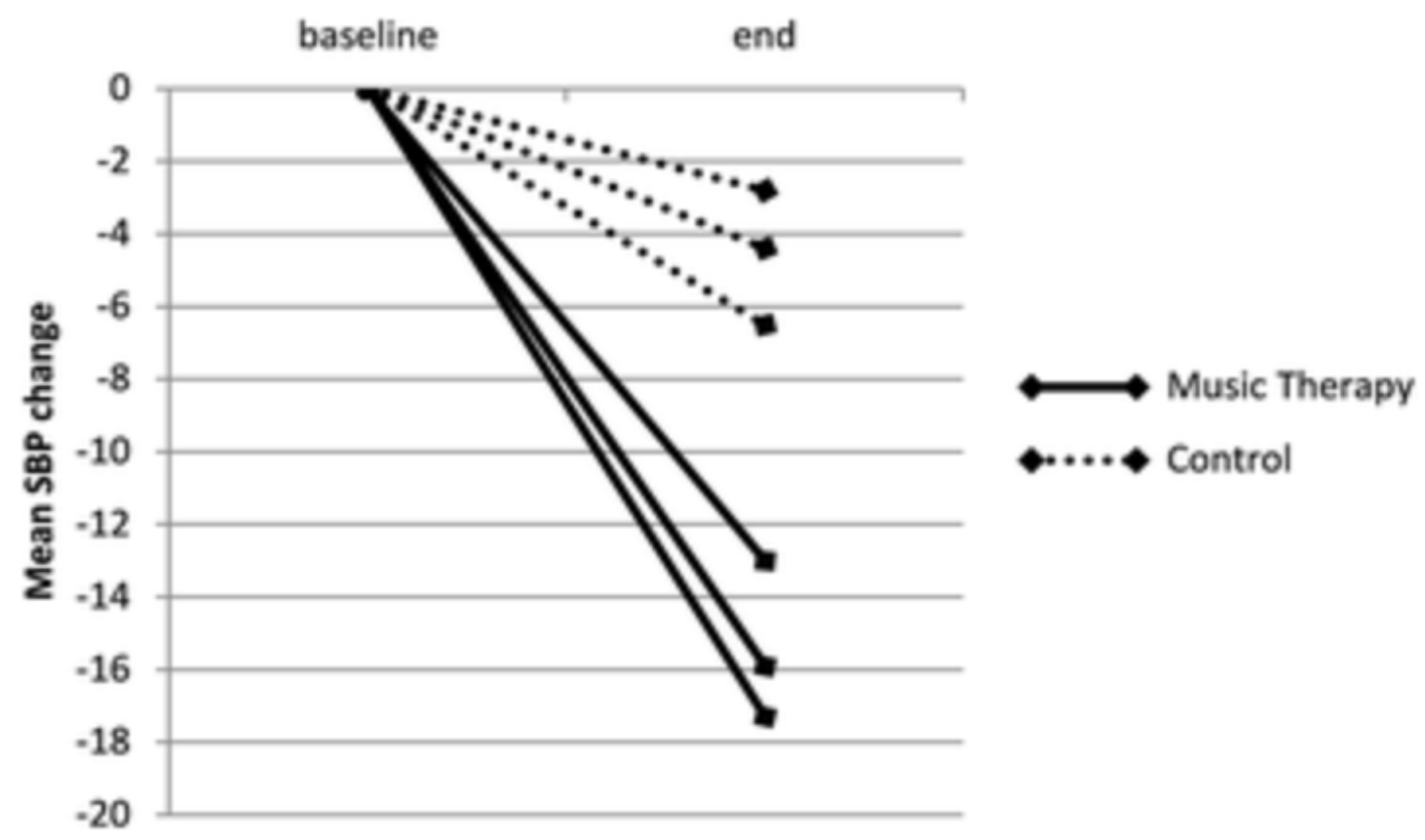

Figure 2: from review by Kuehlmann et al., BMC Cardiovascular Disorders (2016) 16:69

\section{REFERENCES}

1. Bernardi L, Porta C, Sleight P. Cardiovascular, cerebrovascular, and respiratory changes induced by different types of music in musicians and non-msicians: the importance of silence. Heart 2006; 9: 445-452. DOI: 10.1136/ hrt.2005.064600 
2. Chafin S, Roy M, Gerin W, Christenfeld N. Music can facilitate blood pressure recovery from stress. Br J Health Psychol. 2004 Sep;9(Pt 3):393-403. DOI: 10.1348/1359107041557020

3. Daiber A, Kroeller-Schön S, Oelze M, Hahad O, Li H, Schulz R, Steven S, Muenzel T. Oxidative stress and inflammation contribute to traffic noise-induced vascular and cerebral dysfunction via uncoupling of nitric oxide synthases. Redox Biol. 2020 Apr 20:101506.. doi: 10.1016/j.redox.2020.101506.

4. Fogari R, Zoppi A, Vanasia A et al. Occupational noise and blood pressure. J Hyp 1994; 12: 475-479

5. Holst GJ, Paarup HP, Baelum J. A cross-sectional study of psychosocial work environment and stress in the Danish symphony orchestras. Int Arch Occup Eviron Health 2011; 85,6: 639-649. doi: 10.1007/s00420-011-0710-z

6. Koelsch, Stefan; Jaencke, Lutz. Music and the heart. European Heart Journal 2015, 36(44):3043-3049. doi: 10.1093/eurheartj/ehv430

7. Kuehlmann AY, Etnel JR, Roos-Hesselink JW, Jeekel, . Bogers AJ, Takkenberg JJ. Systematic review and meta-analysis of music interventions in hypertension treatment: a quest for answers. BMC Cardiovascular Disorders (2016) 16:69. doi: 10.1186/s12872-016-0244-0

8. Mulcahy D, Keegan J, Fingret A. Circadian variation of heart rate is affected by environment: a study of continuous electrocardiographicmonitoring in members of a symphony orchestra. Heart 1990; 64:388-392. doi: 10.1136/hrt.64.6.388

9. Paul M. Death of the conductor - cardiovascular deaths on orchestra podium and opera stage. Dtsch Med Wochenschr 2012;13700: 2712-2714. doi: 10.1055/s-0032-1327363

10. Sutoo D; Akiyama K. Music improves dopaminergic neurotransmission: demonstration based onthe effect of music on blood pressure regulation. Brain Research 2004; 1016, 255-262. doi: 10.1016/j.brainres.2004.05.018

11. Schmidt JH, Pedersen ER, Juhl PM et al. Sound exposure of symphony orchestra musicians. Ann Occup Hyg 2011; 55,8: 893-905. doi: 10.1093/annhyg/mer055

12. Zeeb H, Hegewald J, Schubert M, Wagner M, Droege P, Swart E, Seidler A. Traffic noise and hypertension results from a large case-control study. Environ Res. 2017; 157:110-117. doi: 10.1016/j.envres.2017.05.019

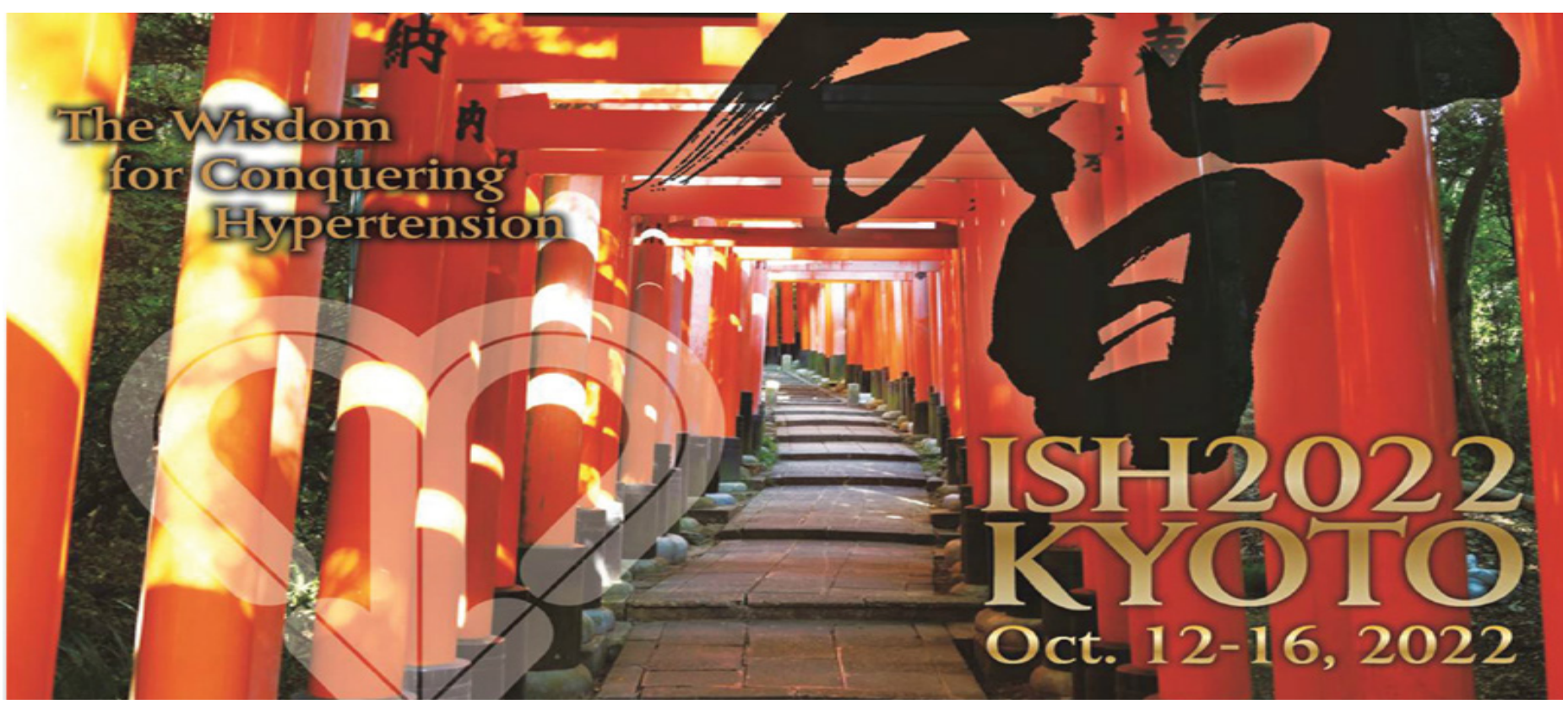




\section{"DDD" DYLAN'S DISTRIBUTION DATA}

DYLAN BURGER

Ottawa Hospital Research Institute

Ottawa, Canada

Quite a bit has changed since my last update on Hypertension News Distribution. The March issue was released to a strong reception but under the cloud of a global pandemic that affected all of our lives. Despite this, the March 2020 issue still received almost 5000 views. While a decrease from the previous issue this is still amongst our highest totals; a major accomplishment under the circumstances.

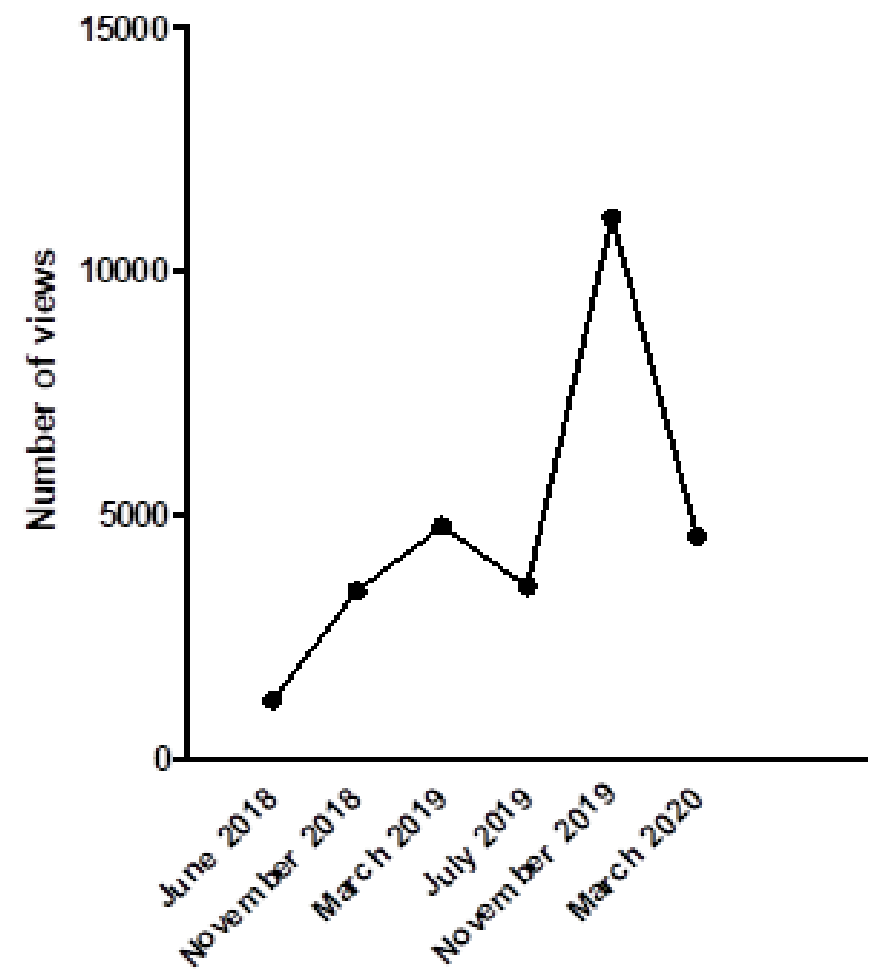

Dylan's Distribution Data (March 2020-May 2020)

\begin{tabular}{|l|l|}
\hline Total Estimated Readership & $\mathbf{4 5 6 0}$ \\
\hline Accessed via Twitter & 350 \\
\hline Accessed via Facebook & 318 \\
\hline Accessed via DOI & 3298 \\
\hline Accessed via Web Site & 594 \\
\hline
\end{tabular}

Dylan Burger - dburger@uottawa.ca

On 22 March 2020, when the Swedish Prime Minister Mr. Stefan Löfven addressed the Swedes on TV News, half the population watched. This applied to our family cats as well: On the photo, Don Pudro is watching while his sister Carmencita (for photo, see the March issue of HT News) is busy elsewhere. Most Swedes (stable 80+\%, over time) say that they follow the recommendations given by the Swedish Institute of Public Health.

Photo with permission from Li Winther (from the Lindholm family).

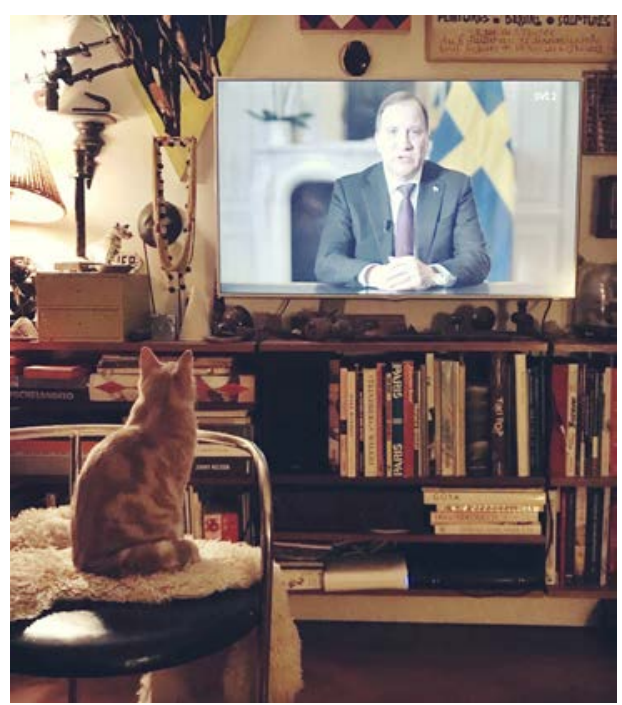




\title{
2020 ISH GLOBAL
}

HYPERTENSION GUIDELINES

The New 2020 ISH Global

Hypertension Guidelines: What is new, what is different?

\section{THOMAS UNGER}

CARIM - School for Cardiovascular Research,

Maastricht University, Maastricht, The Netherlands

\author{
ALTA SCHUTTE \\ Faculty of Medicine, University of New South Wales, \\ The George Institute for Global Health, \\ Sydney, Australia
}

DOI: $10.30824 / 2006-9$

On May 6, 2020, the International Society of Hypertension (ISH) has released new guidelines entitled "2020 ISH Global Hypertensive Practice Guidelines" which were published online concomitantly in the Journal of Hypertension and Hypertension. These guidelines follow those published by ISH in conjunction with the American Society of Hypertension (ASH) published in the Journal of Hypertension and Journal of Clinical Hypertension in 2014.
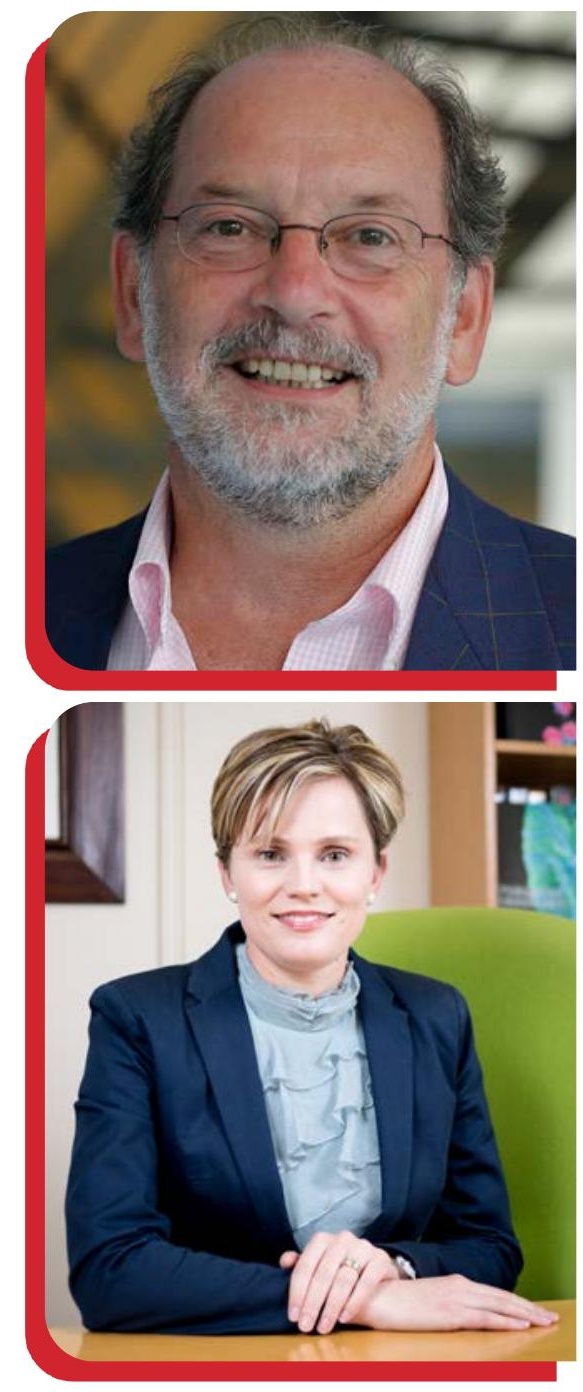

What is new, what is different from other clinical guidelines published in recent years?

New guidelines always have to justify their existence. Normally they do this by extracting most recent evidence from the literature exceeding or correcting earlier evidence on which their respective predecessors are based. One could also say, they reflect the evidence-based state of the art of a given time, period, and shape recommendations from current evidence. Since they want to be detailed and to exhaust the literature in a more or less comprehensive fashion, they tend to become quite voluminous which impairs readability and practical use. In addition, these guidelines, e.g. the recent ESH/ESC or ACC/AHA or Japanese hypertension guidelines, come from affluent regions of the world and predominantly subserve populations in high income settings or countries (HIC) where resources and facilities of medical care are abundant, but they tend to ignore the situation in less affluent settings, not only in low- and middle income countries (LMIC) but also in their own countries.

The new ISH hypertension guidelines are quite different in this respect, and this relates to their novelty. In the introduction of the ISH guidelines the authors state:

"...the adoption of guidelines from high income regions are sometimes impractical as low resource settings are confronted with a substantial number of obstacles including severe lack of trained healthcare professionals, unreliable electricity in rural clinics, low access to basic office BP devices and limited ability to conduct basic recommended diagnostic procedures and poor access to affordable high-quality medications. In both low and high income regions, the ambiguities of latest guidelines are often met with confusion among healthcare providers, anxiety among patients, and they resulted in a call for global harmonization. Guidelines from high income regions may thus not fit global purpose." 
In view of the fact that recent blood pressure trends show a clear shift of the highest blood pressures from high income-to low income regions with an estimated 349 million with hypertension in HICs and 1.04 billion in LMICs in 2010, it becomes clear that a globally acting society like ISH with the mission "to reduce the global burden of raised blood pressure" has to act by providing recommendations not only for HICs but also for low resource settings. And this is the major thrust of the new ISH guidelines.

To achieve this goal, the ISH guidelines committee decided for three major structural elements of the document:

1. not to review the current evidence again since this had been done by recent guidelines such as ESC/ESH- or ACC/AHA guidelines, but extract the evidence-based content from recently published guidelines and tailor them to the needs of both, high and low resource settings,

\section{2. advise on essential and optimal standards of diagnostics and care and}

3. make the guideline concise, simplified and easy to use by clinicians, nurses and community health workers.

\section{What is essential, what optimal?}

In the ISH guidelines this is defined as follows:

"Optimal care refers to evidence-based standard of care articulated in recent guidelines and summarized here, whereas essential standards recognize that optimal standards would not always be possible. Hence essential standards refer to minimum standards of care. To allow specification of essential standards of care for low resource settings, the Committee was often confronted with the limitation or absence in clinical evidence, and thus applied expert opinion."

This may be regarded as betrayal of the holy grail of evidence-based medicine, but it was felt to be an inevitable compromise.

Whereas most sections of the new ISH guidelines follow the principle of dividing the recommendations in essential (green) and optimal (blue) this was not always possible, for instance in the sections on cardiovascular risk factors or comorbidities. Also, the authors were aware of the fact that even "some recommended essential standards may not be feasible in low income settings, e. g. out-of-office blood pressure measurement, multiple visits for the diagnosis of hypertension of single pill combination therapy". But these limitations had to be accepted. Thus, under 'essential' recommendations, one often finds a remark as to feasibility, for instance when it comes to hypertension diagnosis: "Confirm office blood pressure with ABPM or home measurement if possible". Likewise, with respect to drug treatment: "If systematic, stepwise drug combination according to the recommended scheme (as under optimal conditions) is not available: Use any available drug to lower blood pressure."

The strict, almost continuous division between recommendations concerning essential versus optimal standards is certainly the hallmark and major raison d'être of our new ISH guidelines. However, there are several other features which differentiate them from previous ones.

In contrast to previous guidelines, definition and grading of hypertension have been simplified: "Normal Blood Pressure" is defined as up to $<130 / 85$ mm Hg followed by "High-normal Blood Pressure" up to 139/89 mmHg, followed by "Grade 1 Hypertension" (140-159/90-99 mmHg) and "Grade 2 Hypertension" (>160/100 mmHg).

The threshold of hypertension concurs with the one in the ESC/ESH guidelines but differs from the ACC/AHA guidelines in that "Hypertension" is defined from 140/90 $\mathrm{mmHg}$ and above versus ACC/AHA: 130/80 mmHg. Grade 1 Hypertension in the ISH guidelines thus corresponds to Grade 2 Hypertension in the ACC/AHA guidelines. In addition, in the new ISH guidelines there is no category of "Elevated blood pressure" as in ACC/AHA guidelines, and no category of "Optimal blood pressure" and "Grade 3 hypertension" as in the ESC/ESH guidelines. This simplifies the issue substantially and facilitates understanding of document.

Concerning drug treatment, the division into essential and optimal impacts mainly the essential part: Regarding optimal standards, treatment decisions and targets are pretty well aligned with the European- and to a certain degree also with the US guidelines, the difference comes again with the recommendations concerning 'essential' conditions: While under optimal conditions, blood pressure should generally be lowered to $<130 / 80$ 
$\mathrm{mmHg}$ except in frail elderly patients, the essential recommendations go for a general blood pressure reduction of $20 / 10 \mathrm{mmHg}$, ideally to $140 / 90 \mathrm{~mm}$ $\mathrm{Hg}$ (again individualized in the elderly based on frailty). This takes care of circumstances of poor drug availability, where blood pressure lowering as such is primordial to reduce cardiometabolic risk, whereas well defined, evidence-related blood pressure targets are less important.
In addition: If under 'essential' conditions in Grade 1 hypertensives blood pressure cannot be controlled after 3-6 months of lifestyle intervention, the guidelines recommend to start drug treatment in those aged 50-80 years. This aspect of triage may fuel discussions, but it merely recognizes the fact that under essential conditions, i.e. limited drug availability in this case, a practical choice has to be made.

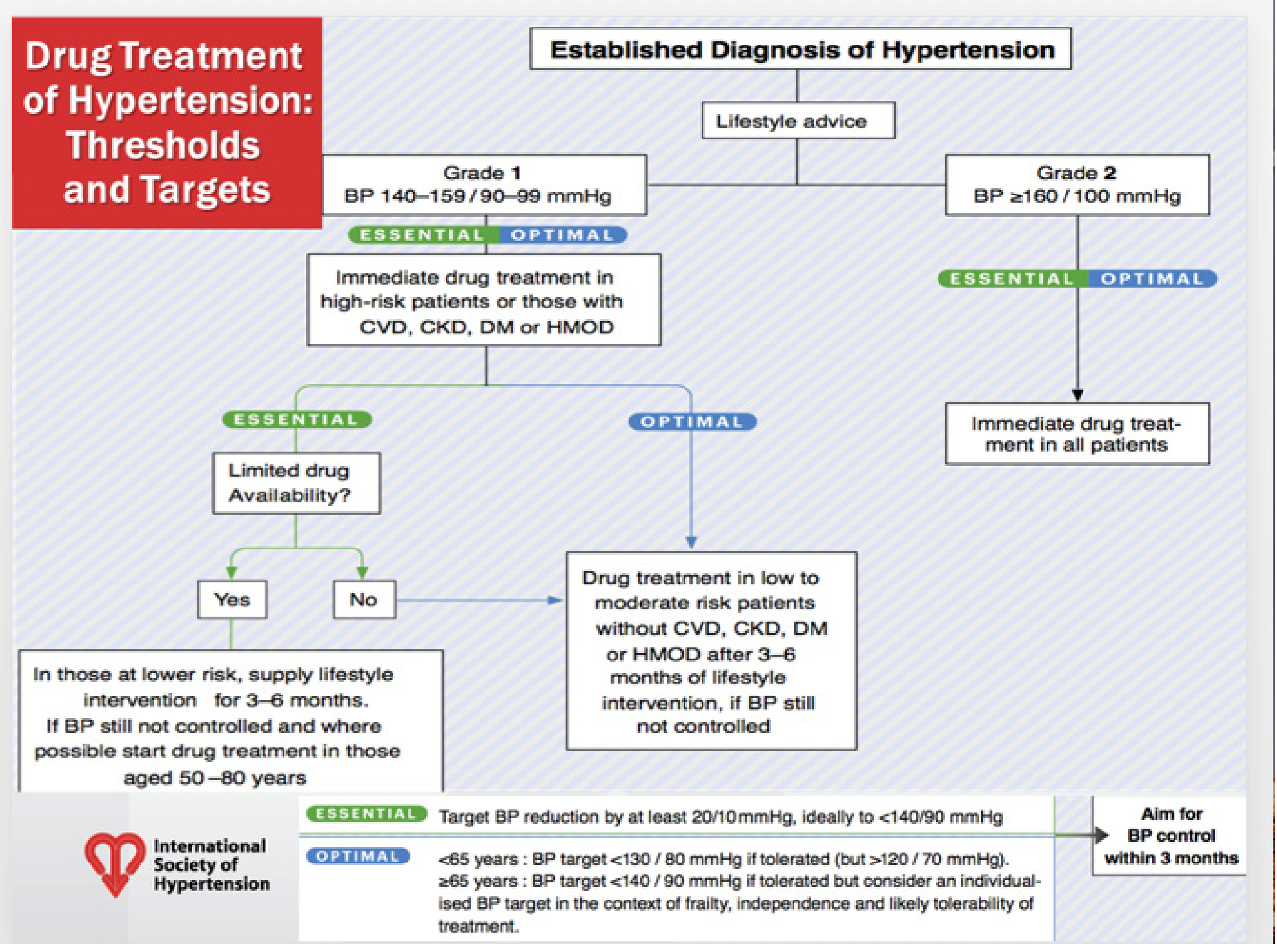

As outlined in a joined editorial in Hypertension and Journal of Hypertension by the respective editors, Anna Dominiczak and Giuseppe Mancia, there is another facet in the drug treatment section which distinguishes the new ISH guidelines from the previous European ones: Instead of going from the initial dual combination directly to triple drug treatment, there is an intermediate step in the ISH guidelines to increase the dose of the initial dual drug combination from low to high. The authors remark that this would provide physicians with a greater treatment flexibility giving them a major treatment advantage worldwide. Although this applies mainly to treatment in the realm of optimal conditions, the recent listing of single pill antihypertensive combination therapy in the Essential Medicines list of the World Health Organization, is likely to increase the availability of combination pills also in low resource settings. 
Further elements of novelty in the ISH guidelines include a detailed section on treatment adherence and how to monitor it as well as the introduction of stress avoidance and stress-reducing measures including the avoidance of air pollution wherever possible. New is also a detailed section on factors which may exacerbate or induce hypertension as well as a section featuring uncommon- besides common comorbidities and their management.

The specific influence of ethnicity and race on hypertension in different regions of the globe is given a special section with region-specific treatment recommendations

A final section with two comprehensive figures called "Hypertension management at a glance" constitutes a further novelty of the ISH Guidelines compared to previous ones.

This section also strictly follows the scheme of optimal versus essential summarizing the content of the forgoing pages. Thus, if the reader has no time or is unwilling to go through the whole document, he or she can obtain a concentrated message regarding essential and optimal conditions in a nutshell on two pages.

The guideline document closes with a detailed compilation of resources ranging from previous guidelines from Europe, USA, Japan, China, Latin America, recent guidelines on metabolic disorders, and specific sources of support for low resource settings to listings of validated electronic blood pressure devices and blood pressure management in pediatric populations. These sources of information serve the purpose of the new ISH Guidelines to provide hands-on, practical, and usable information around hypertension and related diseases.

A final note on the authors and reviewers of the ISH guidelines. Since the Council of the ISH include respected scientists from across the globe, the decision was made to make this an in-house writing effort. However, perhaps the most important aspect was to send a first draft of the guidelines to 12 external reviewers covering low to high resource settings, and upon revisions sending it out to another round of 12 external reviewers - with a specific focus to include those with expertise in LMICs. The reviews were comprehensive and contributed immensely to the final version of the published ISH guidelines.

In the introduction, the authors state:

"Although challenging to implement, these guidelines may aid in local initiatives to motivate policy changes and serve as an instrument to drive local improvements in standards of care. Every effort should be made to achieve essential standards of care to reduce hypertension-induced cardiovascular morbidity and mortality".

This represents a further aspect of the ISH guidelines, differentiating them from previous ones and reflecting again the global mission of the Society.

Thomas Unger - thomas.unger@maastrichtuniversity.nl

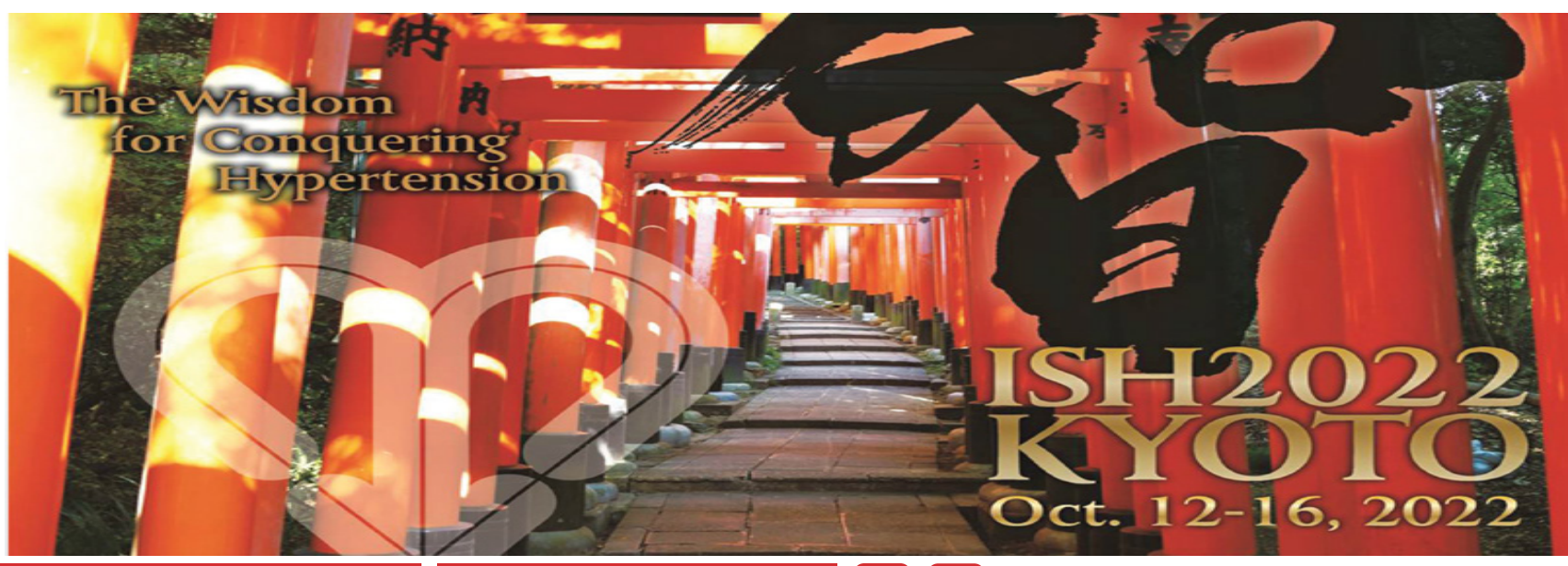




\section{ISH GLOBAL HYPERTENSION GUIDELINES}

Interview with Professor Thomas Unger about the Writing Process of the new ISH Hypertension Guidelines

DOI: $10.30824 / 2006-10$

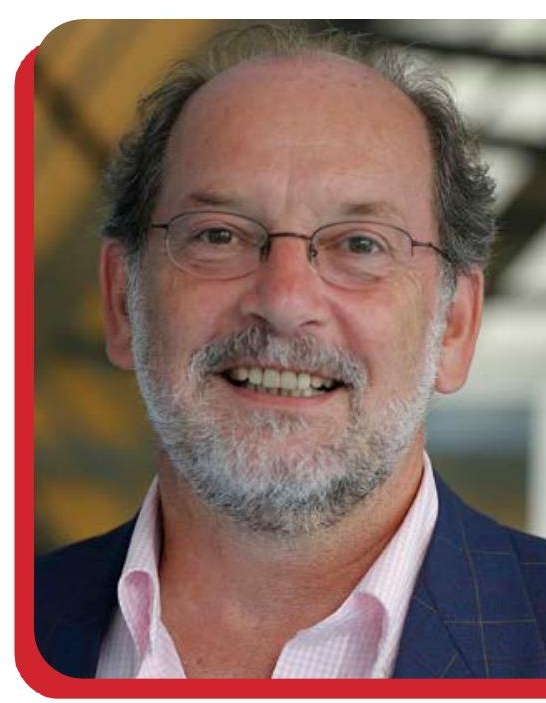

The new 2020 ISH Global Hypertension Practice Guidelines are out, published in the Journal of Hypertension and Hypertension. Hypertension News asked the chair of the ISH Guidelines Committee, Professor Thomas Unger, about the process of writing these guidelines.

HTN News: Professor Unger, why did you and your colleagues from the International Society of Hypertension (ISH) think you had to develop new hypertension guidelines?

Well, this idea had been born some years ago, when it became clear that current hypertension guidelines like the European, US-American or Japanese guidelines would cater for affluent settings in high income countries with abundant resources and facilities in medical care but not for the less affluent settings prevailing in low-and middle income countries and sometimes even in high income countries. It was felt that, in line with the global mission of our society, hypertension guidelines had to be developed with a global perspective which would help doctors, nurses and health workers to combat hypertension not only in high- but also in less affluent settings with limited resources.

HTN News: And how did you go about this demanding task?

Almost two years ago, I was asked by the current ISH president, Prof. Alta Schutte, to chair an ISH Guidelines Committee comprising thirteen members of the Scientific Council of ISH: Claudio Borghi, Fadi Charchar, Nadia Khan, Neil Poulter, Dorairaj Prabhakar, Agustin Ramirez, Markus Schlaich, Alta Schutte, George Stergiou, Maciej Tomaszewski, Richard Wainford, Bryan Williams and myself. They were selected on the basis of previous experience with guidelines writing as well as preclinical, clinical and epidemiological competence and international recognition in different areas of hypertension.

We had our first meeting in London, UK, on February 1st, 2019, to discuss the outline of our endeavor and to assign specific writing tasks to the individual members of the group.

HTN News: In this first round of discussions among the group, was the idea of writing these guidelines unanimous? Were there no critical voices?

Good question. I can tell you, there was a lot of skepticism. First of all, the question arose whether these new guidelines were necessary at all in view of so many excellent, comprehensive, evidence-based hypertension guidelines from several continents. 
Another question related to the issue of practicability in LMICS. And if one would go for the latter, would the guidelines not be too simplistic, ignoring the evidence from the literature? These questions were seriously discussed, but at the end there was consensus that new guidelines were indeed necessary if they could bridge the gap between the affluent and the not-so-affluent, if they were simple, easy to follow and concise.

\section{HTN News: That sounds great but how can you write guidelines ignoring the accumulated evidence?}

We did not ignore the evidence but decided to build on evidence-based existing guidelines such as the recent ESC/ESH or ACC/AHA hypertension guidelines, extract evidence-based content from them but then divide our guidelines structurally in two parts: Essential and Optimal.

\section{HTN News: What do you mean by this?}

Optimal means settings of abundance in medical resources and facilities as you can find in many regions of the industrialized world. Diagnostic and therapeutic recommendations would be evidence-based and similar if not identical to those in the existing guidelines from Europe, USA or Japan. In contrast, Essential takes care of the less affluent settings where evidence-based measures may not be feasible at all. Here, recommendations are no longer based on published evidence but switch to expert opinion.

HTN News: And you have divided the guidelines consistently into these two categories?

At least we tried whenever possible.

\section{HTN News: How did the story continue?}

We had further meetings in Paris, France, Frankfurt, Germany, and Glasgow, UK, to work on the first, second, and final draft. All sections of the first draft were reviewed by another member of the writing group and after this sent out to a first round of external reviewers selected along the criteria mentioned above; the second draft was distributed among a group of external reviewers with a special focus on LMICs. Together, we received comments from 24 external reviewers from all continents as listed in the publications of the document. Their comments and suggestions were taken very seriously, were meticulously discussed piece by piece in endless sessions, and finally incorporated in the paper. This was quite a demanding task, but the result was a substantial improvement of the guideline paper. We did not ignore the evidence but decided to build on evidence-based existing guidelines such as the recent ESC/ESH or ACC/AHA hypertension guidelines, extract evidence-based content from them but then divide our guidelines structurally in two parts: Essential and Optimal.

HTN News: Guidelines are consensus papers. Was there always consensus among the group members?

No, this degree of harmony was not to be expected and also not desired among experts coming from different areas, some of whom equipped with strong opinions. Consensus can only be reached after different, sometimes divergent, views have been allowed to be expressed and discussed. I remember vivid discussions on topics like drug treatment of hypertension, or how much alcohol reduction we should recommend, or what kind of recommendation should go into the essential versus the optimal box. The latter was the most delicate issue because we had to oscillate between evidence-based and expert opinion-based views, consider regional availabilities of resources and finally make a decision. For example: Under which conditions can serum uric acid or lipids be measured? 
Is the dipstick test available under 'essential' conditions? Should thiazide-like drugs be preferred to thiazides under conditions of limited drug availability? And so on. But in the end, all decisions were taken unanimously, and majority votes were not necessary.

HTN News: Once you had finalized the paper, how did you manage to publish so

We had spoken early-on to the editors of the Journal of Hypertension, Giuseppe Mancia, and Hypertension, Anna Dominiczak, and received immediate friendly accommodation. Both editors were interested to publish our new guidelines concomitantly, first online on May 6th followed by the printed versions in their June issues, and the managing teams of both journals did their utmost to guarantee a smooth transition from our text to publishable versions, trying to realize all our specific wishes in a very short period of time. We are extremely grateful to the editors and to the managing teams of both journals for all their efforts.

HTN News: Publication in journals is one thing but today, many people obtain their information also from the so-called social media. Did you consider these channels of disseminating the information?

Yes, we did. We created a slide deck, and on the day of the first online publication in the journals. i.e. May 6th, we made available a voluminous webinar where all members of the committee presented their individual sections and, moreover, where similarities and dissimilarities between the new ISH guidelines and the European, US American, Latin American and Japanese guidelines were discussed. This webinar is available through the homepage of ISH. In addition, a webinar with the Chinese Hypertension League $(\mathrm{CHL})$ with Professors Yuqing Zhang and Jiguan Wang was held on the same day. A press release was issued in many countries and several internet platforms were played on. All this was made technically possible by Dylan Burger, the Deputy Editor of Hypertension News, who is responsible within the ISH Scientific Council for communication issues and who masterly plays the piano of all kinds of internet communications.

HTN News: And now?

I utterly enjoyed working on the guidelines with such a nice group of colleagues, and now I'm quite relieved that we brought this demanding task to such a good end after all. At one point, we decided to write an update every two years. Let's see whether this promise will be held. But now, from the bottom of my heart, I would like to thank all those involved in this flagship endeavor of ISH helping to deliver our new baby.

It is worth noting that attention has been justifiably focused on the ISH Global Hypertension Practice Guidelines- released on May 6th. The response to the guidelines has been overwhelmingly positive. The guidelines reached more than 100,000 individuals on facebook and twitter combined and were featured in news articles in four languages. Our video series highlighting key components of the guidelines have been viewed more than 2400 times combined. Based on Altimetric data the ISH guidelines are rated in the top 5\% of all research outputs worldwide (and top $1 \%$ of all articles in Hypertension and Journal of Hypertension).

Dylan Burger 


\title{
2020 ISH GLOBAL HYPERTENSION GUIDELINES ISH returns to the fray with its own Global Guidelines
}

\author{
JOHN CHALMERS \\ The George Institute for Global Health; \\ University of New South Wales \\ Sydney, Australia
}

DOI: $10.30824 / 2006-11$

A welcome and successful return by the ISH to the crowded field of Guidelines for the Management of Hypertension!

The Mission of the ISH is reflected in its own Guidelines!

Congratulations to the current Council of the ISH for biting the bullet and re-entering the field of guidelines for the management of hypertension ${ }^{1}$ 2 and doing so in a unique fashion suited to the particular mission of the ISH in the crowded space of guidelines commissioned by societies of hypertension or allied disorders. Because the ISH had traditionally accepted responsibility for advising on the management hypertension at the global level, including the vast mass of patients living in disadvantaged communities spread around the world, with large concentrations in Africa, Asia and Latin America. To that end, the ISH had partnered with the World Health Organisation to produce a series of Guidelines known as the "WHO-ISH Guidelines" or "Statements" from the throughout the !970s, through the 1980s and 1990s to 2003, before vacating the field (except for one joint effort with the American Society of Hypertension in 2014, ${ }^{3}$ ), as the task became increasingly laborious, and was taken over by continental and national societies with greater resources and ease of communication at the geographic level. However the SPRINT trial ${ }^{4}$ published in 2015, stimulated a spate of new guidelines from North America, Europe and Asia ${ }^{5}$ $6,7,8,9$ and it is gratifying to see this new set of ISH Guidelines contributing, and bringing its own unique perspective. These ISH guidelines are unusual in separating their recommendations into those that are "ESSENTIAL" and thus applicable to all patients, including those in disadvantaged communities, or in Lower and Middle Income Countries (LMIC), and those that are "OPTIMAL" and thus more suited for use in high income countries (HIC) that can afford more expensive procedures and equipment. This simplifies the tasks for community doctors, nurses, and health care workers, practicing in less affluent societies, who for example would not need to measure blood pressure (BP) using Automated Unattended Blood Pressure Measurement (AOBPM). And even more, it simplifies the regimen for treatment as clearly shown in differentiating the choices for drug treatment (see Figure 1), between those in high income situations, who go down the OPTIMAL path and are offered a progression of single pill combinations (SPC), whereas those in LMIC go down the ESSENTIAL path and are basically offered whatever drugs are available locally, to try and build rational combinations when SPC are not available.

\section{Some Notable Features}

First, congratulations on keeping the guidelines down to just over $\mathbf{2 0}$ pages! including the references, and with good tables and figures. That makes such a difference for the poor, overworked reader, when compared to say the most recent European Guidelines at 90 pages or the American Guidelines at 170 pages. Different missions and different target audiences, but for a physician or nurse in rural practice in India, or Vietnam, or Nigeria or Brazil, that would make a very welcome difference!! 
Second, a bouquet for backing combination treatment without any hesitation in the OPTIMAL pathway, and with sensible compromise in the ESSENTIAL pathway, and for recommending SPC therapy for all patients who warrant drug therapy, including for the initiation of therapy. Thus, for patients in high income situations, drug therapy starts and continues with SPC, initially low-dose combinations of two drugs, usually at half the standard dose, followed if necessary by dual full dose SPC, and then if necessary by a triple combination, whereas patients in less fortunate situations make do with whatever drugs are available to get as close to the ideal as possible, with good diagrams to illustrate both pathways (see Figure 1).

\section{Essential}

- Use whatever drugs are available with as many of the ideal characteristics (see Table 9) as possible.

- Use free combinations if SPCS are not available or unaffordable

- Use thiazide diuretics if thiazide-like diuretics are not available

- Use alternative to DHPCCBs if these are not available or not tolerated (i.e. Non-DHPCCBs: diltiazem or verapamil).
Ideally Single Pill

Combination

Therapy (SPC

\section{Optimal}
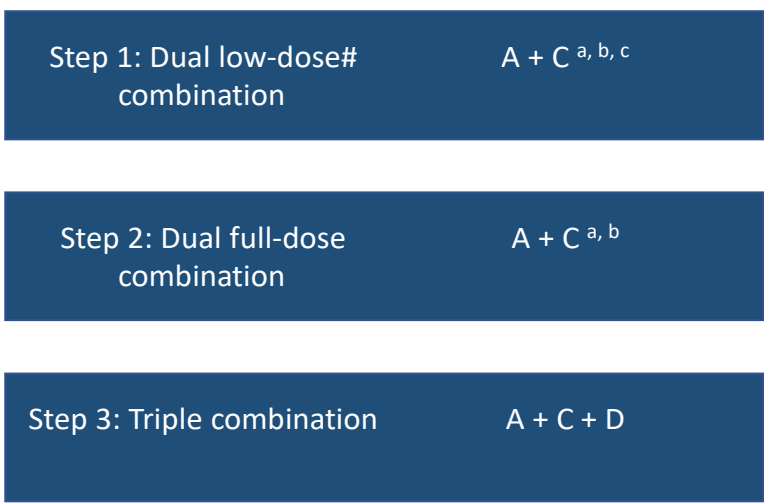

Step 4: (Resistant

Hypertension)

Triple Combination

+ Spironolactone or other drug*

\section{Essential \\ and \\ Optimal}

Consider beta-blockers at any treatment step when there is a specific indication for their use, e.g. heart failure, angina, post-MI, atrial fibrillation, or younger women with, or planning pregnancy. a) Consider monotherapy in low risk grade 1 hypertension or in very old ( $\geq 80 \mathrm{yrs}$ ) or frailer patients.

b) Consider $A+D$ in post-stroke, very elderly, incipient heart failure or CCB intolerance.

c) Consider A + C or C + D in black patients.

d) Caution with spironolactone or other potassium sparing diuretics when estimated GFR $<45 \mathrm{ml} / \mathrm{min} / 1.73 \mathrm{~m} 2$ or $\mathrm{K}+>4.5 \mathrm{mmol} / \mathrm{L}$.

$A=A C E-I n h i b i t o r$ or ARB (Angiotensin Receptor Blocker)

$\mathrm{C}=\mathrm{DHP}-\mathrm{CCB}$ (Dihydropyridine -Calcium Channel Blocker)

$D=$ Thiazide-like diuretic

Supportive references: $A+C, 69,70$ Spironolactone, ${ }^{71}$ Alpha-blocker, ${ }^{72} C+D^{73}$.

* Alternatives include: Amiloride, doxazosin, eplerenone, clonidine or beta-blocker. \# low-dose generally refers to half of the maximum recommended dose

RCT-based benefits between ACE-I's and ARB's were not always identical in different patient populations. Choice between the two classes of RAS-Blockers will depend on patient characteristics, availability, costs and tolerability

\section{Figure 1: ISH Core Drug Treatment Strategy.}

Adapted from Hypertension. 2020;75:1334-1357, Journal of Hypertension. 2020, 38(6):982-1004 
The Guidelines are also unusual in being written by the members of the Council, that is by the members of the governing body of the organisation. While members of a Governing Council or Board are normally responsible for setting the organisation's mission and strategy, it must be unusual for the members of the supreme body in any major organisation, to be those asked to actually write the detailed proposal for how to improve the mission and the daily business of the organisation, and even more unusual to see something sensible emerge! But, I have to say it worked well in this instance, probably because the ISH tries hard to make sure its Council does consist of individuals, each of whom does understand hypertension, and who between them do represent the many disciplines involved and the many large human populations with hypertension on our planet, including that disadvantaged majority that lives in LMIC!

The Measurement of $\mathrm{BP}$ recommended is pretty standard, but very thoroughly described, including out of office BP, with AOBPM only recommended for OPTIMAL situations. Hypertension is defined as $\geq 140 / 90 \mathrm{mmHg}$ when measured in the office or clinic, and the target BP is set at $\leq 140 / 90 \mathrm{mmHg}$ for low risk patients with treatment starting with lifestyle modifications, and at $\leq 130 / 80 \mathrm{mmHg}$ for patients with significant risk factors such as overweight-obesity or diabetes, or Hypertension

The classification of Hypertension, based on office BP (Based on figure1)

\section{$\mathbf{m m H g}$}

Normal BP

$<130 / 85$

High Normal

$130-139 / 85-89$

Definition of Hypertension $\geq 140 / 90$

$140-159 / 90-99$

Grade 2 Hypertension

the $w \geq 160 / 100$

Mediated Organ Damage (HMOD), with easy to read tables and figures to assist the reader. But it is interesting that the authors recommend a target of $\leq 140 / 90 \mathrm{mmHg}$ for those with significant comorbidities over 65 years, instead of $\leq 130 / 80 \mathrm{mmHg}$, which suggests that in effect like many other authorities around the world, they have only accepted part of the messages from SPRINT, and were not convinced by the finding that those over the age of 75 did best with the more intensive BP regime, but there is of course much other evidence to bear on this much debated topic. There are simple but comprehensive sections on lifestyle measures, and importantly on adherence to recommended drug therapy, with a good reminder of the stark findings from the PURE study that the rule of halves still holds and that more patients fail to take their tablets than those that do actually swallow them!

But I am full of admiration that quite apart from these main messages and sections, the authors have succeeded in fitting in useful sections on a large number of important conditions, all within their $20+$ pages!

These include sections on "Common and other comorbidities and complications" which go beyond the expected conditions of Coronary disease, Stroke, Heart Failure, Chronic Kidney Disease, and Diabetes, to include Inflammatory Diseases, Psychiatric Diseases, and quite considerable sections on Secondary Hypertension, on Exacerbators and Inducers of Hypertension, and on Resistant Hypertension. But there are also quite useful pages devoted to Hypertension in Pregnancy, to Hypertensive Emergencies and to Ethnicity, Race and Hypertension. And there are schematic single page diagrammatic summaries of the whole of the ESSENTIAL pathway and the OPTIMAL pathway each of which could easily be printed out onto two sides of an A5 card for carrying on busy daily rounds in hospital or community practice.

\section{A Bouquet to the authors for a very valuable contribution!}


1. Unger T, Borghi C, CharChar F, et al. 2020 International Society of Hypertension global hypertension practice guidelines. Journal of Hypertension 2020;38:982-1004. doi: 10.1097/HJH.0000000000002453

2. Unger T, Borghi C, Charchar F, et al. 2020 International Society of Hypertension Global Hypertension Practice Guidelines. Hypertension 2020;75:00-00.doi:10.1161/ HYPERTENSIONAHA.120.15026

3. Weber MA, Schiffrin EL, White WB, et al. Clinical Practice Guidelines for the Management of Hypertension in the Community. A Statement by the American Society of Hypertension and the International Society of Hypertension. J Hypertension 2014;32:315 doi: $10.1097 / \mathrm{HJH} .0000000000000065$

4. Wright JT, Williamson JD, Whelton PK et al for the SPRINT Research Group. A randomised trial of intensive versus standard blood pressure control. N Engl J Med 2015;373:21032116. doi: 10.1056/NEJMoa1511939

5. Whelton PK, Carey RM, Aronow WS et al (2017) ACC/AHA/AAPA/ABC/ACPM/AGS/APhA/ ASH/ASPC/NMA/PCNA Guidelines for the prevention, detection, evaluation and management of high blood pressure in adults: a report of the American College of Cardiology/American Heart Association Task Force on Clinical Practice Guidelines. J Am Coll Cardiol. 2018;71:e127e248 doi: 10.1016/j.jacc.2017.11.006 [published Online First 2017/11/18]

6. Williams B, Mancia G, Spiering W et al. 2018 ESC/ESH Guidelines for the management of arterial hypertension. Journal of Hypertension 2018; 36:1953-2041. doi: 10.1097/HJH.0000000000001940

7. Nerenberg K, Zarnke KB, Leung AA et al, Hypertension Canada's 2018 Guidelines for Diagnosis, Risk Assessment, Prevention, and Treatment of Hypertension in Adults and Children. Canadian Journal of Cardiology 2018; 34:506-525. doi: 10.1016/j.cjca.2018.02.022

8. The National Institute for Health and Care Excellence. Hypertension in Adults: diagnosis and management. NICE guideline 136.London. National Institute for Health and Care Excellence 2019. https//www.nice.org.uk.guidance/ng136

9. The Japanese Society of Hypertension Guidelines for the Management of Hypertension (JSH 2019). Hypertension Research 2019;42:1235148 doi:10.1038/s41440-019-0284-9

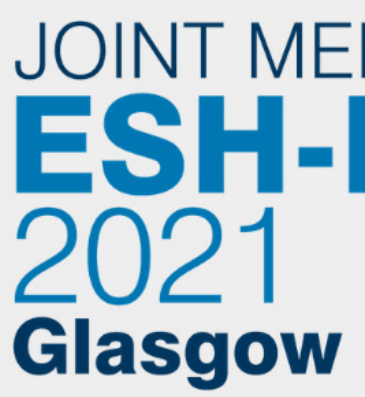

April 11-14, 2021 Scottish Event Campus Glasgow, United Kingdom www.hypertension2021.org
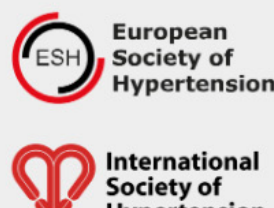

Hypertension

$\downarrow \mathrm{BHS}$ hub

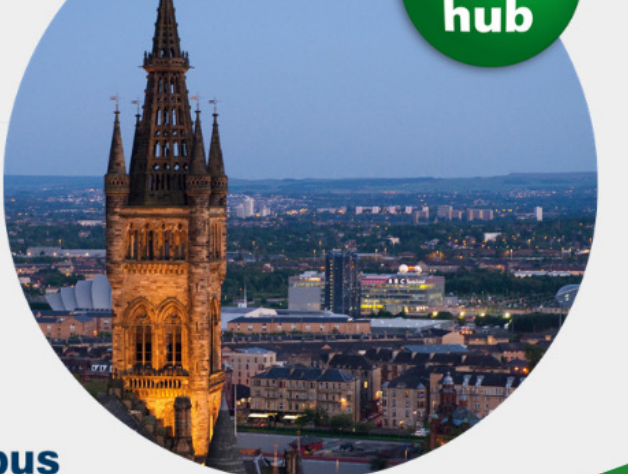
B.HS

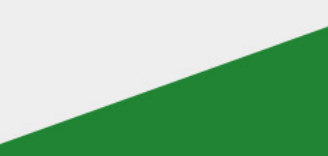




\title{
THE CURRENT COVID-19 PANDEMIC AND HYPERTENSION
}

\section{Pharmacology of renin-angiotensin- system blockers and COVID-19: confusion around ACE2}

\author{
REINHOLD KREUTZ \\ Institute of Clinical Pharmacology and Toxicology, Charitè, University Medicine \\ Berlin, Germany
}

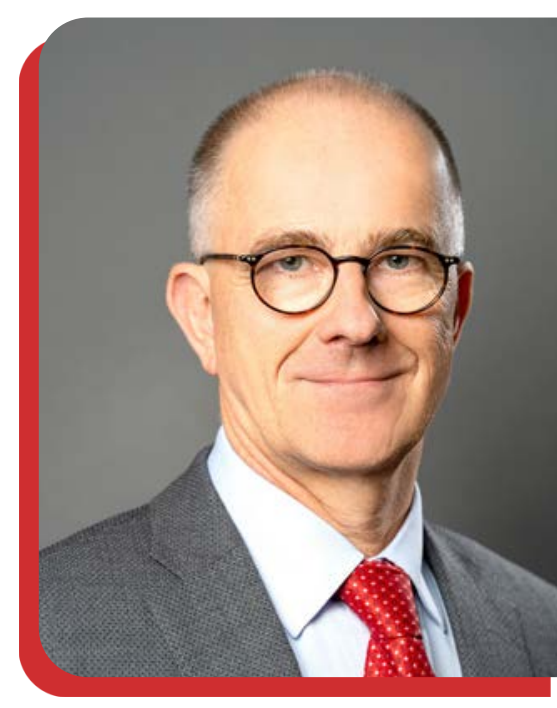

DOI: $10.30824 / 2006-12$

The Renin-Angiotensin System (RAS) is one of the most important blood pressure regulating systems with several effectors, the angiotensin peptides. These are split off from the high-molecular protein angiotensinogen by the enzyme renin and are subsequently generated by other enzymes including the angiotensin-converting enzymes (ACE). The classical $A C E$, which is designated by the abbreviation "ACE", generates angiotensin II (Ang II) as the main effector peptide in the RAS by converting the decapeptide angiotensin I (Ang 1-10) into the octapeptide angiotensin II (Ang 1-8).

Twenty years ago, another enzyme, homologous to ACE was identified ${ }^{1}$ and named ACE2 2,3. Both ACE2 and ACE are very strongly membrane-bound enzymes ${ }^{2,3}$. On the other hand, smaller soluble molecules for ACE and ACE2 can be generated from the respective membrane-bound forms by cleavage and shedding from the membrane. These soluble forms circulate in blood plasma and other body fluids.

Initially, only basic but not clinical scientists were mainly concerned with ACE2, because its clinical relevance was considered low due to its potentially minor role within the RAS. The most important difference between ACE and ACE2, which was already described in the discovery, relates to the fact that ACE2 cannot be inhibited by ACE inhibitors (ACEI) ${ }^{1,4}$. This is due to important structural differences between ACE and ACE2, which affect the respective active center of the enzyme and also explain the differences in their functions. Thus, ACE is a dipeptidyl carboxypeptidase and the most important enzyme for the conversion of Ang I to Ang II. ACE2, in contrast, is a mono-carboxpeptidase, which cleaves one amino acid at the end of peptides and forms another peptide from Ang II with only seven amino acids, i.e. Ang-(1-7). In addition, ACE2 can also cleave one amino acid from Ang I to form Ang 1-9 (Figure 1).

The main axis in the RAS cascade, which is crucial for blood pressure control and aldosterone secretion, concerns the signaling pathway from Ang II to the angiotensin type 1 receptor $\left(A T_{1} R\right)^{4}$. Importantly, by inducing prooxidative, proinflammatory and profibrotic changes, this Ang II/AT $R$ axis is also involved in organ injury not only in the cardiovascular system but also in the lung (Figure 1) and other organs ${ }^{4,5}$. In addition to this damaging axis, the RAS has at least two other counter-regulatory (protective) arms. One arm concerns the signaling pathway via the angiotensin type 2 receptor ( $A T_{2} R$ ), which is also mainly activated by Ang II but additionally also by Ang 1-9. The other, not so long known arm concerns the Mas receptor (MasR) signaling pathway, which is mainly activated by Ang 1-73. Of interest, ACE2 has a pivotal role as the main enzyme responsible for Ang 1-7 formation. The ACE2/Ang 1-7/MasR axis mediates vasodilation, antioxidant, anti-inflammatory and antifibrotic protective functions ${ }^{5}$. ACE2 is formed in the epithelial cells of the upper and lower respiratory tract and in type II alveolar epithelia, among others 5 . In several lung injury models (e.g. sepsis) in animals, impressive protective effects of the ACE2/Ang 1-7/ MasR axis have been demonstrated ${ }^{5,6}$. 
In contrast, activation of the Ang II/AT $R$ axis promotes lung damage. Accordingly, treatment with ACEI or AT, R antagonists (angiotensin receptor blockers [ARB]) may protect the lung6.

\section{New perspective on ACE2 from SARS - coronary viruses}

The view of ACE2 was impressively expanded in 2003 when ACE2 was discovered as a receptor for the binding of the coronary virus (SARS-CoV) responsible for the Severe Acute Respiratory Syndrome (SARS) disease?. This resulted in an unexpected new link between virology and cardiovascular medicine via ACE2 and the RAS. After this relationship had receded into the background after the end of the SARS epidemic in 2002 and 2003, the link between ACE2 and SARS-CoV-2 has currently regained a very strong prominence in the context of the COVID-19 pandemic (Figure). This resulted from the finding that ACE2 is also the binding receptor for SARSCoV-2 responsible for COVID-198. Accordingly, all cells expressing ACE2 and in addition co-express the cellular serine protease TMPRSS2 as another necessary cofactor on their cell surface, can potentially take up and replicate SARS-CoV-2 (Figure 1).

Since the beginning of the COVID-19 pandemic, this connection between ACE2 and COVID-19 has provoked numerous articles, comments and speculations in scientific journals, the press and social media. The concern was raised, that ACEI and ARB might increase the risk of infection and complicate the clinical course of COVID-195,9. Although, as mentioned above, ACEI cannot bind and inhibit ACE2, there are several interactions and feedback loops between the individual components in the RAS 4 . The most well-known is the negative feedback between Ang II on renin secretion via AT, $R$, which explains the high renin levels under therapy with ACEI and ARB. The discussion on the link between ACE2 and the use of RAS blockers was fueled mainly by animal studies that showed a potential upregulation of ACE2 in cardiovascular organs and the kidney after treatment with RAS blockers (especially ARBS) $)^{5}$. It appears, however, that many authors speculating on this link dismissed - among other issues such as concentration dependent basic pharmacological aspects ${ }^{9}$ - to differentiate between the reported effects of RAS blockers on mRNA levels vs. membrane-bound ACE2 tissue protein or soluble ACE2 protein levels (e.g. in the urine), and the resulting potential to modulate COVID-19. If an upregulation of membrane-bound ACE2 protein in response to RAS blocker treatment would indeed occur in humans, one could assume that RAS blockers might increase infectivity for SARS-CoV-2 and thereby exhibit an unfavorable influence on COVID-195. However, a comprehensive assessment of the complex interactions in the RAS and their modulation by RAS blockers as well as their relation to the pathogenesis of COVID19 infection shows that fears of an increased risk from RAS blockers in COVID-19 are not justified according to current knowledge 5,9. The decisive factor here is that a systematic evaluation of the findings published to date has not consistently demonstrated an upregulation of the ACE2 protein at the tissue level ${ }^{5}$. Most importantly, no significant effect of RAS blockers on ACE2 membrane-bound protein in the respiratory tract, as the key entry system for SARS-CoV-2, has been demonstrated ${ }^{5}$. In parallel with this critical appraisal, several statements were published by national and international societies including the European Society of Hypertension and the International Society of Hypertension.

In summary, it was recommended that the treatment with ACEI and ARB in stable patients with hypertension or other indications should not be discontinued or withheld due to concerns during a COVID 19 pandemic. Meanwhile, several well conducted important observational studies that included relatively large numbers of COVID-19 patients and that explored the impact of RAS blockers on COVID-19 were reported in May 2020 (summarized in [10]). Taken together, these studies did not find any evidence for a harmful effect of RAS-blocker use on COVID-19. More details and a clinical perspective on this topic will be discussed in an accompanying article of this issue by Murray Esler. 


\section{THE CURRENT COVID-19 PANDEMIC AND HYPERTENSION}

\section{COVID-19 and hypertension}

MURRAY ESLER

Baker Heart and Diabetes Institute, Melbourne

\section{DANIELLE ESLER}
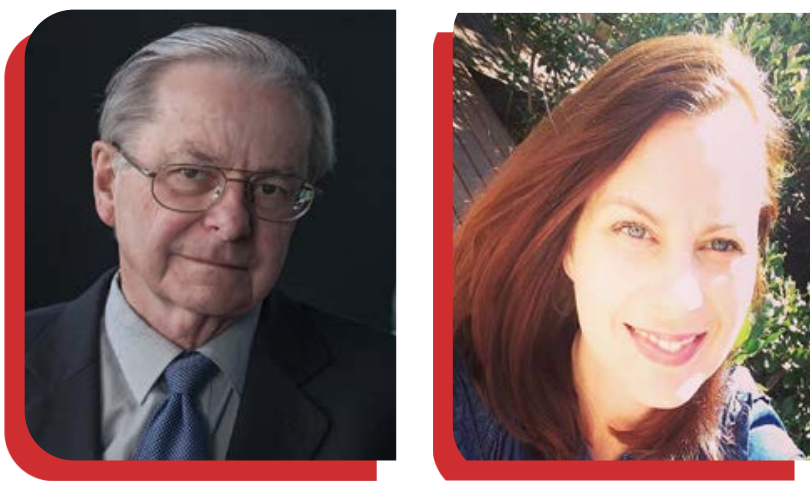

Baker Heart and Diabetes Institute, Melbourne, Australia

Public Health Directorate, Northern Territory Department of Health, Australia

DOI: $10.30824 / 2006-13$

As the COVID-19 pandemic intensified, an early report from Italy indicated that patients with hypertension were at greater risk of developing severe illness, of being admitted to intensive care units, and of succumbing to their illness ${ }^{1}$. This is perhaps a real and independent phenomenon ${ }^{1}$ but, alternatively as suggested by the well-designed study of Mancia and colleagues in the same region of Italy², more likely results from confounding by the age-dependence of hypertension, and from associated comorbidities in the Lombardy communities ${ }^{2}$. If patients with hypertension are at particular risk for severe COVID19 this would be unexpected, as hypertension does not appear to impact other infections. But some medical scientists, including the authors, were not convinced that multivariate analyses of clinical data bases in COVID-19 trouble spots ${ }^{2}$ totally cancels out a possible independent effect of hypertension on disease severity, although at first there were no clues why, for hypertensive patients, the COVID-19 pandemic should be a special case.

\section{Is Pharmacological Renin-Angiotensin Blockade Harmful in COVID-19?}

Unlike other infectious agents, SARS-CoV-2 interacts directly with a cardiovascular regulatory enzyme, ACE2. Viral entry into pulmonary and other cells occurs via membrane ACE2 binding 3 . This came as a revelation to many, especially those working in cardiovascular medicine. Cardiologists and hypertension specialists familiar with ACE2 wondered whether the method of pulmonary cell entry by the coronavirus could perhaps be significant in the morbidity and mortality profile of the illness, particularly in the context of hypertension co-morbidity.

Given the importance of ACE2 in SARS-CoV-2 entry to cells, cardiovascular illnesses or cardiovascular drugs which increase ACE2 expression, and there are several important instances of this ${ }^{4-7}$, could possibly increase human SARS-CoV-2 infectivity and illness severity. Perhaps in the COVID-19 pandemic a new infection risk was arising from special properties of some antihypertensive drugs? Pretty much simultaneously four research groups, including our own, published the suggestion that drugs blocking the renin-angiotensin system may be implicated ${ }^{5,8-10}$, by increasing ACE2 expression, which they commonly do $\left({ }^{6,7}\right)$. This idea does have plausibility. Several types of experiment in animals give credence to the idea that the level of ACE2 expression may perhaps be important in COVID19 infection. Knockout mice genetically modified to have no ACE2 are totally resistant to coronavirus infections ${ }^{11}$. And the converse; transgenic mice bred to over-express human ACE2 exhibit markedly increased infectivity and lethality when exposed to SARS coronavirus ${ }^{12,13}$. A general principle might apply, using an analogy drawn from chemical transporter kinetics, where the rate of reaction is determined by:

- (i) Affinity of the transporter for the substrate

(in this case of ACE2 for the SARS-CoV-2 virus)

- (ii) The number of transporter active sites (here, amount of ACE2 protein in cell membranes)

- (iii) The substrate concentration (in this case coronavirus load). 
The obvious difference is that the active site and substrate are not in kinetic equilibrium, as the ACE2 and coronavirus are internalized after binding.

How might the hypothetical RAS-blockers adverse effect on COVID-19 be tested? One method would be to administer RAS-blockers to COVID-19 sufferers and evaluate the effects. This is actually being done (see, ClinicalTrials.gov Identifier: NCT04312009) for another reason, to test whether RAS-blockade is actually beneficial in the severe illness, with the logic for this described below. Possibly the most immediate and direct clinical testing should come from interrogating the pandemic data bases of China, Italy, France, Spain United Kingdom or United States. From these populations, presence of COVID-19 illness, illness severity and death could be matched against, age, pre-existing medical diagnoses and drugs prescribed at the onset of COVID-19 illness. Perhaps the most convincing analysis of this type was performed by Mancia and colleagues in Lombardy ${ }^{2}$, who found in a large casecontrol analysis an unadjusted apparently adverse effect of all antihypertensives, but this disappeared with multivariate analysis which cancelled out the effect of higher prevalence of cardiovascular disease in RAS-blocker users. There was no evidence that ACEinhibitors or angiotensin receptor-blockers specifically affects the risk of COVID-19. Importantly, if the studies testing whether dosing initiated with ACE-inhibitors or ARBs given during COVID-19, hoping for benefit, actually cause harm this conclusion will need revision.

What remained after multivariate analysis in the Lombardy population was substantially greater use of loop diuretics and spironolactone in COVID19 patients. This might provide an important lead, suggesting COVID-19 risk from these drug classes, this being consistent with the finding that reduction in body sodium, quite independent of ACE-inhibitors and ARBs, increases ACE2 expression. Mineralocorticoid block with spironolactone and loop diuretics increases ACE2 expression ${ }^{14}$; conversely aldosterone and dietary sodium loading reduce ACE2 expression ${ }^{15,16}$.

\section{Pulmonary ACE2 in severe lung injury: A potential therapeutic target?}

The case was first presented in relation to the SARS epidemic ${ }^{11}$ that in severe lung injury pulmonary ACE2 is depleted. A special form of this pulmonary ACE2 depletion is seen with coronavirus infections, where after the virus binds to the ACE2 protein both are internalized, depleting membrane ACE2 ${ }^{11}$.
Depletion of ACE2 is accompanied by accumulation of angiotensin, its substrate, in the lung, with adverse effects. Renin-angiotensin block, through repleting ACE2, is beneficial in non-coronavirus acute respiratory disease caused by influenza viruses, acid inhalation and other noxious influences ${ }^{17}$. Could this benefit extend to COVID-19 infection?

A trial of the ARB losartan in severe COVID-19 infections, based on this line of thinking mentioned above, has commenced (ClinicalTrials.gov Identifier: NCT04312009). But is it possible that such a trial could carry risks of worsening the infection? Benefit from renin-angiotensin system block in acute severe lung disease has not been shown experimentally in coronavirus infections. Augmenting pulmonary ACE2 expression might increase coronavirus uptake and viral load. The classic study of Kuba et $\mathrm{al}^{11}$ is often misquoted as providing evidence of ARBs and ACEinhibitors benefiting coronavirus pneumonia. Kuba et al ${ }^{11}$ actually administered coronavirus fragments, spike protein, not replicable entire virus. The spike fragments depleted pulmonary ACE2 after binding, aggravating the existing experimental pneumonia, which was improved by pharmacological reninangiotensin system block. Neither this study, or any others to our knowledge, have demonstrated benefit or renin-angiotensin block in coronavirus infection. Augmentation of virus uptake and replication might overwhelm any specific pulmonary benefits. The empirical results of the RAS-blocker dosing trials in COVID-19 will inform what has become a theoretical impasse.

\section{Antiviral drugs}

The pro-drug Remdesivir, which targets the SARSCoV-2 virus RNA dependent RNA polymerase, is the antiviral drug holding most promise. Remdesivir is an adenosine C-nucleoside, which it is hoped will have a beneficial action in COVID-19, similar in type to that of sofosbuvir in hepatitis C, achieved by antagonizing RNA synthesis by the virus. Observational results to-date with remdesivir are promising, but of course these do not provide a firm path for future action. The same applies to observational results with hydroxychloroquine, on which discussion now is unfortunately highly politicized. Preliminary results from the Active COVID-19 Treatment Trial, a randomized controlled trial of remdesivir sponsored by the US National Institute of Allergy and Infectious Diseases (NIAID) in 1063 patients, showed significantly shortened recovery time and a non-significant trend towards improved survival. The results from additional, ongoing controlled trials of remdesivir are pending. 


\section{"Herd Immunity"}

Testing for antibodies to SARS-CoV-2, conducted by governments and municipalities in US, Sweden and the United Kingdom, has disclosed unpublished seropositivity rates reported as 4\% (Los Angeles), 7.5\% (Stockholm) and 17\% London (5\% elsewhere in United Kingdom). These values fall far short of the community immunity needed to materially counter the spread of COVID-19. Achieving community immunity will require a safe and effective vaccine. A number of vaccine candidates are progressing, however the ultimate success of these and the timeframe for release remains in question.

Returning to RAS-blocker prescribing in hypertension, our earlier recommendation ${ }^{5}$ was to not discontinue these drugs prior to confirmation of the hypothesis remains, can in fact now be strengthened. Analysis of ACE-inhibitor and ARB use in clinical data bases from regions hard-hit by the pandemic has led to the conclusion that the hypothesis that RASblocker prescribing for hypertension, heart failure and diabetes during the COVID-19 pandemic is adverse can be discounted ${ }^{2}$. Importantly, it should be remembered, however, that patient dosing compliance in hypertension is surprisingly low, perhaps 50\%, which is a confounder, potentially undermining the validity of the conclusion. In addition, the conclusion will need to be revised if the ongoing studies in which RAS-blockade is initiated during the infection show harm. Despite these caveats, treatment changes should not be made in hypertension "just in case". Any resulting destabilizing of blood pressure control in hypertension would carry risks of strokes and heart attacks which are not just hypothetical. Simply discontinuing antihypertensives is strongly discouraged and is not an option 5 .

Moving forward, the co-morbidity profile of those most likely to have a severe outcome with SARSCoV-2 warrants further investigation, as do the morbidity and mortality outcomes of infection in different countries. Broad questions into the role of ACE2 in COVID-19 and implications of changed ACE2 expression as a consequence of medications do remain unanswered, including the status of loop diuretics and aldosterone antagonists in COVID-19 infection. Cardiovascular and hypertension doctors and scientists have an ongoing contribution to make in the understanding of and fight against COVID-19.

\section{Murray Esler - murray.esler@baker.edu.au}

\section{REFERENCES}

1. Grasselli G, Zangrillo A, Zanella A, Antonelli M, Cabrini L, Castelli A, et al. Baseline characteristics and outcomes of 1591 patients infected with SARS-CoV-2 admitted to ICUs of the Lombardy Region, Italy. JAMA 2020. doi: 10.1001/jama.2020.5394

2. Mancia G, Rea F, Ludergnani M, Apolone G, Corrao G. Renin-angiotensin-aldosterone system blockers and the risk of Covid19. N Engl J Med 2020. doi: 10.1056/NEJMoa2006923

3. Zhou P, Yang X. A pneumonia outbreak associated with a new coronavirus of probable bat origin. Nature 2020. doi:10.1038/ s41586-020-2012-7

4. Vaduganathan M, Vardeny $\mathrm{O}$, Michel T, McMurray J, Pfeffer M, Solomon S. Renin-angiotensim-aldosterone system inhibitors in patients with Covid-19. N Engl J Med 2020; 382:1653-1659 doi: 10.1056/NEJMsr2005760

5. Esler M, Esler D. Can angiotensin receptor-blocking drugs perhaps be harmful in the COVID-19 pandemic? Jypertens March 11 2020; 38:781-782 doi: 10.1097/HJH.0000000000002450

6. Zisman LS, Keller RS, Weaver B, Lin Q, Speth R, Bristow M, et al. Increased angiotensin-(1-7) forming activity in failing human heart ventricles: evidence for upregulation of the angiotensin-converting enzyme homologue ACE2. Circulation 2003; 108:17071712 doi: $10.1161 / 01$. CIR.0000094734.67990.99

7. Ishiyama Y, Gallagher PE, Averill DB, Tallant EA, Brosnihan KB, Ferrario CM. Upregulation of angiotensin-converting enzyme 2 after myocardial infarction by blockade of angiotensin II receptors. Hypertension 2004; 43:970-976 doi: 10.1161/01. HYP.0000124667.34652.1a

8. Sommerstein R, Grani C. Preventing a COVID-19 pandemic: ACE inhibitors as a potential risk factor for fatal COVID-19. BMJ 2020;368.m810(https://www.bmj.com/content/368/bmj.m810/rr-2).

9. Fang L, Karakiulakis G, Roth M. Are patients with hypertension and diabetes mellitus at increased risk for COVID-19 infection? Lancet Respir Med 2020 March 11(Epub ahead of print). doi: 10.1016/S2213-2600(20)30116-8

10. Diaz JH. Hypothesis: angiotensin-converting enzyme inhibitors and angiotensin receptor blockers may increase the risk of severe COVID-19. J Travel Med 2020 March 18 (Epub ahead of print). doi: 10.1093/jtm/taaa041 


\section{THE CURRENT COVID-19 PANDEMIC AND HYPERTENSION}

Japanese folk monster "A-MA-BI-E" is re-born as the guardian to avoid COVID-19 in 2020

A new mascot of Japanese Society of Hypertension (JSH) to keep health of people with hypertension in coronavirus infection prevention

\section{HIROSHI ITOH}

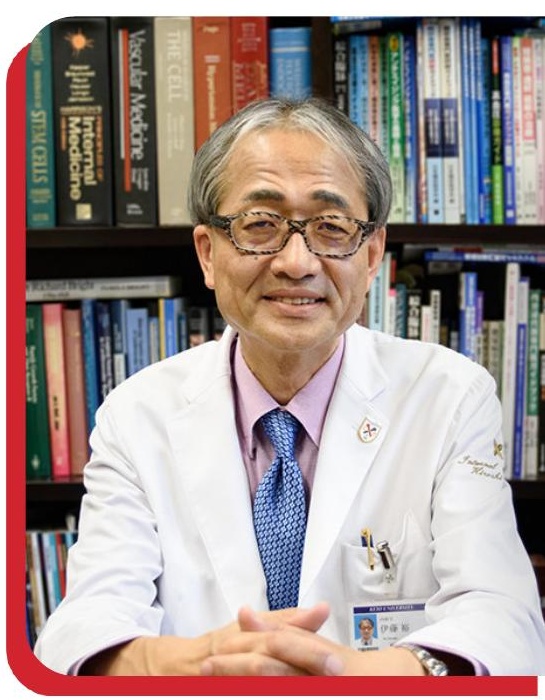

Department of Endocrinology, Metabolism and Nephrology, Keio University School of Medicine, Tokyo, Japan

DOI: $10.30824 / 2006-14$

Our Society, the Japanese Society of Hypertension (USH) has created a new mascot character which is dedicated to keep sound health of those with hypertension coping with COVID-19 under the state of emergency and prohibition of going out (Fig 1).

The original creature has been traditionally called "A-MA-BI-E" ("A" means sea and "MA" means a woman). Old Japanese legend has it that AMABIE suddenly comes from the sea with a shining body to tell us the coming of a new plague.

It has been said that to look at the figure of AMABIE or draw it make it possible for us to escape from the plague. This monster is half-human and half-fish and has three legs and a beak. The original picture is shown in Fig.2, which was drawn in 1846, in Edo Era under Tokugawa Shogunate dynasty.

The Japanese Ministry of Health, Labor and Welfare has adopted this monster for the campaign for prevention of COVID-19 in April 2020.

I myself, tried the re-make of this monster figure and drew the picture shown in Fig.1.

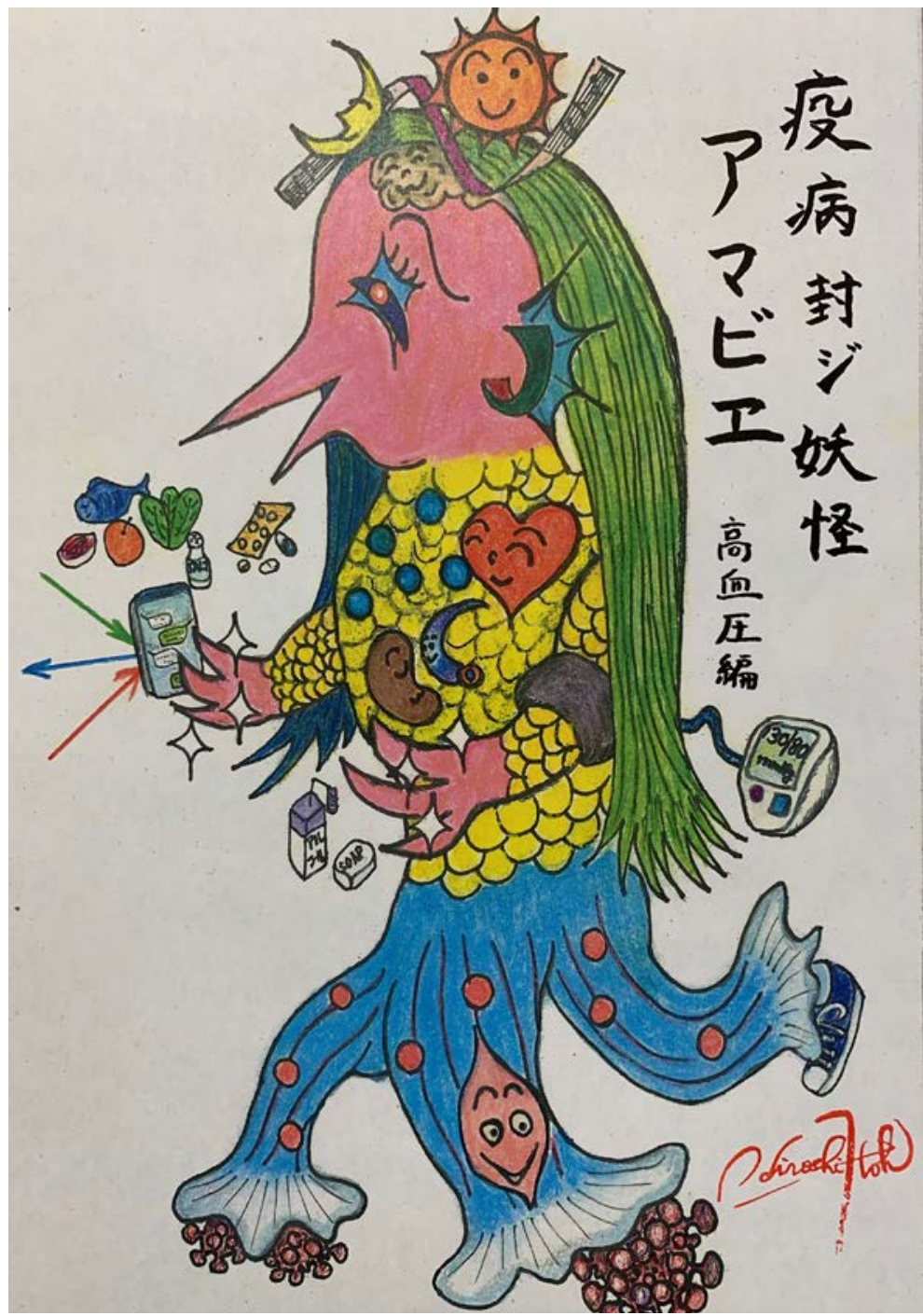

Fig. 1 Japanese Society of Hypertension (JSH) mascot character of re-born "AMABIE" for JSH campaign of COVID-19 and hypertension drawn by the author (HI) 
Using this mascot, we, the member of JSH will do campaign to ask Japanese people with hypertension to lead the regular life with sound daily rhythm and adequate sleep, to do frequently home blood pressure monitoring, to take anti-hypertension drugs regularly, to do appropriate physical activity and lessen sedentary time, not to eat too much confined at home and watching TV, to have connection with others by smart phone or telephone, to find fun and avoid stress, and, of course, to strive for hand hygiene, in order to prevent another Pandemic of Hypertension and other non-communicable diseases, coupled with COVID-19 Pandemic.

AMABIE has another story. She not only foretells the coming of the plague, but also the coming of the great harvest. Thus, we are expecting that tough times bring opportunity, with this re-born guardian against COVID-19.

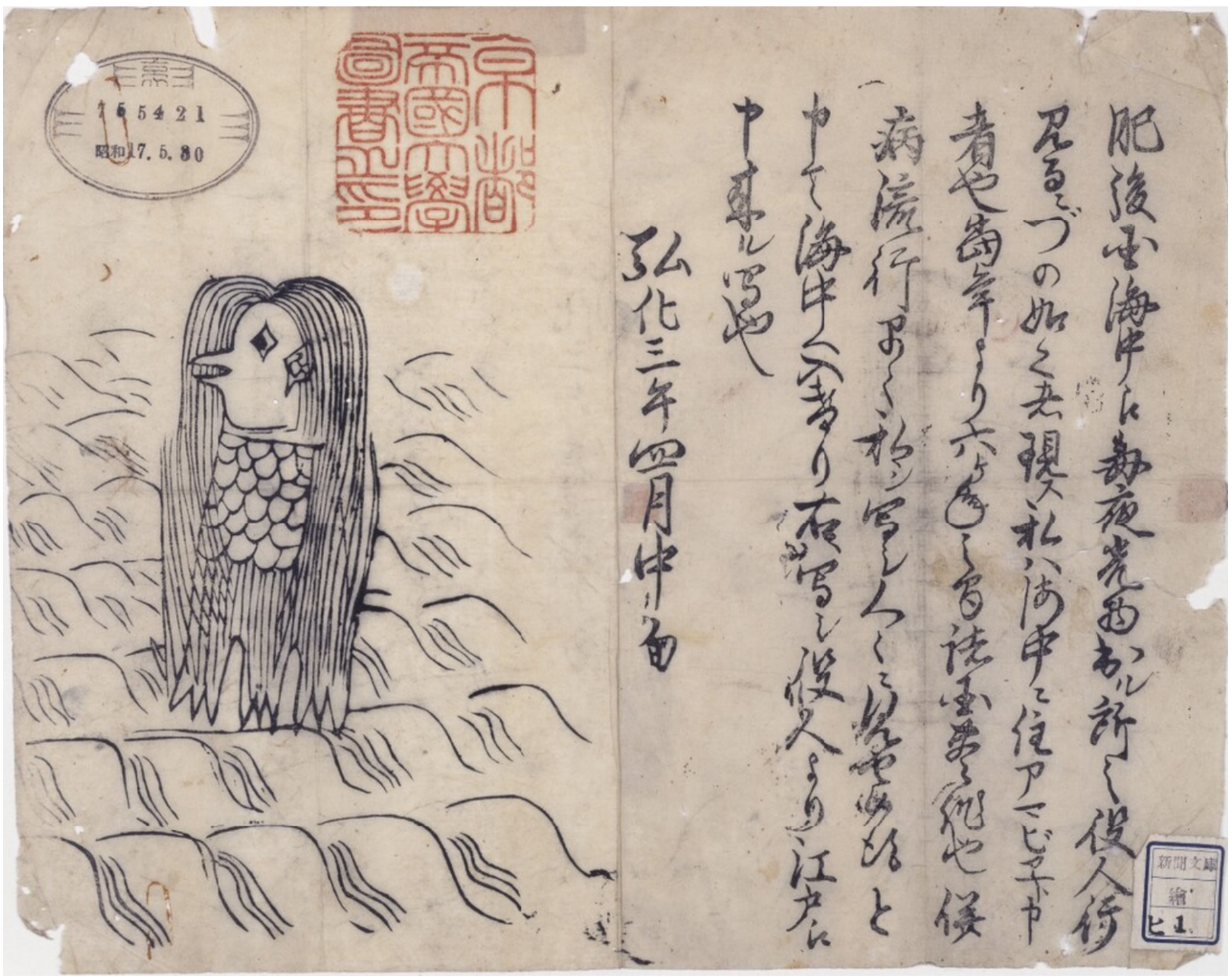

Fig.2 Original AMABIE, a Japanese folk monster shown in a wood-print newspaper in 1846 owned by Kyoto university library

Hiroshi Itoh - hiito@keio.jp 


\section{YOUNG INVESTIGATORS:}

\section{The "Twilight Zone" world of the COVID-19 pandemic: The place, role and future of telehealth in hypertensive patients}

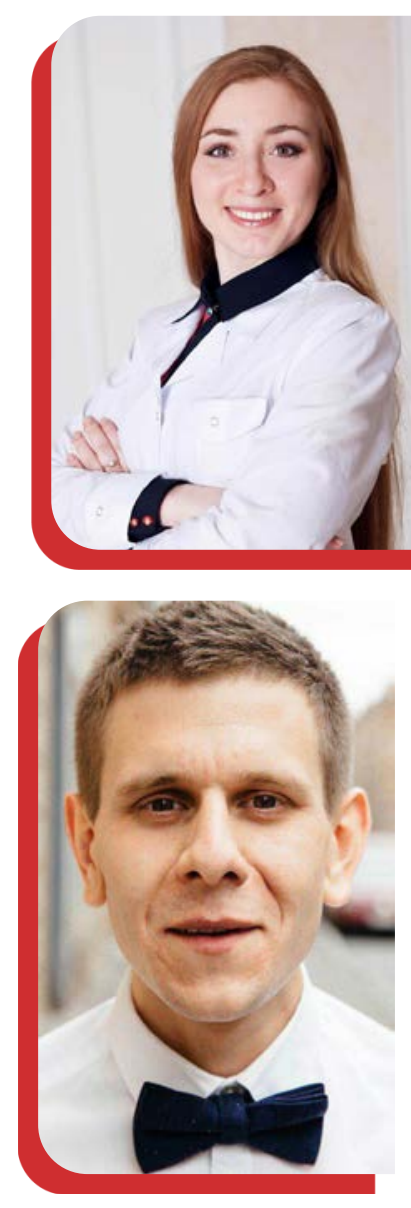

DOI: $10.30824 / 2006-15$

The COVID-19 pandemic compels the use of the vast amounts of human, economic, and material resources to treat and prevent the infection and the global healthcare system has tended to adopt a "tunnel vision" for only those afflicted with COVID-19 infection. The worldwide quarantine and lockdown, as well as rapidly increasing number of COVID-19 victims challenge current healthcare systems. As a result, the COVID-19 pandemic highlights the value of digital health technologies.

The decision to dive into telemedicine looks pretty natural. The massive transition into telemedicine is the most effective tool to comply with social distancing and self-isolation requirements ${ }^{1}$. In many countries, restrictions related to the implementation of telehealth services are being loosened (e.g. for initial inpatient visits) in order to increase the opportunities to screen suspected patients and to diminish personal contacts and the risk of further infection dissemination ${ }^{1}$. Tele-visits are temporarily allowed via Skype, Apple FaceTime or Google Hangouts, despite safety/privacy concerns ${ }^{2}$.
The majority of recent reports focus on teleservices for COVID-19 afflicted patients, while only a few consider other medical issues ${ }^{1,2}$. At the same time, chronic non-communicable diseases (notably hypertension) are frequent comorbidities in COVID19 and are associated with the increased risks of adverse outcomes ${ }^{3}$. During COVID-19 pandemic, when ambulatory practices are temporarily closing or limiting their workload, many patients with chronic diseases are left without access to healthcare. In the setting of lockdown, cut-off from other family members, facing an abrupt decrease in social activities and social support, and increased fear and anxiety disorders, the risk of destabilization of hypertension and cardiovascular diseases has increased. On the other hand, the absence of daily routine and physical activity can also affect blood pressure levels requiring medication adjustment.

Moreover, the recent debate on the use of angiotensin-converting enzyme inhibitors (ACEIs) or angiotensin-receptor blockers (ARBs) during pandemics cast doubts among patients and medical professionals ${ }^{4}$. The majority of professional societies recommend continuing ACEIS/ARBs in patients with COVID-19, while the evidence is obtained ${ }^{4}$. 
Randomized clinical trials of ACEIs/ARBs in COVID19 patients are being planned (NCT04311177, NCT04312009). Nevertheless, the patients require professional guidance right now, and in the majority of cases the help can be easily provided by teleconsultation. This, in turn, could prevent deleterious consequences of self-administered drug withdrawal. In this healthcare crisis with a shortage of specialists, facilities and available funds, telehealth offers a costeffective and useful tool for managing hypertension ${ }^{5}$. Physicians can provide direct supervision remotely through audio/video/text communication thus reducing exposure risks both for the beneficiary and for the healthcare provider.

Healthcare authorities should promote the adjustment of regulation for telemedicine services, including short consultations, personalized answers to certain questions etc., as well as urgent education of medical professionals to use the telehealth facilities. Certainly not all patients can be treated remotely (e.g. interventional procedures).
However, in the face of the pandemic, telehealth is not merely a luxury, but a viable approach for protecting both patients and doctors. With a highspeed Internet connection, integrated Electronic Health Records and Decision Support Systems may also facilitate remote consultations and data collection. The latter is essential for understanding outcomes. The analysis of 2020 data will show whether a sudden increase in telemedicine is beneficial or not, and the intermediate analyses from international datasets might help to optimize the telehealth services to achieve more benefits.

In summary, the COVID-19 pandemic might serve as a powerful incentive for the transformation of healthcare into a more interactive, forceful and flexible system without loss in privacy and security ${ }^{6}$. In the next years we are likely to witness a huge tidal wave of immense data collected remotely (i.e. Apple Heart Studies ${ }^{7}$ ) offering new scientific and clinical challenges.

Lyudmila Korostovtseva- lyudmila_korosto@mail.ru

Mikhail lonov - mikeionov90@gmail.com

\section{REFERENCES}

1. Bashshur R, Doarn CR, Frenk JM, Kvedar JC, Woolliscroft JO. Telemedicine and the COVID-19 pandemic, lessons for the future. Telemed J E-Health.2020. doi:10.1089/tmj.2020.29040.rb.

2. How to start doing telemedicine now (In the COVID-19 Crisis). Medscape n.d. http:// www.medscape.com/viewarticle/927323 (accessed April 14, 2020).

3. Guan W, Liang W, Zhao Y, Liang H, Chen Z, Li Y, et al. Comorbidity and its impact on 1590 patients with Covid-19 in China: A Nationwide Analysis. Eur Respir J 2020. doi:10.1183/13993003.00547-2020.

4. Bavishi C, Maddox TM, Messerli FH. Coronavirus disease 2019 (COVID-19) infection and renin angiotensin system blockers. JAMA Cardiol 2020. doi:10.1001/jamacardio.2020.1282.

5. Omboni S, Gazzola T, Carabelli G, Parati G. Clinical usefulness and cost effectiveness of home blood pressure telemonitoring: meta-analysis of randomized controlled studies. J Hypertens 2013;31:455-67. doi:10.1097/HJH.0b013e32835ca8dd.

6. Nittari G, Khuman R, Baldoni S, Pallotta G, Battineni G, Sirignano A, et al. Telemedicine Practice: Review of the Current Ethical and Legal Challenges. Telemed J E Health 2020 doi: 10.1089/tmj.2019.0158

7. Perez MV, Mahaffey KW, Hedlin H, Rumsfeld JS, Garcia A, Ferris T, et al. Large-Scale Assessment of a Smartwatch to Identify Atrial Fibrillation. NEJM. 2019;381:1909-17. doi:10.1056/NEJMoa1901183. 


\title{
YOUNG INVESTIGATORS: The cardiovascular profile of the low renin phenotype in a population of African descent
}

\author{
LEBO GAFANE-MATEMANE \\ Hypertension in Africa Research Team \\ North-West University, South Africa
}

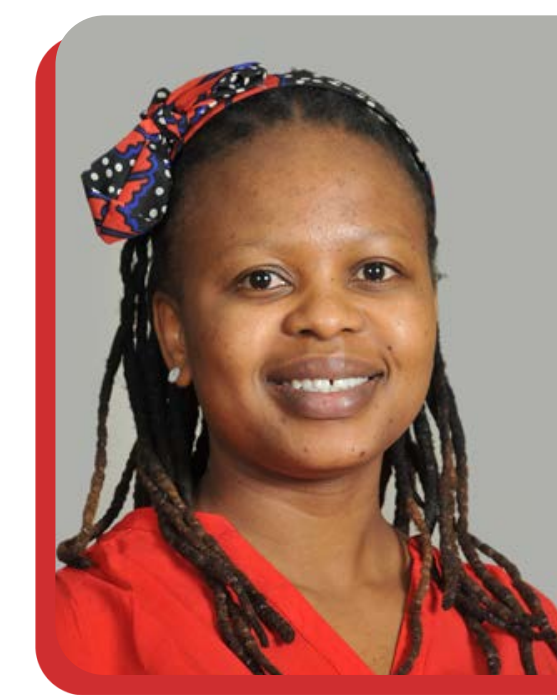

DOI: $10.30824 / 2006-16$

Populations of African ancestry (referred to as "black" hereafter) tend to present with a suppressed reninangiotensin-aldosterone system (RAAS) and severe forms of hypertension-mediated organ damage ${ }^{1}$. Relationships between components of the RAAS and cardiovascular disease are well established in other populations, however such information in Africa is scant. An attempt was made from the Sympathetic activity and Ambulatory Blood Pressure in Africans (SABPA) study to examine the cardiovascular profile of black South African school teachers. The study explored associations of renin and aldosterone with cardiovascular responses to stress and potential cardiac injury. The study population was aged 20-63 years and included both normotensives and hypertensives.

The main measurements included: (1) 24-hour systolic blood pressure (SBP), diastolic blood pressure (DBP) and heart rate (HR), from which percentage dipping was calculated, (2) a cold pressor test which was performed to measure cardiovascular and renin reactivity, (3) blood samples which were analysed for active renin, aldosterone, $\mathrm{N}$-terminal prohormone B-type natriuretic peptide (NTproBNP) as a measure of volume expansion, cardiac troponin $\mathrm{T}(\mathrm{cTnT})$ as measure of cardiomyocyte injury and copeptin as a surrogate measure of vasopressin. Basic characteristics of the population are described in Table 1.

\section{Main findings in the form of manuscripts}

\section{Plasma renin and cardiovascular responses to the cold pressor test differ in black and white populations}

Despite lower levels of renin (compared to white teachers) at rest and during stress, renin associated positively with vascular resistance only in black teachers when the cardiovascular system was challenged with the cold pressor test.

\section{Aldosterone and renin in relation to} surrogate measures of sympathetic activity

- Aldosterone and its ratio to renin were associated with less dipping of night-time HR, while renin showed a positive association with 24-hour HR only in the black population [3].

- There was also a borderline significant ( $P=0.051$ ) positive association between aldosterone and norepinephrine in the black group.

- It is therefore probable that aldosterone's direct effects and its relation to the sympathetic nervous system may impact cardiovascular function adversely in low renin states.

Of note: aldosterone levels were higher in the white group, however, the black group had a higher aldosterone-to-renin ratio (ARR).

3. Relation of the renin-angiotensinaldosterone system with potential cardiac injury and remodelling

- A marker of cardiomyocyte injury (CTnT) was positively associated with renin and a surrogate measure of vasopressin (copeptin).

- NTproBNP, an indicator of cardiac stress due to volume expansion was positively associated with copeptin 4 .

- Possible factors driving the association between cTnT and renin could be a pre-existing pressure and volume overload, as well as constant sympathetic activation due to emotional distress, which is well-established in the SABPA cohort 5 . 


\begin{tabular}{|c|c|c|c|}
\hline Manuscript 1 & Black $(\mathrm{N}=153)$ & White $(\mathrm{N}=188)$ & $P$ \\
\hline Age (years) & $43.1 \pm 7.71$ & $43.9 \pm 10.6$ & 0.38 \\
\hline Women, n (\%) & $73(47.7)$ & $99(52.7)$ & 0.36 \\
\hline Office SBP (mmHg) & $140 \pm 17.6$ & $130 \pm 13.3$ & $<0.001$ \\
\hline Office DBP (mmHg) & $81.1 \pm 9.83$ & $76.3 \pm 7.82$ & $<0.001$ \\
\hline $\operatorname{Renin}(\mathrm{pg} / \mathrm{ml})$ & $4.19 \pm 2.62$ & $6.32 \pm 3.07$ & $<0.001$ \\
\hline Manuscript 2 & Black ( $N=127)$ & White ( $N=179)$ & $P$ \\
\hline 24-hour SBP (mmHg) & $132 \pm 16.8$ & $125 \pm 12.9$ & $<0.001$ \\
\hline 24-hour DBP (mmHg) & $83.2 \pm 11.2$ & $77.0 \pm 8.20$ & $<0.001$ \\
\hline 24-hour HR (bpm) & $79.3 \pm 9.70$ & $73.7 \pm 10.2$ & $<0.001$ \\
\hline \% dipping SBP $(\mathrm{mmHg})$ & $10.1 \pm 6.34$ & $12.2 \pm 6.33$ & 0.003 \\
\hline \% dipping DBP (mmHg) & $15.9 \pm 11.9$ & $18.2 \pm 7.90$ & 0.042 \\
\hline \% dipping HR (bpm) & $14.6 \pm 8.78$ & $17.2 \pm 9.25$ & 0.015 \\
\hline Renin (pg/ml) & $3.47(0.95 ; 9.33)$ & $5.75(2.24 ; 12.3)$ & $<0.001$ \\
\hline Aldosterone (pg/ml) & $43.7(10.5 ; 170)$ & $55.0(21.8 ; 219)$ & 0.015 \\
\hline Aldosterone-to-renin ratio & $12.5(2.95 ; 67.6)$ & $9.55(2.88 ; 33.1)$ & 0.007 \\
\hline Manuscript 3 & Black $(\mathrm{N}=162)$ & White $(\mathrm{N}=206)$ & $P$ \\
\hline 24-hour SBP (mmHg) & $131 \pm 13.7$ & $124 \pm 10.4$ & $<0.001$ \\
\hline 24-hour DBP (mmHg) & $83 \pm 10.7$ & $77 \pm 8.04$ & $<0.001$ \\
\hline 24-hour HR (bpm) & $79 \pm 10.7$ & $72.0 \pm 9.55$ & $<0.001$ \\
\hline Hypertensive status, n (\%) & $87(62.6)$ & $66(39.8)$ & $<0.001$ \\
\hline Cardiac troponin T (ng/L) & $6.26(2.58 ; 8.64)$ & $5.66(2.67 ; 10.6)$ & 0.015 \\
\hline NTproBNP (pg/ml) & $30.4(7.20 ; 116)$ & $32.8(9.46 ; 114)$ & 0.47 \\
\hline Copeptin (pmol/L) & $4.95(2.02 ; 12.8)$ & $4.71(2.05 ; 12.4)$ & 0.38 \\
\hline Renin (pg/ml) & $3.40(0.95 ; 9.24)$ & $5.83(1.88 ; 14.6)$ & $<0.001$ \\
\hline Aldosterone (pg/ml) & $44.9(10.2 ; 197)$ & $52.3(22.0 ; 151)$ & 0.078 \\
\hline Aldosterone-to-renin ratio & $13.2(2.9 ; 61.1)$ & $8.96(2.68 ; 27.2)$ & $<0.001$ \\
\hline
\end{tabular}

Overall, the SABPA study showed that even in low renin states, sympathetic dominance due to stress may contribute to the adverse associations between some components of the RAAS and cardiovascular structure and function. Raised BP and volume retention may increase the vulnerability to cardiac injury as a result of RAAS dysregulation and interactions with other pathways involved in volume regulation. In addition to physiological factors, socioeconomic and psychosocial factors such as chronic stress may contribute to the unfavourable cardiovascular profile in black populations with a suppressed RAAS.

There is a need to further our understanding of the complex mechanisms involved in the pathophysiology of hypertension in black populations, particularly the low renin phenotype. Impactful knowledge can be generated by performing studies that quantify salt sensitivity and profile the entire RAAS, including angiotensin converting enzyme 2 (ACE-2)Angiotensin-(1-7)-Mas receptor axis and angiotensin II type 2 receptor pathway. Evidence regarding the effect of tissue RAS on circulating RAAS and $B P$ regulation may shed light on the mechanisms that lead to raised BP when the circulating RAAS is suppressed. Such data have the potential to facilitate the development of efficient ethnicityspecific and/or personalised treatment approaches for hypertension.

Lebo Gafane-Matemane - lebo.gafane@nwu.ac.za

\section{REFERENCES}

1. Jane Lindhorst NA, Juliet Blignaut and Brian Rayner. Differences in hypertension between blacks and whites: an overview. Cardiovasc J Afr. 2007; 18:241-247.

2. Gafane LF, Schutte R, Van Rooyen JM, et al. Plasma renin and cardiovascular responses to the cold pressor test differ in black and white populations: The SABPA study. J Hum Hypertens. 2016; 30:346-351. doi: 10.1038/ jhh.2015.88

3. Gafane-Matemane LF, Van Rooyen JM, Schutte R, et al. Aldosterone and renin in relation to surrogate measures of sympathetic activity. Cardiovasc J Afr. 2019; 30:34-40.

4. Gafane-Matemane LF, Mokae NL, Breet Y, et al. Relation of the renin-angiotensin-aldosterone system with potential cardiac injury and remodelling: the SABPA study. Blood Press. 2020; 29:31-38. doi: 10.1080/08037051.2019.1645587

5. Malan L, Hamer M, Frasure-Smith N, et al. Cohort profile: Sympathetic activity and Ambulatory Blood Pressure in Africans (SABPA) prospective cohort study. Int J Epidemiol. 2015; 44:1814-1822. doi: 10.1093/ije/dyu199 


\title{
YOUNG INVESTIGATORS:
}

\section{Putting the pressure on nonvalidated blood pressure monitors}

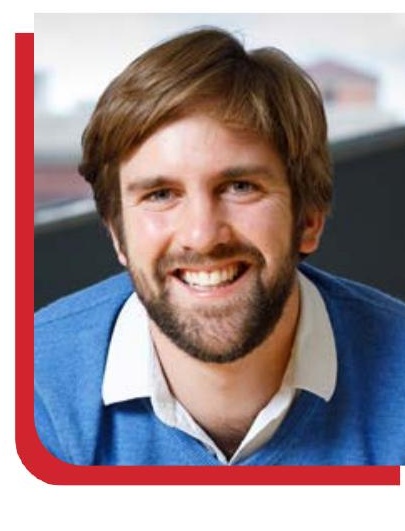

\author{
DEAN PICONE \& JAMES SHARMAN
}

Menzies Institute for Medical Research, University of Tasmania, Australia

DOI: $10.30824 / 2006-17$

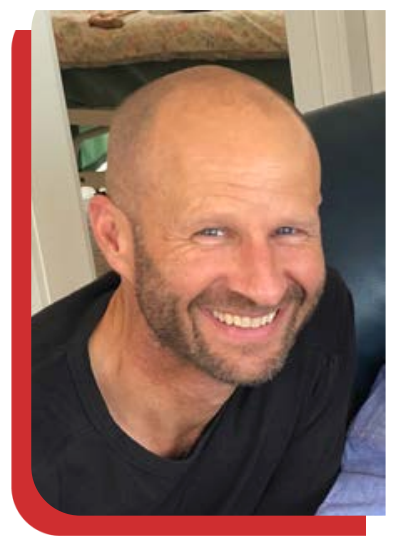

In 2016, the Lancet Commission on Hypertension identified ten key actions to improve the management of blood pressure (BP). ${ }^{1}$ One of these actions was Measurement Quality, specifically, better quality of $B P$ measurements through endorsed protocols and certified and validated BP monitors. Hypertension guidelines invariably recommend that the measurement of BP is performed using monitors that are validated for accuracy. Indeed, this recommendation is classed as essential in the recent International Society of Hypertension guidelines. Accuracy testing should be carried out by independent parties due to conflict of interest on behalf of the manufacturer. Testing should also be according to an internationally-accepted and standardised protocol, where the monitor is compared with reference BP measures. ${ }^{2}$ Unfortunately, due to regulatory loopholes, rigorous accuracy testing may not be performed on many of the BP monitors cleared by regulatory authorities for sale worldwide. This is a problem because non-validated monitors are more likely to be inaccurate ${ }^{3}$ and thus decisions using BP data from these monitors could lead to mismanagement of BP and sub-optimal clinical outcomes.

\section{Most home BP monitors available for purchase are nonvalidated}

To understand the extent of this problem, our team recently examined the availability of validated home BP monitors for purchase online in Australia. ${ }^{4}$ The findings are a cause for concern because of the 972 unique monitors identified only $7 \%$ were validated for accuracy. Validated monitors were more often upper arm cuff devices (18\% of 278 devices versus $8 \%$ of 162 wrist cuff devices). More than half of the monitors were wristband (activity-tracker style) wearables and none of these were validated. On average, non-validated monitors were significantly less expensive than validated ones.

The results suggest that people looking to buy a BP monitor are inundated with choice and due to the high prevalence of lower cost, nonvalidated monitors and lack of credible information on validation at the point of sale, are probably more likely to purchase one that has not been validated for accuracy. The findings would probably be replicated in other countries because over $90 \%$ of the monitors available in Australia were from e-commerce businesses (e.g. Amazon, eBay), which provide shipping to many countries. One of the study limitations was that sales data on purchases of validated versus nonvalidated BP monitors was not available so the number of people using nonvalidated monitors is unknown. Previous studies from countries other than Australia suggest the prevalence of patients using nonvalidated BP monitors may range from $30 \%$ to $70 \% .^{3}$ 


\section{A practical resource to guide the purchase of validated blood pressure monitors}

The study showed nonvalidated monitors dominate the online marketplace. Importantly, there was rarely reliable information at the point of sale about which monitors are clinically validated. To help consumers identify validated BP monitors, we have developed this practical resource which describes all the validated device listings (e.g. STRIDE BP) available globally and how to search them. The tool is designed for use by the general public, health professionals and policy makers to promote the uptake and use of validated BP monitors and is currently being translated to several languages other than English.

\section{Ongoing efforts}

Work of the Lancet Commission on Hypertension translational group is ongoing. This includes the development of a consensus statement on procurement of validated BP monitors. Another relatively new group is the Accuracy In Measurement of Blood Pressure (AIM-BP) collaborative, which has been established to increase awareness of, and advocate for best practice in BP measurement globally. The collaborative aims to identify, summarize, and knowledge translate important resources in the field of BP measurement in a central repository and to propose future work. Further details on AIM-BP can be found here: https://www.whleague.org/ index.php/j-stuff/awareness-and-screening/ aim-bp

In conclusion, nonvalidated BP monitors are highly prevalent and are likely to be more inaccurate than validated ones, potentially leading to mismanagement of BP. A new practical resource has been developed to help consumers use validated device listings to identify validated BP monitors. Ultimately, an increase in the availability of validated BP monitors should lead to improved measurement and management of BP and better health outcomes related to $\mathrm{BP}$ globally.

Dean Picone - dean.picone@utas.edu.au

James Sharman - james.sharman@utas.edu.au

REFERENCES

1. Olsen MH, Angell SY, Asma S, Boutouyrie P, Burger D, Chirinos JA, et al. A call to action and a lifecourse strategy to address the global burden of raised blood pressure on current and future generations: the Lancet Commission on hypertension. Lancet. 2016;388(10060):2665-712. doi: 10.1016/S0140-6736(16)31134-5

2. Sharman JE, O'Brien E, Alpert B, Schutte AE, Delles C, Hecht Olsen M, et al. Lancet Commission on Hypertension group position statement on the global improvement of accuracy standards for devices that measure blood pressure. J Hypertens. 2020;38(1):21-9. doi: 10.1097/HJH.0000000000002246

3. Akpolat T, Dilek M, Aydogdu T, Adibelli Z, Erdem DG, Erdem E. Home sphygmomanometers: validation versus accuracy. Blood Press Monit. 2009;14(1):26-31. doi: 10.1097/MBP.0b013e3283262f31

4. Picone DS, Deshpande RA, Schultz MG, Fonseca R, Campbell NRC, Delles C, et al. Nonvalidated Home Blood Pressure Devices Dominate the Online Marketplace in Australia: Major Implications for Cardiovascular Risk Management. Hypertension. 2020:HYPERTENSIONAHA12014719. doi: 10.1161/HYPERTENSIONAHA.120.14719

5. Ringrose JS, Polley G, McLean D, Thompson A, Morales F, Padwal R. An Assessment of the Accuracy of Home Blood Pressure Monitors When Used in Device Owners. Am J Hypertens. 2017;30(7):683-9. doi: 10.1093/ajh/ hpx041 


\section{YOUNG INVESTIGATORS:}

\section{Vascular ageing biomarkers: are we ready for the hypertension guidelines? RACHEL CLIMIE}
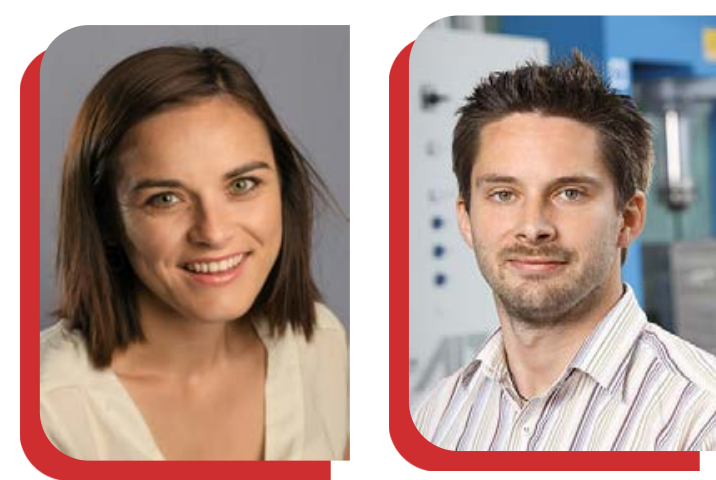

Baker Heart and Diabetes Institute, Melbourne, Australia \& Université de Paris, France

\section{CHRISTOPHER MAYER}

AlT Austrian Institute of Technology GmbH, Vienna, Austria

\section{ROSA MARIA BRUNO}

Université de Paris, France \& Hôpital Européen Georges Pompidou, Paris, France

DOI: $10.30824 / 2006-18$

Vascular ageing refers to the age-related deterioration in vascular structure and function and is accelerated in the presence of cardiovascular risk factors. In an optimally functioning cardiovascular system, the elastic properties of the large arteries (i.e. aorta) ensure that pulsations in pressure and flow generated by left ventricular contraction are dampened so that less pulsatile pressure/flow are delivered at the microvascular level. However, the cushioning (elastic) properties of the large arteries are progressively lost over time. While age-related arterial damage typically appears in the fifth decade of life, there is wide variability between individuals, with some displaying early vascular ageing. This has led to the concept that vascular age, as opposed to chronological age, may be better related to the prognosis of CVD ${ }^{1}$, is the driving force behind agerelated chronic disease in multiple organs, and is responsible for the largest proportion of disease burden worldwide?

Among vascular ageing biomarkers, one of the most robust and promising is arterial stiffness (a proxy for arteriosclerosis). Carotid to femoral pulse wave velocity (PWV) is currently the gold standard non-invasive method for determining large artery stiffness in a clinical setting. Many studies have shown that the stiffness of the large arteries is related to elevated CVD risk in adults, independently of traditional cardiovascular risk factors ${ }^{3}$. In an individual participant meta-analysis involving data from 17635 participants, Ben-Shlomo et al. showed that after adjusting for age and sex, a 1-SD difference in log-transformed carotid to femoral PWV was associated with a 35\% increased risk of future CVD events over the 5-year follow-up period, independent of cardiovascular risk factors and medications ${ }^{4}$. Furthermore, the addition of carotid to femoral PWV to traditional Framingham risk factors in a group at intermediate risk of CVD, improved risk stratification by $13 \%{ }^{4}$.

While arterial stiffness is an important component, other measures depicting the atherosclerotic process of vascular ageing at various stages, such as carotid intima media thickness and plaque, coronary calcium score and endothelial function are available. Given that factors influencing vascular age are numerous and their impact on vascular health various between individuals, a direct, non-invasive assessment of arterial health status is advisable. However, recommendations for the assessment of vascular aging is strikingly underrepresented in the current guidelines on hypertension and CVD prevention from international societies. Carotid ultrasound, ankle-brachial index and CT coronary artery calcium (CAC) score are recommended according to the European Society of Cardiology (ESC) guidelines for cardiovascular prevention because of their reclassification potential in addition to classical cardiovascular risk scores ${ }^{5}$, whereas the American College of Cardiology/American Heart Association (ACC/AHA) guidelines recommend only $\mathrm{CAC}^{6}$.

However, these biomarkers only depict the atherosclerosis phenomenon, which is only one side of the coin. Furthermore, CAC require a CT scan, thus is not feasible for large population screening in low-resource settings and carries inherent risk. 
When turning to guidelines for the management of hypertension, according to the 2007 and 2013 ESC/ European Society of Hypertension (ESH) guidelines, quantification of total cardiovascular risk must include an investigation of subclinical vascular organ damage. However in the 2018 guidelines, the systematic use of PWV (as well as carotid ultrasound and ankle brachial index) is not recommended, despite being mentioned in the hypertension-associated organ damage list ${ }^{7}$, and evidence confirming PWV ability to reclassify risk is now available ${ }^{4}$. Finally, the recent ISH guidelines recommend the measurement of PWV only in specific cases, such as isolated systolic hypertension? ${ }^{8}$ Indeed, in the past years a number of vascular aging biomarkers (such as PWV) have been shown to have prognostic significance and simple, low-cost, fully non-invasive devices for measuring such biomarkers are increasingly available. However, studies assessing the clinical value of a reduction in PWV via treatment remain scarce.

\section{Rachel Climie - Rachel.Climie@baker.edu.au}

Christopher Mayer - Christopher.Mayer@ait.ac.at

\section{Rosa Maria Bruno - rosa-maria.bruno@inserm.fr}

\section{REFERENCES}

1. Nilsson PM, Boutouyrie P, Laurent S. Vascular aging: a tale of EVA and ADAM in cardiovascular risk assessment and prevention. Hypertension. 2009;54(1):3-10. doi: 10.1161/ HYPERTENSIONAHA.109.129114

2. Forouzanfar $M H$, Afshin A, Alexander LT, Anderson HR, Bhutta ZA, Biryukov S, et al. Global, regional, and national comparative risk assessment of 79 behavioural, environmental and occupational, and metabolic risks or clusters of risks, 19902015: a systematic analysis for the Global Burden of Disease Study 2015. The Lancet. 2016;388(10053):1659-724. doi: 10.1016/S0140-6736(16)31679-8

3. Vlachopoulos C, Aznaouridis K, Stefanadis C. Prediction of cardiovascular events and all-cause mortality with arterial stiffness: a systematic review and meta-analysis. Journal of the American College of Cardiology. 2010;55(13):1318-27. doi: 10.1016/j.jacc.2009.10.061

4. Ben-Shlomo Y, Spears M, Boustred C, May M, Anderson SG, Benjamin EJ, et al. Aortic pulse wave velocity improves cardiovascular event prediction: an individual participant metaanalysis of prospective observational data from 17,635 subjects. Journal of the American College of Cardiology. 2014;63(7):63646. doi: 10.1016/j.jacc.2013.09.063

5. Piepoli MF, Hoes AW, Agewall S, Albus C, Brotons C, Catapano AL, et al. 2016 European Guidelines on cardiovascular disease prevention in clinical practice: The Sixth Joint Task Force of the European Society of Cardiology and Other Societies on Cardiovascular Disease Prevention in Clinical Practice (constituted
The recently commenced European Cooperation in Science and Technology Action VascAgeNet ("Network for Research in Vascular Ageing", CA18216, www.vascagenet.eu) aims to directly address these unmet needs limiting the measurement of vascular age in routine clinical practice. The purpose of the COST Action is to bring together industry, basic and clinical science to foster innovation ${ }^{9}$ and to refine the approaches for assessing vascular ageing, to harmonize existing data and knowledge and to promote the importance of monitoring vascular age to improve clinical outcomes ${ }^{10}$. Furthermore, the COST Action will promote large-scale, registrybased interventional studies, aimed at assessing the clinical value of the use of vascular aging biomarkers as targets for treatment. It is hoped that through this Action and by addressing these limitations, definitive recommendations for the measurement of vascular age in clinical practice can be incorporated into future guidelines for hypertension and CVD management, ultimately contributing to a reduction in CVD burden globally.

by representatives of 10 societies and by invited experts) Developed with the special contribution of the European Association for Cardiovascular Prevention \& Rehabilitation (EACPR). European heart journal. 2016;37(29):2315-81. doi: 10.1093/eurheartj/ehw106

6. Arnett DK, Blumenthal RS, Albert MA, Buroker AB, Goldberger ZD, Hahn EJ, et al. 2019 ACC/AHA Guideline on the Primary Prevention of Cardiovascular Disease: A Report of the American College of Cardiology/American Heart Association Task Force on Clinical Practice Guidelines. Circulation. 2019;140(11):e596-e646. doi: 10.1161/ CIR.0000000000000678

7. Williams B, Mancia G, Spiering W, Agabiti Rosei E, Azizi M, Burnier M, et al. 2018 ESC/ESH Guidelines for the management of arterial hypertension: The Task Force for the management of arterial hypertension of the European Society of Cardiology (ESC) and the European Society of Hypertension (ESH). European Heart Journal. 2018;39(33):3021-104. doi: 10.1097/HJH.0000000000001940

8. Unger T, Borghi C, Charchar F, Khan NA, Poulter NR, Prabhakaran D, et al. 2020 International Society of Hypertension global hypertension practice guidelines. Hypertension. 2020:HYPERTENSIONAHA. 120.15026. doi: 10.1161/HYPERTENSIONAHA.120.15026

9. Mayer CC, Climie RE, Hametner B, Bruno R-M. The European COST Action VascAgeNet Fostering Innovation-When Industry Comes to Science. Artery Research. 2020.

10. Climie RE, Mayer CC, Bruno RM, Hametner B. Addressing the unmet needs of measuring vascular ageing in clinical practice-European COoperation in Science and Technology Action VascAgeNet. Artery Research. 2020. 


\section{WOMEN IN HYPERTENSION RESEARCH COMMITTEE AND NEW INVESTIGATOR COMMITTEE REPORT}

\section{Representation of the ISH Women}

in Hypertension Research and New

Investigator and Mentorship Committees at

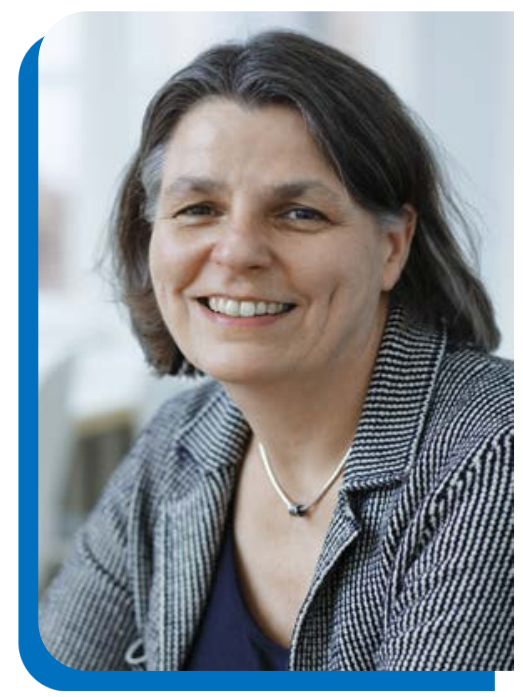

the 14th Meeting of the Indonesian Society of Hypertension (INASH)

\section{ULRIKE MUSCHA STECKELINGS}

University of Southern Denmark, Institute of Molecular Medicine / Dept. of Cardiovascular and Renal Research, Denmark

\section{FADI CHARCHAR}

Federation University Australia, School of Health and Life Sciences, Ballarat, Australia

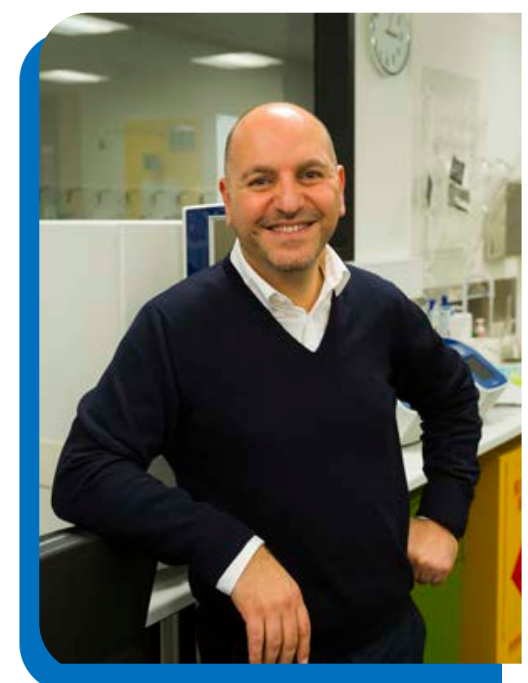

ISH and The Indonesian Society of Hypertension (INASH) have a long-standing, close partnership and collaboration. ISH representatives have been invited to attend INASH meetings and present ISH activities over the past years including participation of ISH Past-President Rhian Touyz and ISH President Alta Schutte.

INASH members are regular attendees of ISH meetings and INASH Past-President and current Officer for Foreign Affairs, Arieska Ann Soenarta, has been recognised for her contributions to hypertension research and for her work for INASH and ISH in 2016 with the ISH Honour for Senior Women Researchers Award.

The 14th Annual Meeting of the Indonesian Society of Hypertension took place from January 21 - 23, 2020, at the Sheraton Grand Gandaria City Hotel in Jakarta. Chairs of the meeting were Ekawati Dani Yulianti (Chair of the Organising Committee), Eka Harmeiwaty (Chair of the Scientific Committee) and current INASH president Tunggul D. Situmorang.
The meeting, which was held under the motto "Hypertension is not just a number, but beyond" was attended by over 1500 participants. The program consisted of scientific, "How to"- and "Meet the expert"-sessions running in three parallel tracks. This core program was rounded up by workshops, a young investigators competition and moderated poster sessions.

The three parallel tracks represent the general structure of the INASH Society. It unites the three disciplines relevant for hypertension research and management: cardiology, nephrology, and neurology, all under one roof.

A highlight of the meeting was the launch of INASH CONSENSUS 2020 on diagnosis and management of hypertension with target organ damage. 


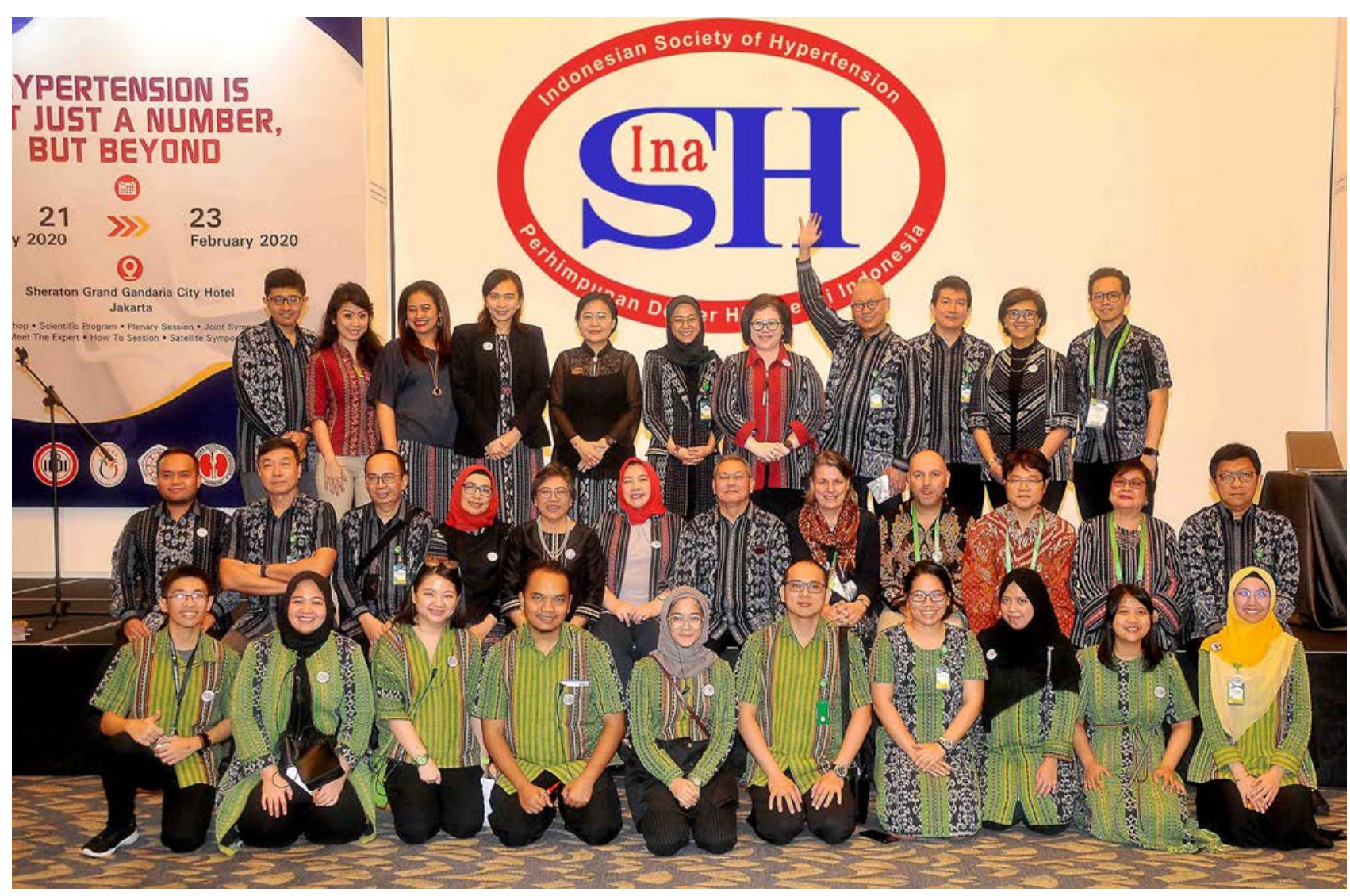

INASH 2020 Faculty

In a joint INASH-ISH Session entitled "Global Challenge in Hypertension Management", we had the opportunity to introduce the ISH Young Investigator and Mentorship and the Women in Hypertension Research Committees and networks and their activities to the audience.

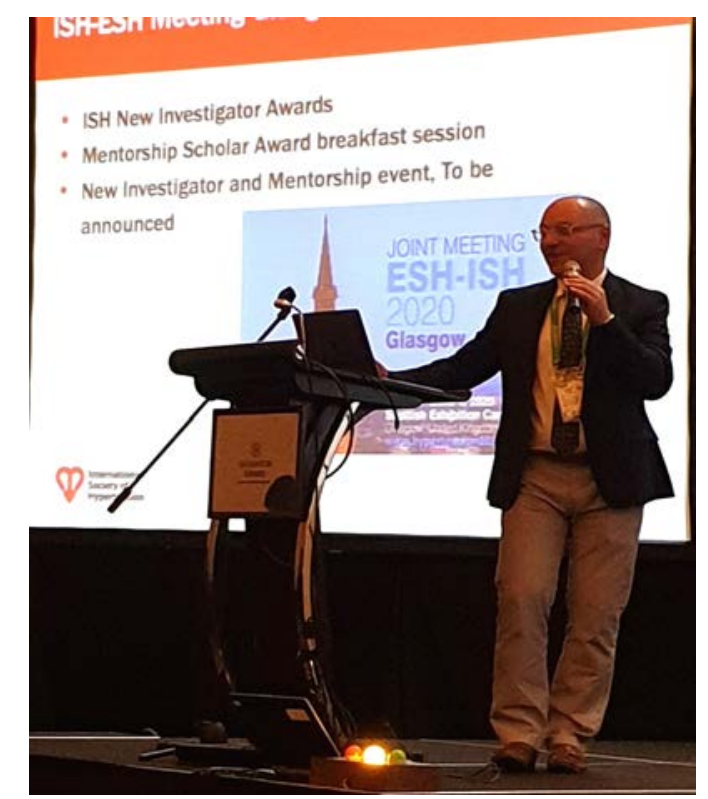

Fadi Charchar, ISH Vice-President, talking about NIC mission and activities at INASH 2020
Fadi Charchar, Vice President of the ISH and Chair of the New Investigator and Mentorship Committee (NIC), presented an overview of NIC. He stressed the importance of recruitment of new investigators in Asia. He described how the society supports new and young investigators across the globe through various schemes such as:

- Mentorship awards for developing countries to helpyoung investigators partner with renowned hypertension researchers from across the globe.

- Annual mentoring event during major ISH/ESH meetings

- Distinguished Mentor Awards

- Features on the ISH website,

- ISH Newsletter and ISH Bulletin to link young investigators across the globe 

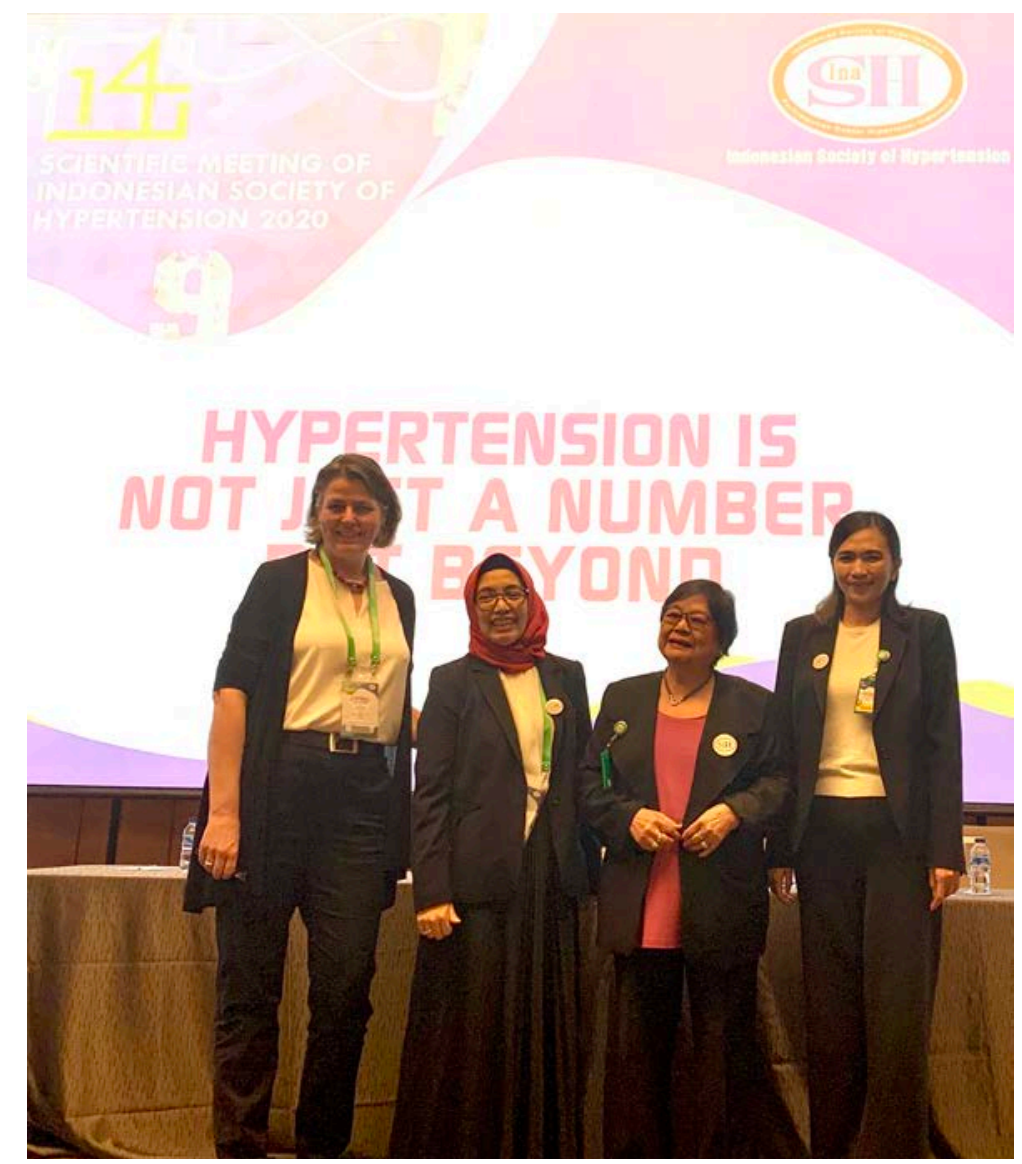

Muscha Steckelings, Chair of WiHRC, with Eka Harmeiwaty, Chair of INASH 2020, Arieska Ann Soenarta, INASH Officer for Foreign Affairs, and Siska Suridanda Danny, faculty member (from left).

The WiHRC was founded to support women in overcoming these difficulties as is set out in the WiHRC's mission:

- To promote women scientists and clinicians so that they can fulfil their career aspirations in hypertension and related CVD

- To provide a platform for networking and mentoring.

- To recognise and promote successes of women in the hypertension community.

- To involve all ISH members in promoting equal opportunities for women in science and medicine based on merit.

- To encourage research in the field of 'hypertension and cardiovascular disease in women'
In her presentation on the mission and activities of the Women in Hypertension Research Committee (WiHRC), Muscha Steckelings, current Chair of WiHRC, pointed out, why it is important that scientific societies worldwide provide support for their female members. The so-called "leaking pipeline", which is the overproportional stepping-out of females from their academic careers, is a world-wide problem and results in women missing out on opportunities and not reaching their potential, which for science and society results in unnecessary loss of talent.

There are multiple reasons for the overproportional loss of women in science careers, some of which are:

- Persistence of traditional role models especially during parenthood

- Lack of mentoring opportunities

- Female role models and clear career paths

- Implicit bias

Current WiHRC activities aiming to help women to overcome challenges within their careers include:

- Initiation of fellowships for ISH members with young children attending ISH meetings in order to provide financial support related to childcare. Initiative by NIC in collaboration with WiHRC

- Sessions on career development at ISH and other meetings

- Enhancement of visibility of women at ISH meetings by increasing the number of female speakers and chairs and by initiating awards

- Spotlights, podcasts about women and their careers on the ISH webpage

- Building a network for female ISH members

- In collaboration with NIC, initiation of mentoring events and programs. 
Our Indonesian colleagues did not only impress us with their well-attended and most interesting meeting, but also with their warm hospitality, the perfect organisation of the meeting, their love for Indonesian traditions and - not least - with their passion for singing and dancing. It was not only during the social get-together that we could enjoy Indonesian music and dance performed by our colleagues, but also in the faculty room during the meeting our colleagues intonated a song on many occasions.

We are looking forward to meeting many of our Indonesian colleagues again at the ESH/ISH Meeting in Glasgow in April 2021, and we hope that the strong links and the collaboration between our societies will continue for many years to come.

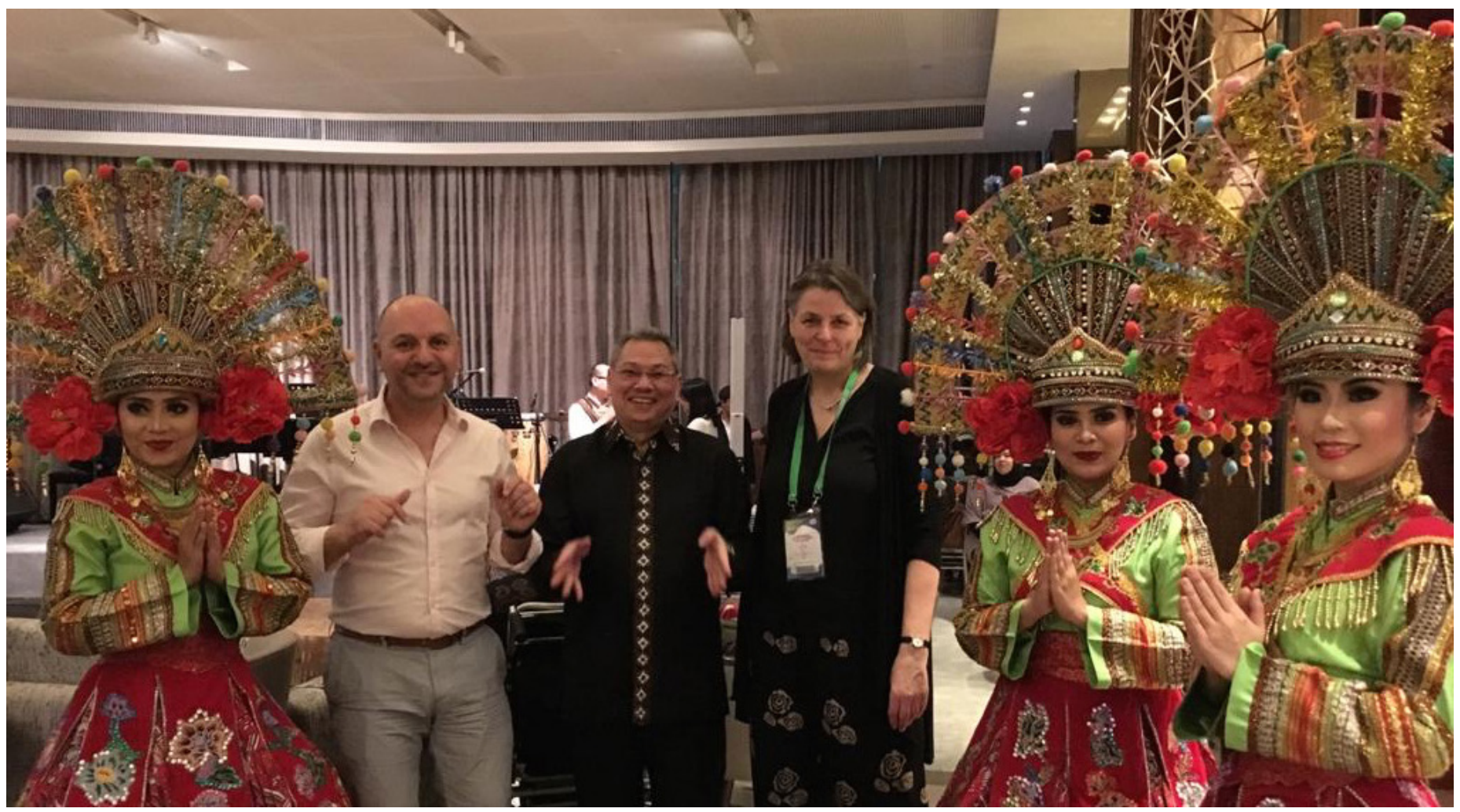

Muscha Steckelings, Chair of WiHRC, with Eka Harmeiwaty, Chair of INASH 2020, Arieska Ann Soenarta, INASH Officer for Foreign Affairs, and Siska Suridanda Danny, faculty member (from left).

Ulrike Muscha Steckelings - usteckelings@health.sdu.dk

Fadi Charchar - f.charchar@federation.edu.au 


\title{
SUMMARY OF THE NORDIC-BALTIC REGION UNIVERSITY RESEARCH COURSE 19-21 SEPTEMBER 2019, GDANSK, POLAND
}

\author{
PETER NILSSON \\ Lund University, Skane University Hospital, Malmö, Sweden
}

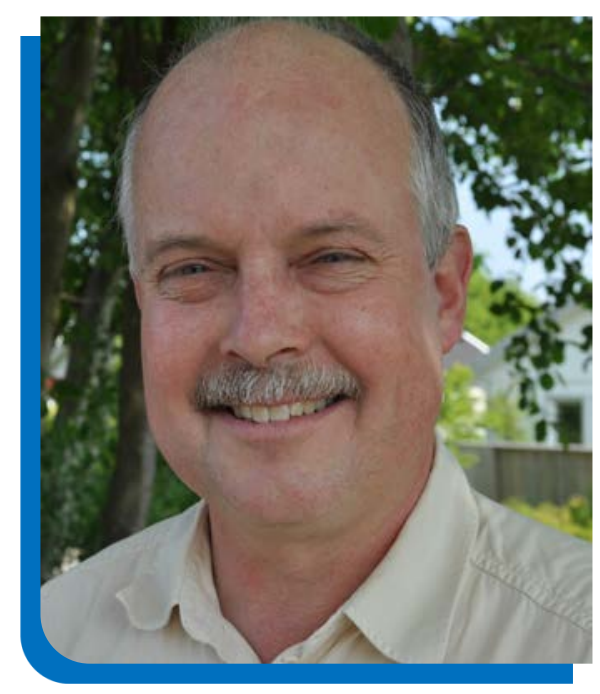

Over the years the Hypertension Societies in the Nordic countries have held bi-annual courses for young researchers and PhD students. Now we wanted to expand this to the Baltic Sea region and involve academic organisations and individuals from neighbouring countries. This resulted in a Nordic-Baltic Regional University Research Course held 19-21 September 2019, Gdansk, Poland, with Professor Krzysztof Narkiewicz, Medical University of Gdansk, as the local host, and with financial support by the International Society of Hypertension (ISH), Region Activity Group (RAG) Europe, under the chairmanship of Professor Peter M Nilsson, Lund University in Sweden. One of the Faculty members was the President-elect of the ISH, Professor Maciej Tomaszewski, University of Manchester, UK, who lectured on the genetics of hypertension in the GWAS era. Also, Professor Ulrike (Muscha) Steckelings, South Denmark University, Odense, Denmark, who is Chair, ISH Women in Hypertension Committee, lectured at the course, talking about the renin-angiotensin system and cerebrovascular disease. The course was also endorsed by the European Society of Hypertension (ESH), Polish Society of Hypertension and the Medical University of Gdansk.

A program committee organised the scientific programme for three days with a focus on Hypertension and Cardiovascular disease: Focus on Brain, Cognition, Stroke and Sympathetic Nervous System Activation. In total 50 young PhD-students attended the course with its Faculty of 25 lecturers. It was important to cover different aspects of epidemiology, mechanisms, clinical aspects, and treatment, but also to encourage group discussions when the students could present their own projects and receive feed-back from 3-4 faculty members. A state-of-the-art lecture was provided by Professor Stèphane Laurent, Paris, on the Reversibility of Early Vascular Ageing - EVA: to what extent?

One of the ISH New Investigators, Dr. Lyudmila Korostovtseva, St. Petersburg, Russia, summarized as follows:

I found the whole course really insightful and interesting. All the talks were inspiring and informative. A quite unexpected debate session on the SPRINT study with Professor Sverre Kjeldsen, Oslo, was brainstorming and mind opening. I believe that such a course which implies combination of lectures, interactive sessions and practical group discussions is the most efficient to receive the knowledge and to develop within the professional field. Moreover, the atmosphere was extremely warm and friendly favourable for networking, discussion, meeting mentors and supervisors which is so important for the early career researchers. I am sure that every participant has enjoyed and profited enormously from this meeting, and I would like to express the gratitude to all the organizers for the opportunity to be the part of it. Undoubtedly, the Nordic-Baltic Region University Research Course is a memorable, important, and thought-provoking experience which will help the PhD participants for further research career development.

ISH New Investigator, Dr Mattias Brunström, Umeå University, Sweden, lectured on how to interpret findings from observational analyses compared to randomized controlled trials. His comment was the following:

The course offered a unique opportunity to network and interact with the most prominent hypertension researchers within the Nordic-Baltic region, as well as tomorrow's leaders in hypertension.

The great hospitality of our Polish hosts contributed to a friendly atmosphere and good learning. The next similar Nordic-Baltic Region PhD course is planned to take place in Denmark in 2021 under the leadership of Professor Michael H Olsen as the local host, and with contribution from the other countries and their hypertension societies and academic institutions. 


\section{International Society of Hypertension Partners in Coalition for Access to NCD Medicines and Products}

COALITION FOR ACCESS

NCD MEDICINES \& PRODUCTS

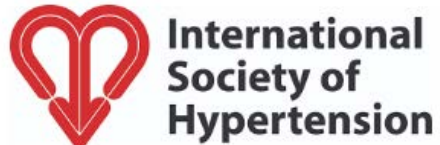

Access to medicine is a well-known barrier to the management of hypertension globally. The ISH aims to address this gap through their membership in the Coalition for Access to NCD Medicines and Products (the Coalition). The Coalition is a global, multisectoral initiative first launched in 2017. The Coalition brings together government agencies, private sector entities, nongovernmental organizations, philanthropic foundations, and academic institutions to work at the global, regional, and national levels to increase access to medicines and health products for noncommunicable diseases, including hypertension.

ISH members may be particularly interested in two current initiatives:

- NCD Demand Forecasting: Current approaches and systems for procurement and distribution of cardiovascular disease (CVD) essential medicines and health products (EMPs) are inefficient and are not meeting existing needs. EMPs for NCDs are rarely available in $80 \%$ of public or private facilities, and even less available in the rural areas and at the lowest levels of care. The lack of a demand forecasting methodology for NCD medicines and products has been noted as a critical barrier through the Coalition's literature review, studies conducted by PATH, and stakeholder interviews in East Africa and Senegal. Along with key stakeholders in Kenya and Uganda, a technical working group has been assembled to develop this demand forecast algorithm and model - which will be used to forecast demand for hypertension and diabetes medicines. The Coalition aims to pilot this model in Kenya and Uganda in late 2020, then scale it in the East Africa Region with the intent of it serving as a global good.

- Capacity Building: In 2016, NCDs accounted for 33\% of deaths in Uganda and 22\% of premature mortality. Eleven percent of the population has CVD or is at high risk, but only $14 \%$ of high-risk persons receive any drug therapy or counselling. Less than 25\% of primary health care centers even offer CVD risk stratification. To address this rising burden, the Uganda Ministry of Health $(\mathrm{MOH})$ prioritized NCD prevention, early diagnosis, and management. The Coalition has partnered with Uganda since its launch in 2017 and prioritized Uganda to implement initiatives addressing NCD care and specifically access to NCD medicines and products. The emergence of COVID-19which disproportionately targets patients living with NCDs - only heightens the urgency of this work. Discussions with Hon. Minister Jane Aceng and Dr. Gerald Mutungi, NCD lead, as well as other stakeholders have highlighted not only limited supply of equipment and supplies for NCD management, but also a lack of health worker training on NCD care. To address this, the Coalition is working with the MOH to develop critical capacity-building strategies and interventions for primary health care workers (PHCWs) to support NCD front-line management.

In addition to these activities, the Coalition is supporting PATH's collaboration with the World Health Organization and the United Nations NCD Task Force to support scaling-up access to tobacco cessation support as part of the COVID-19 response. The goal is to increase supply and demand for tobacco cessation services, broaden the number of manufacturers producing nicotine replacement therapy (NRT), encourage the development of new forms of NRT, explore opportunities for more effective ap-proaches to procurement with more competitive product pricing, and to put in place robust monitoring and evaluation mechanisms. The plan is to have an initial emergency phase established during the COVID-19 pandemic and then a long-term sustainable program.

In addition to existing project implementation, Coalition members have initiated a blog and webinar series to highlight the importance of access to NCD medicines and products during the COVID-19 response, as well as after. The Coalition also aims to highlight its work done to date in the access to medicines and products space (demand forecasting tools, supply chain costing, capacity building, and advocacy activities) to strengthen the resiliency of the system for the future.

- Blog \#1: "Taking Critical Action on NCDs during the COVID-19 Response and Beyond"

- Blog \#2: "Exacerbated Supply Chain Challenges During the COVID-19 Crisis \&

Creative Solutions that Bring Hope for People Living with NCDs"

- Slides from Webinar \#1 - "Ensuring Access to NCD Medicines and Products during the COVID-19 Crisis: Innovations, Partnerships, and Initiatives that Bring Hope"

For further information on the Coalition for Access to NCD Medicines and Products members are encouraged to visit The Coalition's web site: https://coalition4ncds.org/ 


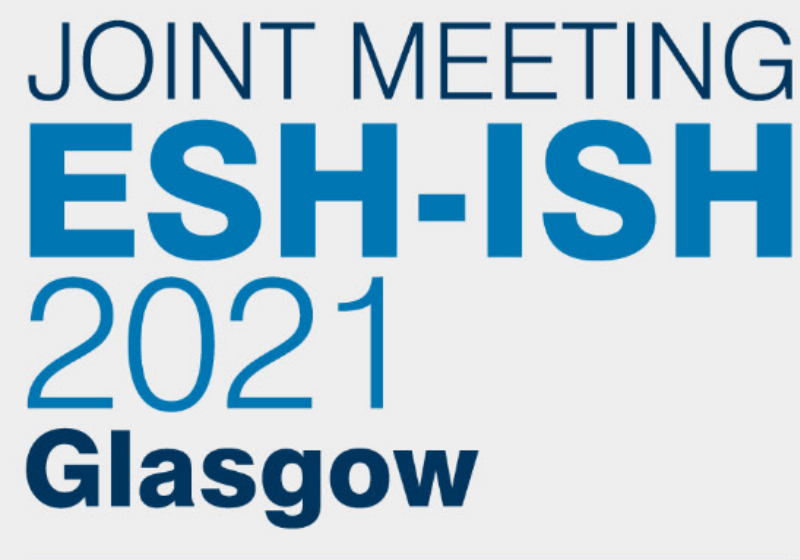

April 11-14, 2021 Scottish Event Campus Glasgow, United Kingdom

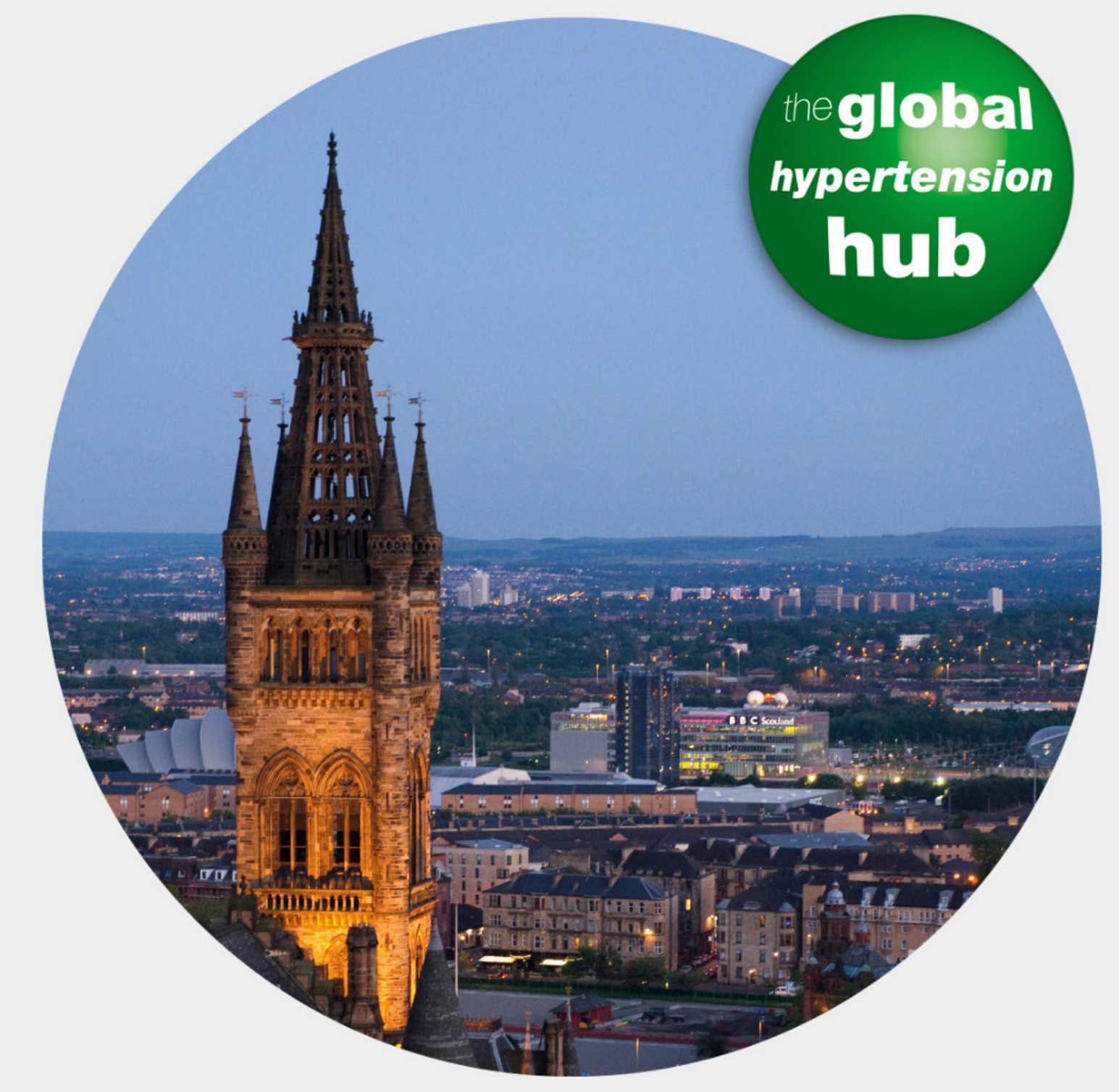

\section{www.hypertension2021.org}

\section{\#hypertension2021}

Y @ESH_Annual / @ESHypertension / @ISHBP / @BIHSoc_Events

f @ESHAnnualMeetings / @ISHBP / @bihsocevents 


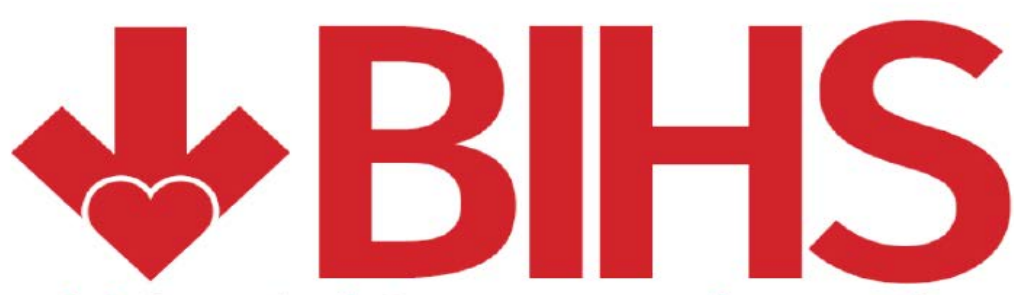

British and Irish Hypertension Society Committed to preventing cardiovascular disease

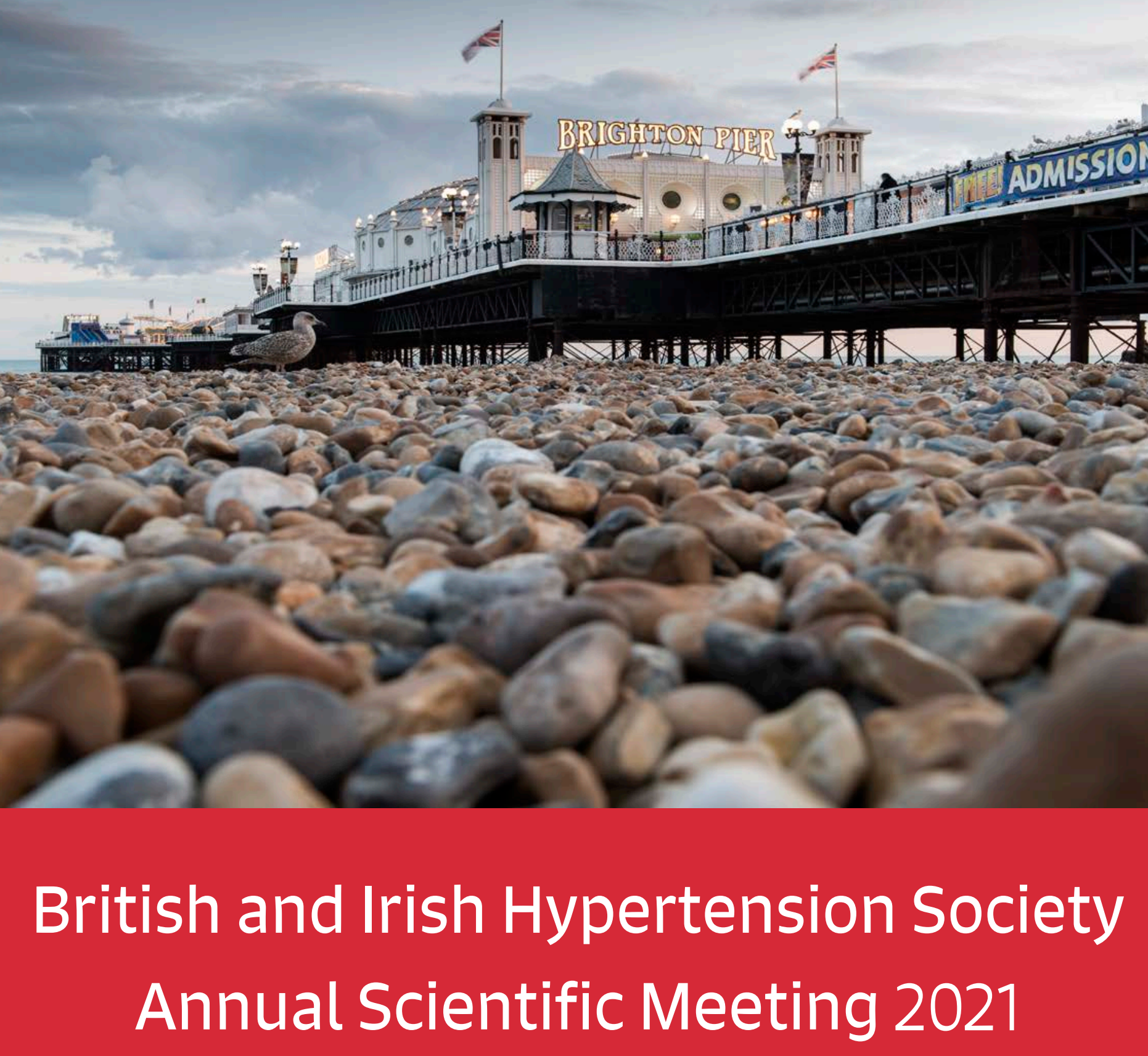

$13^{\text {th }}-15^{\text {th }}$ SEPTEMBER 2021

Hilton Brighton Metropole Hotel 
HYPERTENSION

REMAINS ONE

OF THE

LARGEST

UNMET NEEDS

IN HEALTHCARE.

Many patients struggle to lower their blood pressure with drugs and lifestyle changes alone. For many, it's not enough.

Medtronic.com/hypertension

\section{$35 \%$}

of treated hypertension patients remain uncontrolled. ${ }^{1,2}$

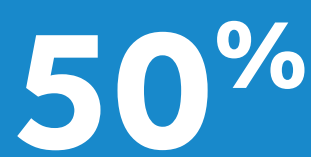

Nearly $50 \%$ of patients become non-adherent to therapy within one year. ${ }^{3}$

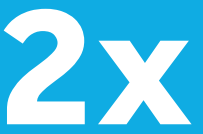

Non-adherence levels double when patients move from 2 to 3 drugs. ${ }^{4-6}$

\section{Medtronic}

References

${ }^{1}$ CDC. Vital Signs, 2012;61(35):703-709. Available at:

https://wwwcdc gov/mmwr/preview/mmwrhtml/mm6135a3 htm. Accessed May 22. 2019

Berra E, et al. Hypertension. 2016;68:297-306

Jung O, et al. Hypertension. 2013;31:766-774.
${ }^{4}$ Hutchins R, et al. Circ Cardiovasc Qual Outcomes. 2015;8:155-163. ${ }^{5}$ Gupta P. et al. Hypertension. 2017:69:1113-1120.

${ }^{6} \mathrm{Li}$ J, et al. BMJ Open. 2014;4:e004920.

\section{Medtronic}

3576 Unocal Place

Santa Rosa, CA 95403

USA

Tel: 707.525.0111

LifeLine Customer Support

Tel: 877.526 .7890

Tel: 763.526 .7890

Product Services

Tel: 888.283.7868

Fax: 800.838 .3103
Europe

Medtronic Intl. Trading

SARL

Route du Molliau 31

Case Postale

$\mathrm{CH}-1131$ Tolochenaz

Switzerland

Tel: 41.21 .802 .7000

Fax: 41.21.802.7900
Canada

Medtronic of Canada Ltd.

99 Hereford Stree

Brampton, Ontario L6Y OR3

Canada

Tel: 905.460 .3800

Fax: 905.460 .3998

Toll-free: 800.268 .5346
Asia Pacific

Medtronic Intl. Ltd.

49 Changi South Avenue 2

Nasaco Tech Centre

Singapore 486056

Singapore

Tel: 65.6436 .5000

Fax: 65.6776.6335
Latin America

Medtronic USA, Inc.

Doral Corporate Centre II

3750 NW 87th Avenue, Suite 700

Miami, FL 33178

USA

Tel: 305.500 .9328

Fax: 786.709.4244 


\section{ISH HYPERTENSION NEWS TEAM}

\section{MEMBERS}

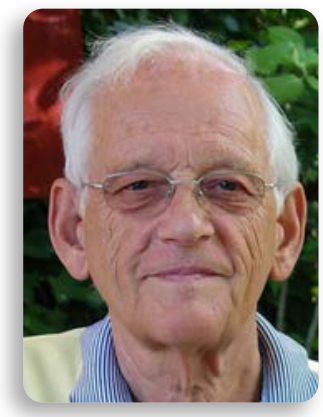

Lars H. Lindholm

Editor of Hypertension News, Sweden

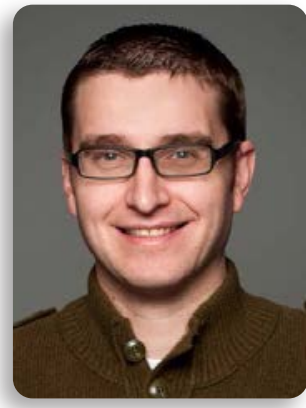

Dylan Burger

Deputy Editor of Hypertension News, Canada

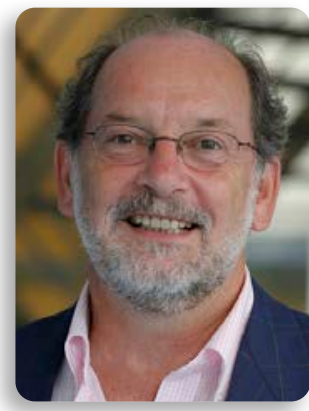

Thomas Unger

ISH Secretary, The Netherlands

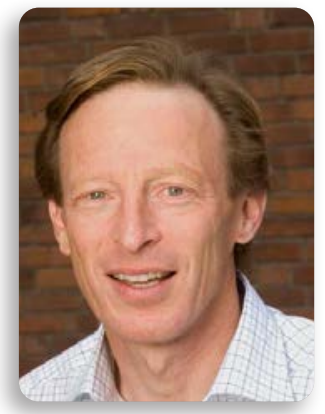

Thomas Kahan

Sweden

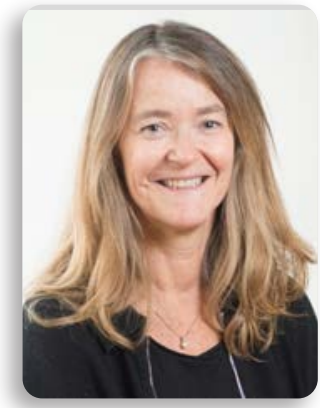

Maria-Christina Zennaro

France

ISH CORPORATE MEMBERS
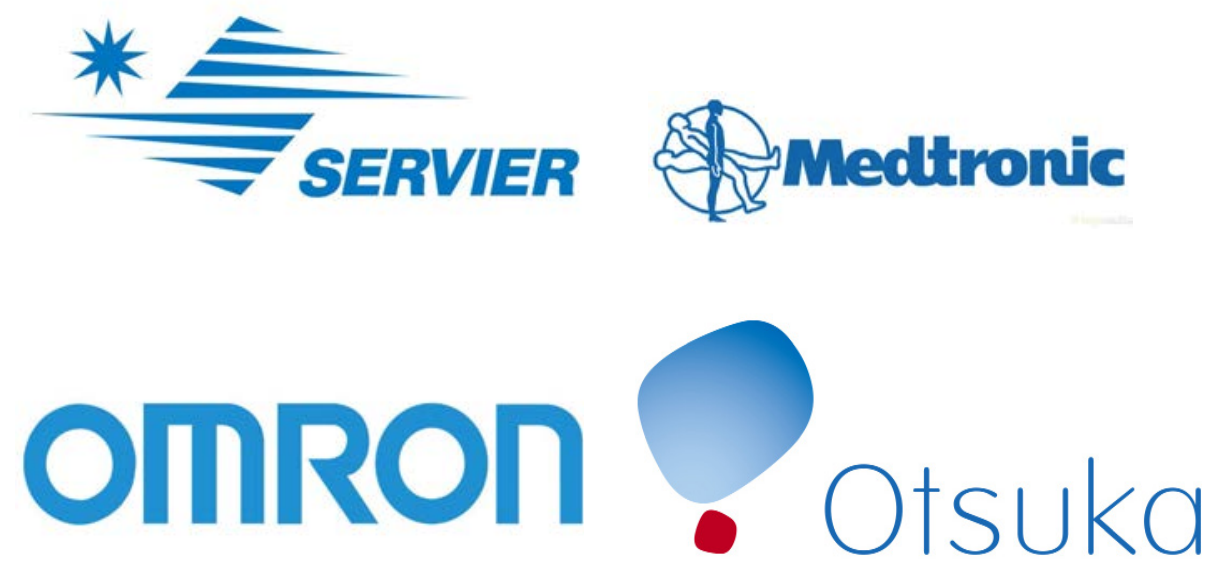

\section{ISH Secretariat}

Contact:

c/o In Conference Ltd

Unit 1 Q Court, Quality Street,

Edinburgh, UK, EH4 5BP

Tel (UK):

+44(0)1313364203

Email:

secretariat@ish-world.com

ISH Registered Charity No: 1122135

The opinions expressed by contributors in this issue of Hypertension News do not necessarily reflect

or represent the opinions of policy positions of ISH or its Council of Trustees. 